\title{
Modelos baseados em pseudo-valores e sua aplicabilidade em credit scoring
}

Liliane Travassos da Silva

DissertaÇÃo APRESEntAdA

$\mathrm{AO}$

Instituto de Matemática e EstatísticA

DA

Universidade DE SÃo PaUlo

PARA

OBTENÇÃO DO TÍTULO

$\mathrm{DE}$

Mestre em CiÊnCIAS

\author{
Programa: Estatística \\ Orientadora: $\operatorname{Prof}^{a}$. Dr ${ }^{a}$. Gisela Tunes da Silva
}

São Paulo, agosto de 2010 


\title{
Modelos baseados em pseudo-valores e sua aplicabilidade em credit scoring
}

\author{
Este exemplar corresponde à redação \\ final da dissertação devidamente corrigida \\ e defendida por Liliane Travassos da Silva \\ e aprovada pela Comissão Julgadora.
}

Banca Examinadora:

- $\operatorname{Prof}^{a}$. Dr ${ }^{a}$. Gisela Tunes da Silva (orientadora) - IME-USP.

- Prof. Dr. Antonio Carlos Pedroso de Lima - IME-USP.

- Prof. Dr. Rinaldo Artes - IBMEC-SP. 
"Se as coisas são inatingíveis... ora! Não é motivo para não querê-las... Que tristes os caminhos se não fora A mágica presença das estrelas!" Mário Quintana 
Aos meus pais. 


\section{Agradecimentos}

Agradeço à Gisela e ao Antonio Carlos, pelas sugestões, ensinamentos, pelo acompanhamento de cada etapa de meu trabalho e por estarem sempre disponíveis.

Ao Banco Central do Brasil, pela oportunidade em cursar o mestrado por meio de seu Programa de Pós Graduação e por autorizar o uso dos dados do Sistema de Informações de Crédito.

Ao Sérgio Mikio e ao Clodoaldo Annibal, pela valiosa ajuda na coleta dos dados e sugestões para o trabalho.

Ao Gustavo Pereira, por partilhar comigo sua experiência em credit scoring.

À Patricia Nagami, à Francyelle Lima e ao Rafael Paixão, pelo companheirismo e ajuda durante o mestrado.

Ao Paolo Pani, por estar sempre disposto a me apoiar nos momentos mais difíceis.

Aos meus pais, por tudo o que me proporcionaram para eu chegar até aqui. 


\section{Resumo}

Os modelos de credit scoring têm sido bastante difundidos nos últimos anos como uma importante ferramenta para agilizar e tornar mais confiável o processo de concessão de crédito por parte das instituições financeiras. Esses modelos são utilizados para classificar os clientes em relação a seus riscos de inadimplência. Neste trabalho, é avaliada a aplicabilidade de uma nova metodologia, baseada em pseudo-valores, como alternativa para a construção de modelos de credit scoring. O objetivo é compará-la com abordagens tradicionais como a regressão logística e o modelo de riscos proporcionais de Cox. A aplicação prática é feita para dados de operações de crédito pessoal sem consignação, coletados do Sistema de Informações de Crédito do Banco Central do Brasil. As performances dos modelos são comparadas utilizando a estatística de Kolmogorov-Smirnov e a área sob a curva ROC. 


\section{Abstract}

Credit scoring models have become popular in recent years as an important auxiliary tool in the credit granting process, making it more expedite and reliable. The models are mainly considered to classify customers according to their default risk. In this work we evaluate the applicability of a new methodology, based on pseudo-values, as an alternative to constructing credit scoring models. The objective is to compare this novel methodology with traditional approaches such as logistic regression and Cox proportional hazards model. The models are applied to a dataset on personal credit data, collected from the Credit Information System of Central Bank of Brazil. The performances of the models are compared via Kolmogorov-Smirnov statistic and the area under ROC curve. 


\section{Sumário}

Lista de Figuras $\quad$ xi

Lista de Tabelas xiii

\begin{tabular}{lll}
\hline & Introdução & 1
\end{tabular}

2 Metodologia 5

2.1 Regressão Logística . . . . . . . . . . . . . . . . . . 5

2.2 Análise de Sobrevivência . . . . . . . . . . . . . . . . . 8

$2.2 .1 \quad$ Estimador de Kaplan-Meier . . . . . . . . . . . . . . 10

2.2 .2 Modelo de Riscos Proporcionais de Cox . . . . . . . . 12

2.3 Pseudo-valores . . . . . . . . . . . . . . . . . . . . . . . . . . . 16

2.3.1 Estimação dos Parâmetros do Modelo de Regressão . 21

2.3 .2 Exemplo 1 - Probabilidade de Inadimplência . . . . . 27

2.3.3 Exemplo 2 - Tempo Médio de Inadimplência . . . . . 28

2.4 Medidas de Performance . . . . . . . . . . . . . . . . . . . . 29

$2.4 .1 \quad$ Estatística de Kolmogorov-Smirnov . . . . . . . . . . 29

2.4 .2 Curva ROC (Receiver Operating Characteristic) e Coeficiente de Ginil . . . . . . . . . . . . . . . . . 30

3 Aplicação a Dados de Crédito Pessoal 33

3.1 Sistema de Informações de Crédito do Banco Central do Brasil (SCR) . . . . . . . . . . . . . . . 33

3.2 Descrição e Análise dos Dados do Estudo . . . . . . . . . . . . 34

3.3 Ajuste dos Modelos . . . . . . . . . . . . . . . . . . . 37

$3.3 .1 \quad$ Regressão Logística . . . . . . . . . . . . . . . . . . . 39

3.3.2 Modelo de Cox . . . . . . . . . . . . . . . . . 40

3.3 .3 Pseudo-valores . . . . . . . . . . . . . . . . . . . . . . 41

3.4 Comparação dos Modelos. . . . . . . . . . . . . . . . . . . . 42

3.5 Modelos para Dados sem Censura . . . . . . . . . . . . . . 45 
\begin{tabular}{lll}
\hline 4 Conclusão & 49
\end{tabular}

A Tabelas e Gráficos da Análise Descritiva 53

B Tabelas dos Resultados dos Modelos 59

C Gráficos das Medidas de Performance 73

\begin{tabular}{ll}
\hline Referências Bibliográficas & 81
\end{tabular} 


\section{Lista de Figuras}

$2.1 \quad$ Gráfico KS . . . . . . . . . . . . . . . . . . . . . . . . . . . . . . . 31

2.2 Curva ROC $\ldots \ldots \ldots \ldots \ldots$

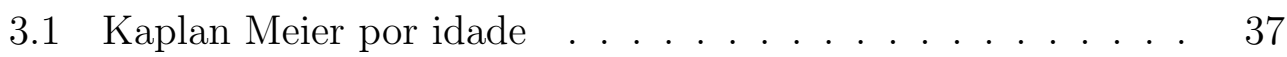

A.1 Kaplan Meier por sexo . . . . . . . . . . . . . . . . . . . 55

A.2 Kaplan Meier por região . . . . . . . . . . . . . . . . 56

A.3 Kaplan Meier por tempo de relacionamento . . . . . . . . 56

A.4 Kaplan Meier por prazo da operação … . . . . . . . 57

A.5 Kaplan Meier por indexador da operação . . . . . . . . . . 57

A.6 Kaplan Meier por total da operação . . . . . . . . . . . . . 58

A.7 Kaplan Meier por autorização do cliente . . . . . . . . . . 58

C.1 Gráfico KS - Probabilidade de inadimplência - Regressão logística com características de cliente e operação . . . . . . . . . . 73

C.2 Gráfico KS - Probabilidade de inadimplência - Modelo de Cox com características de cliente e operação . . . . . . . . . . 73

C.3 Gráfico KS - Probabilidade de inadimplência - Pseudo-valores com características de cliente e operação . . . . . . . . . . . 74

C.4 Gráfico KS - Tempo médio de inadimplência - Modelo de Cox com características de cliente e operação . . . . . . . . . . . 74

C.5 Gráfico KS - Tempo médio de inadimplência - Pseudo-valores com características de cliente e operação . . . . . . . . . . 74

C.6 Curva ROC - Probabilidade de inadimplência - Regressão logística com características de cliente e operação $\ldots . . .75$

C.7 Curva ROC - Probabilidade de inadimplência - Modelo de Cox com características de cliente e operação . . . . . . . . . 75

C.8 Curva ROC - Probabilidade de inadimplência - Pseudo-valores com características de cliente e operação . . . . . . . . . 75 
C.9 Curva ROC - Tempo médio de inadimplência - Modelo de Cox com características de cliente e operação . . . . . . . . . 76

C.10 Curva ROC - Tempo médio de inadimplência - Pseudo-valores com características de cliente e operação . . . . . . . . . 76

C.11 Gráfico KS - Probabilidade de inadimplência - Regressão logística com características de cliente . . . . . . . . . . . . . 76

C.12 Gráfico KS - Probabilidade de inadimplência - Modelo de Cox com características de cliente . . . . . . . . . . . . . . . 77

C.13 Gráfico KS - Probabilidade de inadimplência - Pseudo-valores com características de cliente . . . . . . . . . . . . . . 77

C.14 Gráfico KS - Tempo médio de inadimplência - Modelo de Cox com características de cliente . . . . . . . . . . . . . . 77

C.15 Gráfico KS - Tempo médio de inadimplência - Pseudo-valores com características de cliente . . . . . . . . . . . . . 78

C.16 Curva ROC - Probabilidade de inadimplência - Regressão logística com características de cliente. . . . . . . . . . . . 78

C.17 Curva ROC - Probabilidade de inadimplência - Modelo de Cox com características de cliente . . . . . . . . . . . . . 78

C.18 Curva ROC - Probabilidade de inadimplência - Pseudo-valores com características de cliente . . . . . . . . . . . . . . . 79

C.19 Curva ROC - Tempo médio de inadimplência - Modelo de Cox com características de cliente . . . . . . . . . . . . . . . 79

C.20 Curva ROC - Tempo médio de inadimplência - Pseudo-valores com características de cliente . . . . . . . . . . . . . . . 79 


\section{Lista de Tabelas}

2.1 Nível de discriminação para diferentes valores de KS . . . . . 30

2.2 Nível de discriminação para diferentes valores de área abaixo

- . . . . . . . . . . . . . . . 32

3.1 Distribuição de bons e maus clientes para covariável idade . 36

3.2 Medidas de performance - Modelos probabilidade de inadimplência com características de cliente e operação - Covariáveis categorizadas. .................... . . . 44 44

3.3 Medidas de performance - Modelos probabilidade de inadimplência com características de cliente e operação - Covariáveis quantitativas ..................... . . . 45

3.4 Medidas de performance - Modelos tempo médio de inadimplência com características de cliente e operação - Covariáveis categorizadas. . . . . . . . . . . . . . . . . . 45

3.5 Medidas de performance - Modelos tempo médio de inadimplência com características de cliente e operação - Covariáveis quantitativas .................... 46

3.6 Medidas de performance - Modelos probabilidade de inadimplência com características de cliente - Covariáveis categorizadas . . 46

3.7 Medidas de performance - Modelos probabilidade de inadimplência com características de cliente - Covariáveis quantitativas . . 47

3.8 Medidas de performance - Modelos tempo médio de inadimplência com características de cliente - Covariáveis categorizadas . . 47

3.9 Medidas de performance - Modelos tempo médio de inadimplência com características de cliente - Covariáveis quantitativas . . 47

3.10 Medidas de performance - Modelos para dados sem censura Covariáveis categorizadas . . . . . . . . . . . . . . 47

3.11 Medidas de performance - Modelos para dados sem censura Covariáveis quantitativas . . . . . . . . . . . . . . . . . 48 
A.1 Distribuição de bons e maus clientes para covariável sexo . . 53

A.2 Distribuição de bons e maus clientes para covariável região . 53

A.3 Distribuição de bons e maus clientes para covariável tempo de relacionamento . . . . . . . . . . . . . . . 54

A.4 Distribuição de bons e maus clientes para covariável prazo da operação . . . . . . . . . . . . . . . . . . 54

A.5 Distribuição de bons e maus clientes para covariável indexador da operação . . . . . . . . . . . . . . . . . . 54

A.6 Distribuição de bons e maus clientes para covariável total da operação . . . . . . . . . . . . . . . . . . 54

A.7 Distribuição de bons e maus clientes para covariável autorização do cliente . . . . . . . . . . . . . . . . . . . 55

B.1 Valores para as covariáveis categorizadas . . . . . . . . . . . 59

B.2 Estimativas dos coeficientes e erros padrão do modelo de regressão logística para probabilidade de inadimplência, com características de cliente e operação - Covariáveis categorizadas 60

B.3 Estimativas dos coeficientes e erros padrão do modelo de regressão logística para probabilidade de inadimplência, com características de cliente e operação - Covariáveis quantitativas 61

B.4 Estimativas dos coeficientes e erros padrão do modelo de Cox para probabilidade de inadimplência, com características de cliente e operação - Covariáveis categorizadas . . . . . . . . 62

B.5 Estimativas dos coeficientes e erros padrão do modelo de Cox para probabilidade de inadimplência, com características de

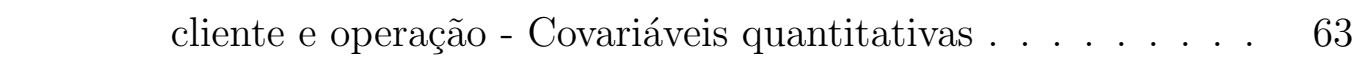

B.6 Estimativas dos coeficientes e erros padrão do modelo de pseudovalores para probabilidade de inadimplência, com características de cliente e operação - Covariáveis categorizadas . . . . . . . 64

B.7 Estimativas dos coeficientes e erros padrão do modelo de pseudovalores para probabilidade de inadimplência, com características de cliente e operação - Covariáveis quantitativas . . . . . . . 65

B.8 Estimativas dos coeficientes e erros padrão do modelo de pseudovalores para tempo médio de inadimplência, com características de cliente e operação - Covariáveis categorizadas . . . . . . . 65 
B.9 Estimativas dos coeficientes e erros padrão do modelo de re-

\begin{tabular}{|c|}
\hline gressão logística para probabilidade de inadimplência, com \\
\hline características de cliente - Covariáveis categorizadas . . . . . 66
\end{tabular}

B.10 Estimativas dos coeficientes e erros padrão do modelo de regressão logística para probabilidade de inadimplência, com características de cliente - Covariáveis quantitativas . . . . . 66

B.11 Estimativas dos coeficientes e erros padrão do modelo de Cox para probabilidade de inadimplência, com características de cliente - Covariáveis categorizadas . . . . . . . . . . . . . 67

B.12 Estimativas dos coeficientes e erros padrão do modelo de Cox

\begin{tabular}{|c|}
\hline para probabilidade de inadimplência, com características de \\
\hline clicnte - Covariáveis quantitativas
\end{tabular}
cliente - Covariáveis quantitativas . . . . . . . . . . . 67

B.13 Estimativas dos coeficientes e erros padrão do modelo de pseudovalores para probabilidade de inadimplência, com características de cliente - Covariáveis categorizadas . . . . . . . . . . . . . 68

B.14 Estimativas dos coeficientes e erros padrão do modelo de pseudovalores para probabilidade de inadimplência, com características de cliente - Covariáveis quantitativas . . . . . . . . . 68

B.15 Estimativas dos coeficientes e erros padrão do modelo de pseudovalores para tempo médio de inadimplência, com características de cliente - Covariáveis categorizadas . . . . . . . . . . . . 69

B.16 Estimativas dos coeficientes e erros padrão do modelo de pseudovalores para tempo médio de inadimplência, com características de cliente - Covariáveis quantitativas . . . . . . . . . . . 69

B.17 Estimativas dos coeficientes e erros padrão do modelo de regressão logística para dados sem censura - Covariáveis categorizadas. . . . . . . . . . . . . . . . 70

B.18 Estimativas dos coeficientes e erros padrão do modelo de regressão logística para dados sem censura - Covariáveis quantitativas . . . . . . . . . . . . . . 70

B.19 Estimativas dos coeficientes e erros padrão do modelo de Cox para dados sem censura - Covariáveis categorizadas . . . . . 71

B.20 Estimativas dos coeficientes e erros padrão do modelo de Cox para dados sem censura - Covariáveis quantitativas . . . . . 71

B.21 Estimativas dos coeficientes e erros padrão do modelo de pseudovalores para dados sem censura - Covariáveis categorizadas . 
B.22 Estimativas dos coeficientes e erros padrão do modelo de pseudovalores para dados sem censura - Covariáveis quantitativas . 72 


\section{Capítulo 1}

\section{Introdução}

Dentre os diversos tipos de risco aos quais uma instituição financeira está exposta ao desenvolver suas atividades, o risco de crédito é um dos principais a ser gerenciado. Segundo Assaf Neto e Silva (1997), o termo crédito diz respeito à troca de bens presentes por bens futuros. No caso de crédito bancário, a instituição financeira doa recursos ao cliente no presente em troca de uma remuneração a ser paga por ele no futuro. O risco de crédito representa a possibilidade de que a expectativa de remuneração futura não se cumpra e engloba o risco de inadimplência, que é o risco de não pagamento por parte do cliente.

Como uma maneira de mitigar o risco de inadimplência, é importante uma análise que permita decidir se o crédito deve ou não ser concedido a um determinado cliente, por qual prazo e a qual taxa de juros. Com o expressivo crescimento, a partir dos anos 50, do mercado de crédito internacional, as instituições financeiras viram-se impelidas a aprimorar e agilizar seus métodos de decisão para concessão de crédito. No Brasil, esse crescimento deu-se após a implementação do Plano Real, em 1994, pois os bancos, que deixaram de lucrar com a desvalorização da moeda, viram nos empréstimos um bom negócio (Rosa, 2000). A massificação do processo de concessão de crédito levou ao desenvolvimento de técnicas quantitativas mais sofisticadas e a implementação de sistemas tecnológicos mais robustos.

O interesse em aperfeiçoar ainda mais os modelos de gerenciamento do risco de crédito foi reforçado pela implementação, em 2004, do Novo Acordo de Capital da Basiléia (Basel Committee on Banking Supervision, 2004), um documento assinado pelos principais Bancos Centrais do mundo. O Novo Acordo permitiu aos bancos a utilização de modelos internos para cálculo de 
alocação de capital regulamentar para cobrir o risco de crédito. Com isso, criou-se um interesse muito grande por parte das instituições financeiras em desenvolver modelos que refletissem da forma mais precisa possível os riscos aos quais estão expostas.

Os modelos de credit scoring ou escoragem de crédito foram bastante difundidos nos últimos anos. Credit scoring é o termo utilizado para descrever os métodos usados para classificar os clientes em relação a seus riscos de inadimplência (Malik e Thomas, 2007). Com base nesses métodos, os clientes recebem uma pontuação (escore) cujo valor é inversamente proporcional ao seu risco de inadimplência. Em geral, é definido um escore de corte, de forma que os clientes com pontuação acima desse escore são considerados "bons", enquanto aqueles com pontuação abaixo são considerados "maus". Segundo Chaia (2003), a principal vantagem desses métodos é que as decisões sobre a concessão de crédito são tomadas com base em procedimentos impessoais e padronizados, gerando um maior grau de confiabilidade.

Dentre as inúmeras metodologias utilizadas para a construção de escores de crédito, pode-se citar métodos estatísticos como regressão logística, árvore de decisão, análise de sobrevivência e análise discriminante. Também são usados métodos não estatísticos como programação linear, programação inteira, redes neurais, vizinho mais próximo e algoritmos genéticos. Uma breve descrição dessas metodologias pode ser vista em Thomas et al. (2002).

Neste trabalho, é avaliado o uso de uma nova metodologia, baseada nos pseudo-valores da técnica jackknife, como alternativa para a construção de modelos de credit scoring. O objetivo é compará-la com duas metodologias já bastante difundidas: a regressão logística e a análise baseada no modelo de riscos proporcionais de Cox. Essas metodologias são descritas no Capítulo 2. Em alguns modelos, os escores são contruídos com base na probabilidade da inadimplência do cliente ocorrer após um determinado instante de tempo e, em outros, com base no tempo médio até a inadimplência do cliente. Nos dois casos, são utilizados o modelo de Cox e a técnica baseada nos pseudovalores. A regressão logística é utilizada da forma usual, isto é, para o cálculo de escores baseados na probabilidade de inadimplência.

Os dados utilizados para aplicação prática dos modelos considerados referem-se a operações de crédito pessoal sem consignação e foram coletados do Sistema de Informações de Crédito do Banco Central do Brasil (SCR). 
Maiores detalhes são apresentados no Capítulo 3.

Os modelos são comparados por meio de medidas de performance amplamente difundidas: a curva ROC e a estatística de Kolmogorov-Smirnov, que são detalhadas no Capítulo 2. Os resultados são apresentados no Capítulo 3 e as conclusões no Capítulo 4. 


\section{Capítulo 2}

\section{Metodologia}

Neste capítulo, são descritas as metodologias usadas neste trabalho para relacionar uma variável resposta com variáveis explicativas, ou covariáveis. Essas metodologias servem como base para a criação de modelos de credit scoring, utilizando-se como variável resposta alguma medida associada à inadimplência do cliente e como covariáveis características associadas a esse cliente e/ou às operações envolvidas. Inicialmente, a regressão logística é brevemente discutida, seguida da análise de sobrevivência e de uma metodologia baseada em pseudo-valores. Além disso, são também descritas algumas medidas de performance (curva ROC, coeficiente de Gini e estatística de Kolmogorov-Smirnov) usadas para comparar os diferentes modelos de credit scoring.

\section{$2.1 \quad$ Regressão Logística}

Na regressão logística usual, a variável resposta é binária. A ocorrência ou não de um evento, dentro de um intervalo de tempo pré-fixado, pode ser representada por esse tipo de variável. Em análise de crédito, pode-se definir que a variável resposta assuma o valor 1, quando observa-se a inadimplência de um cliente em um período considerado, e o valor 0 , caso contrário. O objetivo é relacionar a variável resposta com variáveis explicativas, ou covariáveis. Por exemplo, a ocorrência da inadimplência de um cliente pode

ser influenciada por características como sua idade e seu sexo. Nesse caso, essas características são as covariáveis do modelo.

Seja $X_{i}$ uma variável binária, que assume valores 0 e 1 , e considere $\mathbf{Z}_{i}=$ $\left(1, Z_{i 1}, \ldots, Z_{i p}\right)$ o vetor de covariáveis associado ao indivíduo $i, i=1, \ldots, n$. Os dados do $i$-ésimo indivíduo são então representados pelo par de variáveis 
$\left(X_{i}, \mathbf{Z}_{i}\right)$. Considere a seguinte notação

$$
\pi\left(\mathbf{z}_{i}\right)=E\left[X_{i} \mid \mathbf{Z}_{i}=\mathbf{z}_{i}\right]
$$

Observe que, como a variável $X_{i}$ assume somente os valores 0 e $1, \pi\left(\mathbf{z}_{i}\right)$ é a probabilidade de $X_{i}$ ser igual a 1 e $\left[1-\pi\left(\mathbf{z}_{i}\right)\right]$ é a probabilidade de $X_{i}$ ser igual a 0, dado o valor das covariáveis. Logo, a distribuição condicional de $X_{i}$ dado $\mathbf{Z}_{i}=\mathbf{z}_{i}$ é $\operatorname{Binomial}\left(1, \pi\left(\mathbf{z}_{i}\right)\right)$ e assim sua variância é $\pi\left(\mathbf{z}_{i}\right)\left[1-\pi\left(\mathbf{z}_{i}\right)\right]$. Em análise de crédito, $\pi\left(\mathbf{z}_{i}\right)$ representa a probabilidade do cliente $i$ tornar-se inadimplente dentro de um determinado período, dadas as características $\mathbf{z}_{i}$ associadas a esse cliente.

Geralmente, dados binários resultam de uma relação não linear entre $\pi\left(\mathbf{z}_{i}\right)$ e $\mathbf{z}_{i}$ (Agresti, 2002). O modelo de regressão logística pode expressar essa relação da seguinte forma:

$$
\pi\left(\mathbf{z}_{i}\right)=\frac{e^{\mathbf{z}_{i} \boldsymbol{\beta}}}{1+e^{\mathbf{z}_{i} \boldsymbol{\beta}}}, \quad i=1, \ldots, n
$$

em que $\boldsymbol{\beta}$ é um vetor de dimensão $(p+1)$ de parâmetros desconhecidos.

Aplicando a transformação logito, tem-se:

$$
g\left(\mathbf{z}_{i}\right)=\ln \left[\frac{\pi\left(\mathbf{z}_{i}\right)}{1-\pi\left(\mathbf{z}_{i}\right)}\right]=\mathbf{z}_{i} \boldsymbol{\beta}
$$

A importância dessa transformação é que $g\left(\mathbf{z}_{i}\right)$ tem muitas das propriedades desejáveis de um modelo de regressão linear: é linear em seus parâmetros, é contínuo e pode variar de $-\infty$ a $+\infty$, dependendo do intervalo de variação de $\mathbf{z}_{i}$ (Hosmer e Lemeshow, 2000).

Os parâmetros $\boldsymbol{\beta}$ da regressão logística são geralmente estimados pelo método de máxima verossimilhança. Por esse método, a estimativa de máxima verossimilhnça é o valor de $\boldsymbol{\beta}$ que maximiza a função de verossimilhança. Esta função é definida como a função de distribuição conjunta de $X_{1}, \ldots, X_{n}$ vista como uma função dos parâmetros desconhecidos $\boldsymbol{\beta}$, para valores observados $x_{1}, \ldots, x_{n}$ e $\mathbf{z}_{1}, \ldots, \mathbf{z}_{n}$. Neste caso, a função de verossi- 
milhança fica dada por

$$
L(\boldsymbol{\beta})=\prod_{i=1}^{n} \pi\left(\mathbf{z}_{i}\right)^{x_{i}}\left[1-\pi\left(\mathbf{z}_{i}\right)\right]^{1-x_{i}}
$$

em que $\pi\left(\mathbf{z}_{i}\right)=\frac{e^{\mathbf{z}_{i} \boldsymbol{\beta}}}{1+e^{\mathbf{z}_{i} \boldsymbol{\beta}}}$

O valor de $\boldsymbol{\beta}$ que maximiza $L(\boldsymbol{\beta})$ é a solução das equações encontradas ao derivar $L(\boldsymbol{\beta})$, ou seu logaritmo, em relação a $\boldsymbol{\beta}$ e igualar essas derivadas a zero. Como as expressões encontradas são não lineares em $\boldsymbol{\beta}$, é preciso recorrer a métodos numéricos para resolvê-las. As estimativas podem ser obtidas pelo processo iterativo de Newton-Raphson ou pelo método de scoring de Fisher (Paula, 2004). Vale ressaltar que a estimativa de máxima verossimilhança é definida para valores observados $\mathbf{z}_{i}, i=1, \ldots, n$ e que o estimador de máxima verossimilhança $\hat{\boldsymbol{\beta}}$ é definido em função das variáveis $\mathbf{Z}_{i}$

A matriz de informação observada, $\mathbf{I}(\boldsymbol{\beta})$, é a segunda derivada em relação a $\boldsymbol{\beta}$ do oposto do logaritmo de $L(\boldsymbol{\beta})$. O estimador da matriz de variânciacovariância de $\hat{\boldsymbol{\beta}}$ é dado pela inversa de $\mathbf{I}(\boldsymbol{\beta})$, avaliada em $\hat{\boldsymbol{\beta}}$, que neste caso fica dado por

$$
\widehat{\operatorname{Var}}(\hat{\boldsymbol{\beta}})=[\mathbf{I}(\hat{\boldsymbol{\beta}})]^{-1}=\left(\mathbf{Z}^{T} \mathbf{V Z Z}\right)^{-1}
$$

em que

$\mathbf{Z}$ é uma matriz de dimensão $n \times(p+1)$, em que cada linha corresponde ao vetor $\mathbf{Z}_{i}$ e

$\mathbf{V}=\operatorname{diag}\left\{\hat{\pi}\left(\mathbf{Z}_{1}\right)\left[1-\hat{\pi}\left(\mathbf{Z}_{1}\right)\right], \ldots, \hat{\pi}\left(\mathbf{Z}_{n}\right)\left[1-\hat{\pi}\left(\mathbf{Z}_{n}\right)\right]\right\}$.

A interpretação dos parâmetros da regressão logística é feita por meio da razão de chances. A chance do evento ocorrer é definida por

$$
\frac{\pi\left(\mathbf{z}_{i}\right)}{1-\pi\left(\mathbf{z}_{i}\right)}=e^{\mathbf{z}_{i} \boldsymbol{\beta}} .
$$

Para dois indivíduos com valores das covariáveis dados por $\mathbf{z}_{i}$ e $\mathbf{z}_{j}$, a razão de chances fica dada por

$$
\psi_{i j}=\frac{\pi\left(\mathbf{z}_{i}\right)\left[1-\pi\left(\mathbf{z}_{j}\right)\right]}{\pi\left(\mathbf{z}_{j}\right)\left[1-\pi\left(\mathbf{z}_{i}\right)\right]}=e^{\left(\mathbf{z}_{i}-\mathbf{z}_{j}\right) \boldsymbol{\beta}} .
$$


Se essa razão é maior que 1, por exemplo igual a $K$, significa que o indivíduo com características dadas por $\mathbf{z}_{i}$ tem chance $(K-1)$ vezes maior de tornar-se inadimplente dentro de um determinado período do que o indivíduo com características dadas por $\mathbf{z}_{j}$.

\subsection{Análise de Sobrevivência}

$\mathrm{Na}$ análise de sobrevivência, a resposta de interesse é o tempo até que um evento ocorra, medido a partir de um instante precisamente definido (origem). Esse tempo é denominado tempo de sobrevivência ou tempo de falha e pode ser medido em diversas escalas como, por exemplo, dias, semanas, meses ou anos. No caso dos dados de crédito considerados neste trabalho, o evento de interesse é a inadimplência do cliente.

A função de sobrevivência é definida como a probabilidade de um indivíduo sobreviver além de um tempo $t$ (Klein e Moeschberger, 1997). Representando o tempo de sobrevivência pela variável aleatória contínua $T$, com função de densidade de probabilidade $f(t)$, a função de sobrevivência é então dada por

$$
S(t)=\mathrm{P}(T>t)=\int_{t}^{\infty} f(u) d u, \quad t \geq 0 .
$$

Para a aplicação considerada neste trabalho, $S(t)$ é a probabilidade da inadimplência do cliente ocorrer após um determinado instante de tempo $t$.

Note que a função de distribuição acumulada pode ser escrita como

$$
F(t)=1-S(t) .
$$

Portanto, $S(t)$ é uma função monótona e não crescente com $S(0)=1$ e $S(\infty)=\lim _{t \rightarrow \infty} S(t)=0$.

Outra função importante é a função de taxa de falha, que pode ser interpretada como o potencial instantâneo, por unidade de tempo, de um evento ocorrer, dado que o evento não ocorreu até o tempo $t$ (Kleinbaum, 1995). Esta função é definida por

$$
\lambda(t)=\lim _{\Delta t \rightarrow 0} \frac{\mathrm{P}(t \leq T<t+\Delta t \mid T \geq t)}{\Delta t},
$$


de tal forma que $\lambda(t) \geq 0$, para todo $t \geq 0$.

No estudo considerado, a função de taxa de falha representa o potencial instantâneo de um cliente tornar-se inadimplente no tempo $t$, dado que ele ainda não era inadimplente até esse instante.

Com base na função de taxa de falha pode-se definir a função de taxa de falha acumulada

$$
\Lambda(t)=\int_{0}^{t} \lambda(u) d u, \quad t \geq 0 .
$$

A função de taxa de falha acumulada não tem uma interpretação direta, mas pode ser útil quando $\lambda(t)$ é difícil de ser estimada Colosimo e Giolo, 2006).

É possível estabelecer uma relação direta entre a função de sobrevivência e a função de taxa de falha. Como no caso estudado $T$ é uma variável contínua, pode-se escrever

$$
\lambda(t)=\frac{f(t)}{S(t)}=-\frac{d}{d t} \log S(t)
$$

ou, equivalentemente,

$$
S(t)=\exp \left[-\int_{0}^{t} \lambda(u) d u\right]=\exp [-\Lambda(t)]
$$

Percebe-se que as funções $f(t), F(t), S(t)$ e $\lambda(t)$ fornecem especificações matematicamente equivalentes para a distribuição de $T$ (Lawless, 2003).

O tempo médio de sobrevivência ou, neste caso, o tempo médio até um cliente tornar-se inadimplente, pode ser obtido pela área sob a função de sobrevivência, isto é,

$$
\mu=E[T]=\int_{0}^{\infty} S(t) d t
$$

Muitas vezes não é possível conhecer o tempo de sobrevivência exato de um indivíduo, caracterizando o que é conhecido como censura. Uma observação censurada é aquela cujo valor é incompleto devido a fatores aleatórios para cada indivíduo (Hosmer et al., 2008). Três tipos de censura são usualmente definidos: censura à direita, censura à esquerda e censura intervalar. 
No caso de censura à direita, sabe-se que o evento aconteceu após o instante de censura, mas não se sabe exatamente quando ocorreu. Este estudo envolve dados censurados à direita e o período de acompanhamento, pré-determinado, é igual para todos os indivíduos. Quando se trata de dados de crédito, a censura pode ser devida, por exemplo, à perda de contato com o cliente ou à não ocorrência da inadimplência até o final do período de acompanhamento.

A censura à esquerda dá-se quando o evento de interesse ocorreu antes do começo do estudo. No caso da censura intervalar, sabe-se apenas que o evento ocorreu dentro de um intervalo de tempo e, portanto, este tipo de censura é considerado como uma generalização dos outros dois tipos. Este é o caso, por exemplo, quando os dados são coletados de tempos em tempos.

Os dados censurados não devem ser excluídos da análise estatística, pois, mesmo sendo incompletas, as observações censuradas fornecem informação sobre o tempo de sobrevivência e também porque a omissão das censuras no cálculo pode subestimar as quantidades de interesse, acarretando conclusões viciadas.

Os dados do estudo serão representados pelo par de variáveis aleatórias $\left(X_{i}, \delta_{i}\right), i=1, \ldots, n$, em que $X_{i}$ representa o tempo observado para o cliente $i$ e $\delta_{i}$ indica se $X_{i}$ é um tempo de falha $\left(\delta_{i}=1\right)$ ou um tempo de censura $\left(\delta_{i}=0\right)$. Denotando por $T_{i}$ a variável aleatória que representa o tempo de falha e por $C_{i}$ a variável aleatória, independente de $T_{i}$, que representa o tempo de censura, então, como os dados apresentam censura à direita, $X_{i}=\min \left(T_{i}, C_{i}\right) \mathrm{e}$

$$
\delta_{i}= \begin{cases}1 & \text { se } T_{i} \leq C_{i} \\ 0 & \text { se } T_{i}>C_{i}\end{cases}
$$

A análise de sobrevivência para dados censurados é usualmente feita por meio da estimação da função de sobrevivência pelo método não paramétrico de Kaplan-Meier e do estudo da relação da resposta com as covariáveis por meio do modelo semiparamétrico de Cox. Ambos são descritos a seguir.

\subsubsection{Estimador de Kaplan-Meier}

Por causa da presença de censuras, não é possível recorrer às técnicas gráficas convencionais para descrever os dados. O principal componente na 
análise descritiva envolvendo dados de sobrevivência é a função de sobrevivência (Colosimo e Giolo, 2006). No caso de censura à direita, a função de sobrevivência $S(t)$ pode ser estimada pelo estimador não-paramétrico proposto por Kaplan e Meier (1958). Este estimador, também chamado estimador produto-limite, é uma função escada não-crescente e contínua à esquerda, com saltos nos tempos de falha. É definido por

$$
\widehat{S}(t)= \begin{cases}1 & \text { se } t<t_{(1)} \\ \prod_{i: t_{(i)} \leq t}\left[1-\frac{d_{i}}{Y_{i}}\right] \quad \text { se } t_{(1)} \leq t \quad, \quad t \geq 0,\end{cases}
$$

em que

$t_{(i)}$ é o $i$-ésimo menor tempo de falha, considerando-se que se tem $D$ tempos de falha com $t_{(1)}<t_{(2)}<\ldots<t_{(D)}$;

$d_{i}$ é o número de eventos que ocorreram em $t_{(i)} \mathrm{e}$

$Y_{i}$ é o número de indivíduos em risco no tempo $t_{(i)}$, ou seja, o número de indivíduos que ainda estão no estudo no tempo $t_{(i)}$. O grupo de indivíduos em risco inclui apenas os indivíduos para os quais o evento ou a censura ocorreu em um instante maior ou igual a $t_{(i)}$.

Quando o maior instante de tempo observado, $x_{\max }$, corresponde somente a um tempo de falha, o valor de $\widehat{S}(t)$ é zero para $t \geq x_{\max }$. Já quando $x_{\max }$ corresponde a um tempo de censura, a curva de sobrevivência estimada (curva de Kaplan-Meier) não decai até zero e temos uma indefinição para $\widehat{S}(t)$, que é resolvida arbitrariamente conforme descrito adiante.

A variância do estimador de Kaplan-Meier é estimada pela fórmula de Greenwood (Greenwood, 1926):

$$
\widehat{\operatorname{Var}}[\widehat{S}(t)]=[\widehat{S}(t)]^{2} \sum_{i: t_{(i)} \leq t} \frac{d_{i}}{Y_{i}\left(Y_{i}-d_{i}\right)} .
$$

O tempo médio de sobrevivência pode ser estimado pela área sob a curva de Kaplan-Meier, que é a soma de áreas de retângulos. Um problema na estimação do tempo médio é quando $x_{\max }$ corresponde a um tempo de censura, pois, como a curva de Kaplan-Meier não decai até zero, a área abaixo da curva é infinita. Nesse caso, uma das alternativas é definir $\widehat{S}(t)=0$ para $t \geq x_{\max }$ o que pode levar a uma subestimação do tempo médio de 
sobrevivência.

No caso de dados sem censura, o estimador de Kaplan-Meier se reduz à função de sobrevivência empírica

$$
\widehat{S}(t)=\sum_{i=1}^{n} \frac{I\left(T_{i}>t\right)}{n}
$$

com

$$
I\left(T_{i}>t\right)=\left\{\begin{array}{ll}
1 & \text { se } T_{i}>t \\
0 & \text { se } T_{i} \leq t .
\end{array} \quad, \quad i=1, \ldots, n, \quad t \geq 0 .\right.
$$

\subsubsection{Modelo de Riscos Proporcionais de Cox}

Na maioria da vezes, o interesse é estudar o efeito de covariáveis na sobrevivência, de maneira similar aos modelos de regressão. Por exemplo, em análise de crédito, características do cliente como idade e sexo podem influenciar o tempo até a inadimplência.

Seja $\mathbf{Z}_{i}=\left(Z_{i 1}, \ldots, Z_{i p}\right)$ o vetor de covariáveis associado ao indivíduo $i$, $i=1, \ldots, n$. Os dados para o $i$-ésimo indivíduo serão então representados pelo trio $\left(X_{i}, \delta_{i}, \mathbf{Z}_{i}\right)$.

Das funções que descrevem a distribuição do tempo de sobrevivência, a função de taxa de falha é a que melhor e que mais diretamente captura a essência do processo de sobrevivência (Hosmer et al., 2008). O modelo sugerido por Cox (1972) para relacionar a distribuição do tempo de sobrevivência $T_{i}$ e as covariáveis $\mathbf{Z}_{i}$ é dado por:

$$
\lambda\left(t \mid \mathbf{Z}_{i}=\mathbf{z}_{i}\right)=\lambda_{0}(t) \exp \left(\mathbf{z}_{i} \boldsymbol{\beta}\right)
$$

em que

$\boldsymbol{\beta}$ é um vetor de dimensão $p$ de parâmetros desconhecidos e

$\lambda_{0}(t)$ é uma função arbitrária e desconhecida, porém não-negativa, que representa a função de taxa de falha associada ao tempo de sobrevivência $T_{i}$ quando $\mathbf{Z}_{i}=\mathbf{0}$. Esta função é conhecida como função de taxa de falha basal. 
Note que, em (2.7), garante-se que a função de taxa de falha é estritamente positiva.

O modelo de Cox possui uma componente, $\lambda_{0}(t)$, que pode variar ao longo do tempo $t$. No entanto, ao comparar-se dois indivíduos com valores das covariáveis dados por $\mathbf{z}_{i}$ e $\mathbf{z}_{j}$, por meio da razão das taxas de falha, tem-se que

$$
H R=\frac{\lambda_{0}(t) \exp \left(\mathbf{z}_{i} \boldsymbol{\beta}\right)}{\lambda_{0}(t) \exp \left(\mathbf{z}_{j} \boldsymbol{\beta}\right)} .=\exp \left[\left(\mathbf{z}_{i}-\mathbf{z}_{j}\right) \boldsymbol{\beta}\right] .
$$

Assim, a componente $\lambda_{0}(t)$ é eliminada. Como essa razão é constante ao longo do tempo, o modelo de Cox é também conhecido como modelo de riscos proporcionais.

Com base na função de taxa de falha, pode-se calcular a função de sobrevivência sob o modelo de Cox como

$$
\begin{aligned}
S\left(t \mid \mathbf{Z}_{i}=\mathbf{z}_{i}\right) & =\exp \left[-\int_{0}^{t} \lambda\left(u \mid \mathbf{Z}_{i}=\mathbf{z}_{i}\right) d u\right]= \\
& =\exp \left[-\int_{0}^{t} \lambda_{0}(u) \exp \left(\mathbf{z}_{i} \boldsymbol{\beta}\right) d u\right]= \\
& =\left[\exp \left(-\int_{0}^{t} \lambda_{0}(u) d u\right)\right]^{\exp \left(\mathbf{z}_{i} \boldsymbol{\beta}\right)}
\end{aligned}
$$

ou, equivalentemente,

$$
S\left(t \mid \mathbf{Z}_{i}=\mathbf{z}_{i}\right)=\left[S_{0}(t)\right]^{\exp \left(\mathbf{z}_{i} \boldsymbol{\beta}\right)},
$$

em que $S_{0}(t)=\exp \left(-\int_{0}^{t} \lambda_{0}(u) d u\right)$ é a função de sobrevivência basal.

A média do tempo de sobrevivência sob o modelo de Cox, para um indivíduo com valor de covariáveis $\mathbf{z}_{i}$, fica dada por

$$
\mu\left(\mathbf{z}_{i}\right)=\int_{0}^{\infty}\left[\exp \left(-\int_{0}^{t} \lambda_{0}(u) d u\right)\right]^{\exp \left(\mathbf{z}_{i} \boldsymbol{\beta}\right)} d t
$$

Como a função $\lambda_{0}(t)$ é de interesse secundário, Cox (1975) propôs a utilização da função de verossimilhança parcial para estimar $\boldsymbol{\beta}$. Assumindo-se que a censura é não informativa, que, dado $\mathbf{Z}_{i}=\mathbf{z}_{i}$, os tempos de falha e de censura para o $i$-ésimo indivíduo são independentes (Klein e Moesch- 
berger, 1997) e que não existem empates nos tempos de falha, a função de verossimilhança parcial é expressa por

$$
L(\boldsymbol{\beta})=\prod_{i=1}^{D} \frac{\exp \left[\mathbf{z}_{(i)} \boldsymbol{\beta}\right]}{\left.\sum_{j: j \in R\left(t_{(i)}\right)} \exp \left[\mathbf{z}_{(j)} \boldsymbol{\beta}\right)\right]}
$$

em que

$t_{(i)}$ é o $i$-ésimo tempo de falha, considerando-se $D$ tempos de falha com $t_{(1)}<t_{(2)}<\ldots<t_{(D)}$

$R\left(t_{(i)}\right)$ é o conjunto dos índices dos indivíduos em risco no tempo $t_{(i)} \mathrm{e}$

$\mathbf{z}_{(i)}$ é o vetor de valores observados das covariáveis, associado ao indivíduo cujo tempo de falha é $t_{(i)}$.

Na prática, podem ocorrer empates nos tempos de falha e de censura. O estudo considerado neste trabalho envolve esta situação. Quando ocorrem empates entre os tempos de falha e de censura, adota-se a convenção de que a censura ocorreu após a falha. Para empates entre os tempos de falha, a função de verossimilhança parcial deve ser modificada. Segundo Hosmer et al. (2008), a aproximação sugerida por Efron (1977) é a mais indicada e é dada por

$$
L(\boldsymbol{\beta})=\prod_{i=1}^{D} \frac{\exp \left(\mathbf{s}_{i} \boldsymbol{\beta}\right)}{\prod_{j=1}^{d_{i}}\left[\sum_{k: k \in R\left(t_{(i)}\right)} \exp \left(\mathbf{z}_{k} \boldsymbol{\beta}\right)-\frac{j-1}{d_{i}} \sum_{k: k \in \mathbb{D}\left(t_{(i)}\right)} \exp \left(\mathbf{z}_{k} \boldsymbol{\beta}\right)\right]}
$$

em que

$d_{i}$ é o número de falhas em $t_{(i)}$;

$\mathbb{D}\left(t_{(i)}\right)$ é o conjunto dos índices dos indivíduos que falharam em $t_{(i)}$ e

$s_{i}=\sum_{k \in \mathbb{D}\left(t_{(i)}\right)} \mathbf{z}_{k}$ é a soma dos vetores $\mathbf{z}_{k}$ de todos os indivíduos que falharam em $t_{(i)}$.

O método utilizado para estimar os coeficientes $\boldsymbol{\beta}$ é o de máxima verossimilhança parcial, que consiste em obter o valor de $\boldsymbol{\beta}$ que maximiza o logaritmo de 2.11. Este valor é obtido por meio de métodos numéricos, como o método de Newton-Raphson. 
O estimador da matriz de variância-covariância do estimador de máxima verossimilhança parcial $\hat{\boldsymbol{\beta}}$ é dado por

$$
\widehat{\operatorname{Var}}(\hat{\boldsymbol{\beta}})=\left[\mathbf{I}_{s}(\hat{\boldsymbol{\beta}})\right]^{-1}
$$

em que $\mathbf{I}_{s}(\hat{\boldsymbol{\beta}})$ é a informação observada, baseada em 2.11 e avaliada em $\hat{\boldsymbol{\beta}}$.

Embora os coeficientes $\boldsymbol{\beta}$ sejam as quantidades de maior interesse a serem estimadas, funções relacionadas a $\lambda_{0}(t)$ também são importantes no estudo de modelos de regressão em análise de sobrevivência. Sob o modelo de Cox, algumas dessas funções são a função de taxa de falha acumulada basal

$$
\Lambda_{0}(t)=\int_{0}^{t} \lambda_{0}(u) d u
$$

e a função de sobrevivência basal

$$
S_{0}(t)=\exp \left[-\Lambda_{0}(t)\right]
$$

Uma estimativa para $\Lambda_{0}(t)$, proposta por Breslow (1972), é dada por

$$
\widehat{\Lambda}_{0}(t)=\sum_{i: t_{(i)}<t} \frac{d_{i}}{\left.\sum_{j: j \in R\left(t_{(i)}\right)} \exp \left[\mathbf{z}_{(j)} \hat{\boldsymbol{\beta}}\right)\right]},
$$

em que $\hat{\boldsymbol{\beta}}$ é o estimador de máxima verossimilhança parcial.

A partir de (2.12), pode-se estimar a função de sobrevivência basal por

$$
\widehat{S}_{0}(t)=\exp \left[-\hat{\Lambda}_{0}(t)\right]
$$

e a função de sobrevivência, para uma observação com valor das covariáveis dado por $\mathbf{z}_{i}$, por

$$
\widehat{S}\left(t \mid \mathbf{Z}_{i}=\mathbf{z}_{i}\right)=\left[\hat{S}_{0}(t)\right]^{\exp \left(\mathbf{z}_{i} \hat{\boldsymbol{\beta}}\right)}
$$

A média do tempo de sobrevivência pode ser estimada por

$$
\widehat{\mu}\left(\mathbf{z}_{\mathbf{i}}\right)=\int_{0}^{\infty}\left[\exp \left(-\hat{\Lambda}_{0}(t)\right)\right]^{\exp \left(\mathbf{z}_{i} \hat{\boldsymbol{\beta}}\right)} d t
$$




\section{$2.3 \quad$ Pseudo-valores}

Os pseudo-valores são construídos com base no método conhecido como jackknife, introduzido por Quenouille (1956) com o principal objetivo de construir um estimador, baseado nos pseudo-valores, com viés menor do que o estimador baseado nos valores da amostra. No entanto, Quenouille ainda não utilizava os termos "jackknife" e "pseudo-valor". Segundo Miller (1974), estes termos foram sugeridos por Tukey em um trabalho não publicado. Além disso, Tukey (1958) indicou que os pseudo-valores podiam ser usados para estimação de intervalos de confiança.

Andersen et al. (2003) desenvolveram uma técnica em que os pseudovalores são utilizados como variável resposta em análise de regressão. A principal motivação é estabelecer de forma simples os efeitos de covariáveis em uma variável de interesse, quando os modelos usuais estabelecem essa relação de forma complexa. No trabalho de 2003, a técnica foi aplicada a modelos multi-estados. Esses modelos são utilizados, por exemplo, quando um indivíduo pode ser classificado em diferentes estados a cada instante de tempo. Muitas vezes, o interesse é calcular a probabilidade de transição entre os diferentes estados. Usualmente, modela-se cada intensidade de transição separadamente e calcula-se as probabilidades de transição por meio de complexas funções não lineares dos coeficientes de regressão das intensidades. Por meio da técnica baseada em pseudo-valores, é possível modelar diretamente as probabilidades de transição, simplificando a interpretação da relação das covariáveis.

Andersen et al. (2004) também utilizaram um modelo de regressão baseado em pseudo-valores para avaliar o efeito de covariáveis diretamente sobre a média e a média restrita do tempo de sobrevivência. A média restrita é a média do tempo, calculada ao se considerar a curva de sobrevivência truncada em um determinado instante de tempo. Modelos de regressão para dados de sobrevivência são usualmente especificados por meio da função de taxa de falha. Assim, o efeito das covariáveis sobre o risco de falha é facilmente modelado, mas a média e a média restrita do tempo de sobrevivência podem ser funções complexas das covariáveis e de seus parâmetros. Portanto, os pseudo-valores tornam-se uma alternativa interessante. 
Tunes-da-Silva e Klein (2009) utilizaram a técnica de pseudo-valores para modelar a média do tempo de sobrevivência ajustado à qualidade de vida. Esse tipo de modelo considera aspectos ligados à sensação de bem estar do paciente, caracterizada por diferentes estados de saúde, bem como o tempo em que o paciente permanece em cada um desses estados. Os modelos usuais são especificados em termos da função de taxa de falha das transições entre os estados, o que pode levar a relações de difícil interpretação entre a média do tempo de sobrevivência ajustado à qualidade de vida e as covariáveis. A técnica baseada em pseudo-valores é, portanto, uma alternativa interessante para modelar os efeitos das covariáveis diretamente na média.

O conceito de pseudo-valor pode ser introduzido por meio de um caso simples, que é a estimação da média de uma população (Manly, 1998). Considere uma amostra aleatória de $n$ variáveis aleatórias $X_{1}, \ldots, X_{n}$ retirada de uma população com média $\mu$. Um estimador para $\mu$ é a média amostral, dada por

$$
\bar{X}=\frac{1}{n} \sum_{j=1}^{n} X_{j}
$$

Retirando-se o $i$-ésimo valor da amostra e recalculando-se a média, temse um novo estimador baseado em $(n-1)$ observações, dado por

$$
\bar{X}_{-i}=\frac{1}{n-1}\left(\sum_{j=1}^{n} X_{j}-X_{i}\right) .
$$

Observe que o $i$-ésimo valor pode ser escrito como uma combinação linear de $\bar{X}$ e $\bar{X}_{-i}$ :

$$
X_{i}=n \bar{X}-(n-1) \bar{X}_{-i}
$$

Se o objetivo for estimar outro parâmetro $\theta$, diferente de $\mu$, o estimador não será mais a média amostral $\bar{X}$. Nesse caso, pode não ser possível reescrever o $i$-ésimo valor $X_{i}$ como uma combinação linear envolvendo estimadores de $\theta$. Como será visto a seguir, uma expressão análoga a (2.15 pode ser derivada, dando origem ao $i$-ésimo pseudo-valor.

Suponha agora uma situação mais geral, com as variáveis aleatórias $X_{1}, \ldots, X_{n}$, independentes e identicamente distribuídas, com densidade $p\left(x_{i}\right)$, 
em que o parâmetro de interesse possa ser expresso como

$$
\theta=E\left[h\left(X_{i}\right)\right]=\int h\left(x_{i}\right) p\left(x_{i}\right) d x_{i},
$$

em que $h(\cdot)$ é uma função adequadamente estabelecida.

Suponha, também, que exista um estimador não viesado para $\theta$, representado por $\hat{\theta}_{n}$, isto é,

$$
\begin{aligned}
E\left[\hat{\theta}_{n}\right] & =E\left[\hat{\theta}_{n}\left(X_{1}, \ldots, X_{n}\right)\right]= \\
& =\int \ldots \int \hat{\theta}_{n}\left(X_{1}, \ldots, X_{n}\right) p\left(x_{1}\right) \ldots p\left(x_{n}\right) d x_{1} \ldots d x_{n}=\theta .
\end{aligned}
$$

Por analogia com a expressão 2.15), os pseudo-valores são definidos por

$$
\hat{\theta}_{n, i}=n \hat{\theta}_{n}-(n-1) \hat{\theta}_{n}^{-i}, \quad i=1, \ldots, n,
$$

em que $\hat{\theta}_{n}^{-i}$ é o estimador de $\theta$ baseado na amostra sem a $i$-ésima observação. Portanto, o $i$-ésimo pseudo-valor é uma combinação linear de $\hat{\theta}_{n}$ e $\hat{\theta}_{n}^{-i}$ e calcula-se tantos pseudo-valores quantos forem os dados na amostra.

Quando o interesse é estudar o efeito de covariáveis em $\theta$ por meio de um modelo de regressão, pode ser conveniente utilizar os pseudo-valores como variáveis resposta em substituição à $h\left(X_{i}\right)$. Ao utilizar os pseudo-valores, a ideia é que, ao retirar-se a $i$-ésima observação, tem-se informação sobre como as covariáveis do $i$-ésimo indivíduo afetam o estimador de $\theta$ (Andersen et al., 2003). Segundo Andersen et al. (2003), o uso dos pseudo-valores pode ser justificado pelo fato de $\hat{\theta}_{n, i}$ ter valor esperado igual ao de $h\left(X_{i}\right)$, isto é, pelo seguinte Teorema.

Teorema 1. Sejam as variáveis aleatórias $X_{1}, \ldots, X_{n}$ independentes e identicamente distribuídas e os pseudo-valores definidos por 2.1\%). Então,

$$
E\left[\hat{\theta}_{n, i}\right]=E\left[h\left(X_{i}\right)\right]=\theta, \quad i=1, \ldots, n .
$$

Demonstração. Para verificar (2.18), considere covariáveis $\mathbf{Z}_{1}, \ldots, \mathbf{Z}_{n}$, independentes e identicamente distribuídas, com densidade $q\left(\mathbf{z}_{i}\right)$ e suponha que a densidade conjunta de $X_{i}$ e $\mathbf{Z}_{i}$ é dada por $r\left(x_{i}, \mathbf{z}_{i}\right)$. Observe que a 
densidade marginal de $X_{i}$, dada por

$$
p\left(x_{i}\right)=\int r\left(x_{i}, \mathbf{z}_{i}\right) d \mathbf{z}_{i},
$$

é a mesma para todo $i$ e, por isso, as variáveis $X_{i}$ também são identicamente distribuídas.

Substituindo (2.19) na equação 2.16), tem-se que

$$
\begin{aligned}
\theta & =E_{p}\left[h\left(X_{i}\right)\right]=\int h\left(x_{i}\right) p\left(x_{i}\right) d x_{i}= \\
& =\iint h\left(x_{i}\right) r\left(x_{i}, \mathbf{z}_{i}\right) d x_{i} d \mathbf{z}_{i}=E_{r}\left[h\left(X_{i}\right)\right]
\end{aligned}
$$

em que $E_{p}(\cdot)$ representa a esperança com relação à densidade marginal de $X_{i}$ e $E_{r}(\cdot)$ representa a esperança com relação à densidade conjunta de $X_{i}$ e $\mathbf{Z}_{i}$.

Definindo a variável aleatória $\theta_{i}\left(\mathbf{Z}_{i}\right)=E\left[h\left(X_{i}\right) \mid \mathbf{Z}_{i}\right]$, tem-se que

$$
\theta_{i}\left(\mathbf{z}_{i}\right)=E\left[h\left(X_{i}\right) \mid \mathbf{Z}_{i}=\mathbf{z}_{i}\right]=\int h\left(x_{i}\right) \frac{r\left(x_{i}, \mathbf{z}_{i}\right)}{q\left(\mathbf{z}_{i}\right)} d x_{i}, \quad i=1, \ldots, n .
$$

O primeiro passo para provar a relação 2.18 é provar que $E_{r}\left[h\left(X_{i}\right)\right]=$ $E_{r}\left[\theta_{i}\left(\mathbf{Z}_{i}\right)\right]$.

Utilizando (2.21), a equação 2.20 pode ser reescrita como

$$
\theta=E_{p}\left[h\left(X_{i}\right)\right]=E_{r}\left[h\left(X_{i}\right)\right]=\int \theta_{i}\left(\mathbf{z}_{i}\right) q\left(\mathbf{z}_{i}\right) d \mathbf{z}_{i}=E_{q}\left[\theta_{i}\left(\mathbf{Z}_{i}\right)\right]
$$

em que $E_{q}(\cdot)$ representa a esperança com relação à densidade marginal de $\mathbf{Z}_{i}$.

Além disso, tem-se que

$$
\begin{aligned}
E_{q}\left[\theta_{i}\left(\mathbf{Z}_{i}\right)\right] & =\int \theta_{i}\left(\mathbf{z}_{i}\right) q\left(\mathbf{z}_{i}\right) d \mathbf{z}_{i}=\int \theta_{i}\left(\mathbf{z}_{i}\right) \int r\left(x_{i}, \mathbf{z}_{i}\right) d x_{i} d \mathbf{z}_{i}= \\
& =\iint \theta_{i}\left(\mathbf{z}_{i}\right) r\left(x_{i}, \mathbf{z}_{i}\right) d x_{i} d \mathbf{z}_{i},
\end{aligned}
$$

ou seja,

$$
E_{q}\left[\theta_{i}\left(\mathbf{Z}_{i}\right)\right]=E_{r}\left[\theta_{i}\left(\mathbf{Z}_{i}\right)\right]
$$


Então, por (2.20), (2.22) e (2.24), a seguinte relação também é verdadeira:

$$
E_{r}\left[\theta_{i}\left(\mathbf{Z}_{i}\right)\right]=E_{r}\left[h\left(X_{i}\right)\right]=\theta
$$

Agora basta provar que $E_{r}\left[\theta_{i}\left(\mathbf{Z}_{i}\right)\right]=E_{r}\left[\hat{\theta}_{n, i}\right]$. Para tal, considere a média de $\theta_{i}\left(\mathbf{Z}_{i}\right)$ :

$$
\tilde{\theta}_{n}=\frac{1}{n} \sum_{j} \theta_{j}\left(\mathbf{Z}_{j}\right) .
$$

Como as variáveis $\mathbf{Z}_{1}, \ldots, \mathbf{Z}_{n}$ são identicamente distribuídas, tem-se que:

$$
E_{q}\left[\tilde{\theta}_{n}\right]=\frac{1}{n} n E_{q}\left[\theta_{i}\left(\mathbf{Z}_{i}\right)\right]=E_{q}\left[\theta_{i}\left(\mathbf{Z}_{i}\right)\right]=\theta=E_{p}\left[\hat{\theta}_{n}\right]
$$

Como, por 2.24), $E_{q}\left[\theta_{i}\left(\mathbf{Z}_{i}\right)\right]=E_{r}\left[\theta_{i}\left(\mathbf{Z}_{i}\right)\right]$, tem-se que $E_{q}\left[\tilde{\theta}_{n}\right]=E_{r}\left[\tilde{\theta}_{n}\right]$. Além disso, analogamente à 2.23 , tem-se que $E_{p}\left[\hat{\theta}_{n}\right]=E_{r}\left[\hat{\theta}_{n}\right]$. Logo, a seguinte igualdade também é válida:

$$
E_{r}\left[\tilde{\theta}_{n}\right]=E_{r}\left[\hat{\theta}_{n}\right]
$$

Considere também a média baseada nos $(n-1)$ valores ao excluir-se a $i$-ésima observação $\theta_{i}\left(\mathbf{Z}_{i}\right)$ :

$$
\tilde{\theta}_{n}^{-i}=\frac{1}{n-1} \sum_{j \neq i} \theta_{j}\left(\mathbf{Z}_{j}\right) .
$$

Como, por 2.26$), E_{r}\left[\hat{\theta}_{n}\right]=E_{r}\left[\tilde{\theta}_{n}\right]$, tem-se também que

$$
E_{r}\left[\hat{\theta}_{n}^{-i}\right]=E_{r}\left[\tilde{\theta}_{n}^{-i}\right]
$$

Logo, a esperança do $i$-ésimo pseudo-valor é

$$
\begin{aligned}
E_{r}\left[\hat{\theta}_{n, i}\right] & =n E_{r}\left[\hat{\theta}_{n}\right]-(n-1) E_{r}\left[\hat{\theta}_{n}^{-i}\right]=n E_{r}\left[\tilde{\theta}_{n}\right]-(n-1) E_{r}\left[\tilde{\theta}_{n}^{-i}\right]= \\
& =n E_{r}\left[\frac{1}{n} \sum_{j} \theta_{j}\left(\mathbf{Z}_{j}\right)\right]-(n-1) E_{r}\left[\frac{1}{n-1} \sum_{j \neq i} \theta_{j}\left(\mathbf{Z}_{j}\right)\right]= \\
& =E_{r}\left[\sum_{j} \theta_{j}\left(\mathbf{Z}_{j}\right)-\sum_{j \neq i} \theta_{j}\left(\mathbf{Z}_{j}\right)\right]=E_{r}\left[\theta_{i}\left(\mathbf{Z}_{i}\right)\right]
\end{aligned}
$$


ou seja, a relação

$$
E_{r}\left[\hat{\theta}_{n, i}\right]=E_{r}\left[\theta_{i}\left(\mathbf{Z}_{i}\right)\right]
$$

também é verdadeira.

Portanto, como $E_{r}\left[\hat{\theta}_{n, i}\right]=E_{r}\left[\theta_{i}\left(\mathbf{Z}_{i}\right)\right]$ e, por 2.25$), E_{r}\left[\theta_{i}\left(\mathbf{Z}_{i}\right)\right]=E_{r}\left[h\left(X_{i}\right)\right]$, tem-se que $E_{r}\left[\hat{\theta}_{n, i}\right]=E_{r}\left[h\left(X_{i}\right)\right]$.

Observe que, no caso em que não há censuras, $\hat{\theta}_{n}$ pode ser escrito como a média de $h\left(X_{i}\right)$ e tem-se que

$$
\begin{gathered}
\hat{\theta}_{n}=\frac{1}{n} \sum_{j} h\left(X_{j}\right) \\
\hat{\theta}_{n}^{-i}=\frac{1}{n-1} \sum_{j \neq i} h\left(X_{j}\right) \\
\hat{\theta}_{n, i}=n \frac{1}{n} \sum_{j} h\left(X_{j}\right)-(n-1) \frac{1}{n-1} \sum_{j \neq i} h\left(X_{j}\right)=h\left(X_{i}\right),
\end{gathered}
$$

ou seja, nesse caso o pseudo-valor é a própria função $h\left(X_{i}\right)$. Se $h(\cdot)$ é a função identidade, o pseudo-valor é a própria observação original $X_{i}$.

\subsubsection{Estimação dos Parâmetros do Modelo de Regressão}

Andersen et al. (2003) sugerem a utilização de equações de estimação generalizadas (EEGs) para a obtenção de estimativas dos efeitos de covariáveis nos pseudo-valores. Este tipo de modelagem é importante, por exemplo, no caso de interesse em várias funções $h_{1}\left(X_{i}\right), h_{2}\left(X_{i}\right), \ldots, h_{k}\left(X_{i}\right)$. No caso de uma única função, pode-se considerar os modelos lineares generalizados (MLGs).

A seguir, é feita uma breve descrição das EEGs e dos MLGs e posteriormente discute-se sua aplicação aos pseudo-valores.

\section{Equações de Estimação Generalizadas e Modelos Lineares Gene- ralizados}

As equações de estimação generalizadas foram desenvolvidas como uma extensão dos algoritmos de modelos lineares generalizados de forma a permitir a modelagem de dados correlacionados (Hardin e Hilbe, 2003). A 
classe mais conhecida de equações de estimação generalizadas são aquelas introduzidas por Liang e Zeger (1986).

Uma equação de estimação é aquela cuja solução fornece a estimativa do parâmetro de interesse. No caso de modelos baseados na função de verossimilhança, a equação de estimação é encontrada derivando-se o logaritmo da função de verossimilhança em relação ao parâmetro de interesse e igualando a derivada a zero.

Cada unidade experimental $i, i=1, \ldots, n$, pode ser vista como um grupo de $r_{i}$ indivíduos ou como um único indivíduo em $r_{i}$ instantes de tempo. Seja $\mathbf{Y}_{i}=\left(Y_{i 1}, \ldots, Y_{i r_{i}}\right)^{T}$ o vetor resposta para a $i$-ésima unidade experimental. Assume-se que a distribuição marginal de $Y_{i j}$ é conhecida e pertence à família exponencial, dada por

$$
f\left(y ; \vartheta_{i j}, \phi\right)=\exp \left\{\phi\left[y \vartheta_{i j}-b\left(\vartheta_{i j}\right)\right]+c(y ; \phi)\right\}
$$

em que

$\vartheta_{i j}$ é tal que $E\left(Y_{i j}\right)=\mu_{i j}=b^{\prime}\left(\vartheta_{i j}\right)$;

$V_{i j}=d \mu_{i j} / d \vartheta_{i j}$ é denominada função de variância e

$\phi^{-1}>0$ é o parâmetro de dispersão, em geral desconhecido.

A relação entre a média $\mu_{i j}$ e as covariáveis $\mathbf{Z}_{i j}$ do $j$-ésimo elemento da $i$-ésima unidade experimental pode ser definida por um modelo linear generalizado, com uma função de ligação $g(\cdot)$ tal que

$$
g\left(\mu_{i j}\right)=\eta_{i j}=\mathbf{Z}_{i j} \boldsymbol{\beta}
$$

em que

$\mathbf{Z}_{i j}=\left(1, Z_{i j 1}, \ldots, Z_{i j p}\right) \mathrm{e}$

$\boldsymbol{\beta}$ é um vetor de dimensão $(p+1)$ de parâmetros desconhecidos.

A matriz de variância-covariância de $\mathbf{Y}_{i}$ é dada por

$$
\operatorname{Var}\left(\mathbf{Y}_{i}\right)=\phi^{-1} \mathbf{V}_{i}^{1 / 2} \mathbf{R}_{i} \mathbf{V}_{i}^{1 / 2}
$$

em que

$\mathbf{V}_{i}=\operatorname{diag}\left\{V_{i 1}, \ldots, V_{i r_{i}}\right\} \mathrm{e}$ 
$\mathbf{R}_{i}$ é a matriz de correlação $r_{i} \times r_{i}$ dos elementos da unidade $i$.

Se a matriz de correlação $\mathbf{R}_{i}$ depender de $\boldsymbol{\beta}$, a complexidade do processo de estimação será aumentada (Paula, 2004). Liang e Zeger (1986) propuseram uma matriz de correlação dada por $\mathbf{R}_{i}(\boldsymbol{\rho})$, em que $\boldsymbol{\rho}=\left(\rho_{1}, \ldots, \rho_{q}\right)^{T}$ é um vetor de parâmetros de perturbação que não depende de $\boldsymbol{\beta}$. Assumindo que $r_{i}=r$, tem-se que $\mathbf{R}_{i}(\boldsymbol{\rho})=\mathbf{R}(\boldsymbol{\rho})$ e a matriz de variância-covariância de $\mathbf{Y}_{i}$ é dada por

$$
\operatorname{Var}\left(\mathbf{Y}_{i}\right)=\Omega_{i}=\phi^{-1} \mathbf{V}_{i}^{1 / 2} \mathbf{R}(\boldsymbol{\rho}) \mathbf{V}_{i}^{1 / 2}
$$

em que $\mathbf{R}(\boldsymbol{\rho})$ é denominada matriz trabalho.

Observe que, se for assumida independência entre as observações dentro da unidade experimental, a matriz trabalho reduz-se à matriz identidade e a matriz de variância-covariância fica dada por

$$
\Omega_{i}=\phi^{-1} \mathbf{V}_{i}
$$

A equação de estimação para $\boldsymbol{\beta}$ é definida por

$$
\mathbf{U}(\hat{\boldsymbol{\beta}})=\sum_{i=1}^{n}\left(\frac{\partial \boldsymbol{\mu}_{i}}{\partial \boldsymbol{\beta}}\right)^{T} \boldsymbol{\Omega}_{i}^{-1}\left(\mathbf{Y}_{i}-\boldsymbol{\mu}_{i}\right)=\mathbf{0}
$$

em que

$\boldsymbol{\mu}_{i}=\left(\mu_{i 1}, \ldots, \mu_{i r}\right)^{T} \mathrm{e}$

$\left(\frac{\partial \boldsymbol{\mu}_{i}}{\partial \boldsymbol{\beta}}\right)^{T}$ é uma matriz de dimensão $(p+1) \times r$, em que cada linha corresponde ao vetor $\left(\frac{\partial \boldsymbol{\mu}_{i}}{\partial \beta_{j}}\right)^{T}$.

A estimação dos parâmetros $\rho$ e $\phi$ é feita pelo método dos momentos e usa-se essas estimativas para estimar $\boldsymbol{\beta}$ a cada passo de um processo iterativo, que é uma modificação do método scoring de Fisher.

No caso de cada unidade experimental $i$ possuir apenas um elemento, $r=1$ e pode-se recorrer aos modelos lineares generalizados, já que não é necessária a modelagem da correlação entre os dados da mesma unidade experimental. Nesse caso, as estimação dos parâmetros $\boldsymbol{\beta}$, é feita resolvendo- 
se a equação de estimação

$$
\mathbf{U}(\hat{\boldsymbol{\beta}})=\sum_{i=1}^{n}\left(\frac{\partial \boldsymbol{\mu}_{i}}{\partial \boldsymbol{\beta}}\right)^{T} \phi V_{i}^{-1}\left(\mathbf{Y}_{i}-\boldsymbol{\mu}_{i}\right)=\mathbf{0}
$$

em que $\phi V_{i}^{-1}$ é a variância de $\mathbf{Y}_{\mathbf{i}}$.

A solução da equação pode ser encontrada pelo método scoring de Fisher.

\section{Uso de EEGs e MLGs no Contexto de Pseudo-valores}

No caso de um modelo de regressão tendo os pseudo-valores como variáveis resposta, tem-se, para a $i$-ésima unidade experimental, $\hat{\boldsymbol{\theta}}_{n, i}=\left(\hat{\theta}_{n, i 1}, \ldots, \hat{\theta}_{n, i r}\right)^{T}$, com média $\boldsymbol{\mu}_{i}$. Seja $\boldsymbol{\theta}_{i}=\left(\theta_{i 1}, \ldots, \theta_{i r}\right)^{T}$ a representação simplificada de $\boldsymbol{\theta}_{i}\left(\mathbf{Z}_{i}\right)=E\left[h\left(X_{i}\right) \mid \mathbf{Z}_{i}\right]$. A relação entre $\theta_{i j}$ e $\mathbf{Z}_{i j}$ é dada pela função de ligação

$$
g\left(\theta_{i j}\right)=\mathbf{Z}_{i j} \boldsymbol{\beta}, \quad i=1, \ldots, n \quad e \quad j=1, \ldots, r .
$$

A equação de estimação fica dada por

$$
\mathbf{U}(\hat{\boldsymbol{\beta}})=\sum_{i=1}^{n}\left(\frac{\partial \boldsymbol{\mu}_{i}}{\partial \boldsymbol{\beta}}\right)^{T} \boldsymbol{\Omega}_{i}^{-1}\left(\hat{\boldsymbol{\theta}}_{n, i}-\boldsymbol{\theta}_{i}\right)=\sum_{i=1}^{n} \mathbf{U}_{i}(\hat{\boldsymbol{\beta}})=\mathbf{0} .
$$

No caso de $\theta$ ser um escalar, o vetor de respostas é dado pelos pseudovalores $\left(\hat{\theta}_{n, 1}, \ldots, \hat{\theta}_{n, n}\right)$. A relação entre $\theta_{i}$ e as covariáveis $\mathbf{Z}_{i}$ é dada por

$$
g\left(\theta_{i}\right)=\mathbf{Z}_{i} \boldsymbol{\beta}, \quad i=1, \ldots, n,
$$

e a equação de estimação reduz-se à

$$
\mathbf{U}(\hat{\boldsymbol{\beta}})=\sum_{i=1}^{n}\left(\frac{\partial \boldsymbol{\mu}_{i}}{\partial \boldsymbol{\beta}}\right)^{T} \phi V_{i}^{-1}\left(\hat{\theta}_{n, i}-\theta_{i}\right)=\sum_{i=1}^{n} \mathbf{U}_{i}(\hat{\boldsymbol{\beta}})=\mathbf{0}
$$

Segundo Andersen et al. (2003), para estabelecer as propriedades assintóticas de $\hat{\boldsymbol{\beta}}$, as condições requeridas de que

Condição 1. $E[\mathbf{U}(\boldsymbol{\beta})]=\mathbf{0} \mathrm{e}$

Condição 2. $\mathbf{U}_{i}(\boldsymbol{\beta})$ sejam independentes são satisfeitas no caso dos pseudo-valores. 
A Condição 1 é satisfeita, pois, por 2.28$), E_{r}\left[\hat{\theta}_{n, i}\right]=E_{r}\left[\theta_{i}\left(\mathbf{Z}_{i}\right)\right]$. No entanto, essa relação é válida ao considerar-se certas suposições, como, por exemplo, que as covariáveis $\mathbf{Z}_{i}$ são independentes e identicamente distribuídas.

A Condição 2 é satisfeita no caso de independência dos pseudo-valores. Neste caso, Andersen et al. (2003) baseiam-se na proposta de Tukey (1958) de que os pseudo-valores podem ser tratados como se fossem variáveis aleatórias independentes.

No entanto, outros autores questionam a validade das Condições 1 e 2 . Garthwaite et al. (2002) afirmam que os pseudo-valores não são independentes e Hinkley (1983) afirma que, em geral, eles são correlacionados.

Segundo Thorburn (1976), os pseudo-valores são assintoticamente não correlacionados se as seguintes condições são satisfeitas:

Condição 3. A variância de $\hat{\theta}_{n}$ pode ser escrita como $\operatorname{Var}\left(\hat{\theta}_{n}\right)=\sigma^{2} / n+\varepsilon_{n}$, em que

(i) $\varepsilon_{n}=o\left(n^{-1}\right)$,

(ii) $\varepsilon_{n}-\varepsilon_{n-1}=o\left(n^{-2}\right) \mathrm{e}$

(iii) $\varepsilon_{n}-2 \varepsilon_{n-1}+\varepsilon_{n-2}=o\left(n^{-3}\right)$.

Condição 4. A esperança condicional de $\hat{\theta}_{n+1}$ dados $X_{1}, \ldots, X_{n}$ pode ser escrita como

$$
E\left(\hat{\theta}_{n+1} \mid X_{1}, \ldots, X_{n}\right)=\frac{n}{n+1} \hat{\theta}_{n}+\hat{\varrho}_{n},
$$

em que $\hat{\varrho}_{n}=\hat{\varrho}_{n}\left(X_{1}, \ldots, X_{n}\right)$ é uma variável aleatória tal que

(iv) $\operatorname{Var}\left(\hat{\varrho}_{n}\right)=o\left(n^{-3}\right)$,

(v) $\operatorname{Cov}\left(\hat{\theta}_{n}, \hat{\varrho}_{n}\right)=\delta_{n}=o\left(n^{-2}\right) \mathrm{e}$

(vi) $\delta_{n}-\delta_{n-1}=o\left(n^{-3}\right)$.

O resultado principal sobre os pseudo-valores é que, se as Condições 3 e 4 são satisfeitas, tem-se que

$$
\begin{aligned}
& \operatorname{Var}\left(\hat{\theta}_{n, i}\right)=\sigma^{2}+o(1), \\
& \operatorname{Cov}\left(\hat{\theta}_{n, i}, \hat{\theta}_{n, j}\right)=o\left(n^{-1}\right), \quad i \neq j,
\end{aligned}
$$

o que implica que os pseudo-valores são assintoticamente não-correlacionados. 
Além disso, Thorburn (1977) provou que, se os pseudo-valores $\hat{\theta}_{n, i}$ convergirem em média quadrática para variáveis aleatórias $\hat{\theta}_{i}$, para todo $i$, então $\hat{\theta}_{1}, \hat{\theta}_{2}, \ldots$ são independentes, o que implica que os pseudo-valores são assintoticamente independentes.

Graw et al. (2009) estudam um caso específico de aplicação dos pseudovalores em modelos de riscos competitivos e afirmam que, nesse caso, a relação (2.28) parece não ser sempre válida. Na verdade, a relação foi demonstrada supondo-se que as covariáveis são variáveis aleatórias identicamente distribuídas, o que nem sempre ocorre. Assim, Graw et al. (2009) mostram que, se

Condição 5. o tempo de censura $C_{i}$ é independente do tempo de falha $T_{i}$ e das covariáveis $\mathbf{Z}_{i}$ e

Condição 6. são considerados apenas tempos $t<\tau$, tais que a função de sobrevivência da censura, $G(\tau)$, seja maior que zero,

então, tem-se que:

(i) os pseudo-valores $\hat{\theta}_{n, i}$ podem ser aproximados por variáveis aleatórias independentes e identicamente distribuídas,

(ii) $E\left(\hat{\theta}_{n, i}\right)=E\left[h\left(X_{i}\right)\right]+o(1) \mathrm{e}$

(iii) $E\left(\hat{\theta}_{n, i} \mid \mathbf{Z}_{i}\right)=\theta_{i}\left(\mathbf{Z}_{i}\right)+o(1)$.

Logo, se as Condições 5 e 6 são satisfeitas, então as Condições 1 e 2 são assintoticamente satisfeitas. Apesar da prova dos resultados ter sido feita para modelos de riscos competitivos, os autores sugerem que os resultados podem ser estendidos para outras situações. Quando tem-se o interesse em estimar a probabilidade de inadimplência em um instante $t$ fixado, o problema pode ser visto como um caso particular de riscos competitivos.

Sabe-se que, no caso em que não há censuras, os pseudo-valores reduzemse a $h\left(X_{i}\right)$. Como os $X_{i}$ 's são independentes, os $h\left(X_{i}\right)$ 's também o são. Portanto, no caso sem censuras, os pseudo-valores são independentes.

No caso com censuras, conforme já discutido, a demonstração da independência dos pseudo-valores não é trivial. Neste trabalho, será assumido que as condições que garantem o uso dos pseudo-valores como variáveis resposta em um modelo de regressão são satisfeitas. Esta suposição foi feita em 
outros trabalhos, como em Andersen et al. (2003), Andersen et al. (2004) e Helms (2003).

A seguir, são apresentados alguns exemplos de uso dos pseudo-valores em modelos de regressão.

\subsubsection{Exemplo 1 - Probabilidade de Inadimplência}

Seja $T_{i}$ o tempo de inadimplência e $\mathbf{Z}_{i}$ o vetor de covariáveis associadas ao cliente $i, i=1, \ldots, n$. Neste caso, a quantidade de interesse é a função de sobrevivência em um determinado instante de tempo fixo $t^{*}$, que pode ser interpretada como a probabilidade da inadimplência do cliente ocorrer após o instante $t^{*}$, ou seja,

$$
\theta=S\left(t^{*}\right)=\mathrm{P}\left(T_{i}>t^{*}\right)
$$

Portanto, se

$$
h\left(T_{i}\right)=I\left(T_{i}>t^{*}\right)
$$

então

$$
\theta=E\left[h\left(T_{i}\right)\right]=\mathrm{P}\left(h\left(T_{i}\right)=1\right)=\mathrm{P}\left(T_{i}>t^{*}\right)=S\left(t^{*}\right) .
$$

Um estimador para $S(t)$ é o estimador de Kaplan-Meier $\widehat{S}(t)$ e, quando os tempos de censura são independentes de $T_{i}$ e de $\mathbf{Z}_{i}$ (Andersen et al., 1993), tem-se que

$$
\hat{\theta}_{n}=\widehat{S}\left(t^{*}\right)
$$

O estimador $\hat{\theta}_{n}^{-i}=\widehat{S}\left(t^{*}\right)_{n}^{-i}$ é o estimador de Kaplan-Meier recalculado ao retirar-se o $i$-ésimo cliente da amostra. Os pseudo-valores são calculados por

$$
\hat{\theta}_{n, i}=n \hat{S}\left(t^{*}\right)_{n}-(n-1) \hat{S}\left(t^{*}\right)_{n}^{-i}, \quad i=1, \ldots, n
$$

e posteriormente podem ser usados como variável resposta em um modelo linear generalizado. Neste caso, esse modelo avalia os efeitos das características associadas ao cliente na probabilidade da inadimplência ocorrer após o instante $t^{*}$. Como os pseudo-valores podem assumir qualquer valor na reta, uma escolha para a distribuição utilizada no MLG seria a Normal. A função de ligação mais apropriada seria a logito, pois $S\left(t^{*}\right)$ está entre 0 e 1. A função de sobrevivência no instante $t^{*}$, dadas as covariáveis, é estimada 
por

$$
\hat{S}\left(t^{*} \mid \mathbf{Z}_{i}=\mathbf{z}_{i}\right)=\frac{e^{\mathbf{z}_{i} \hat{\boldsymbol{\beta}}}}{1+e^{\mathbf{z}_{i} \hat{\boldsymbol{\beta}}}}, \quad i=1, \ldots, n
$$

Observe que, no caso sem censuras, $\widehat{S}(t)$ é dada pela função de sobrevivência empírica, então

$$
\widehat{S}\left(t^{*}\right)=\frac{1}{n} \sum_{i} I\left(T_{i}>t^{*}\right)
$$

e assim, o $i$-ésimo pseudo-valor será igual a $I\left(T_{i}>t^{*}\right)$.

Por isso, a regressão logística pode ser considerada um caso particular da metodologia de pseudo-valores quando utiliza-se um modelo linear generalizado com distribuição Binomial e função de ligação logito.

\subsubsection{Exemplo 2 - Tempo Médio de Inadimplência}

Seja $T_{i}$ o tempo de inadimplência e $\mathbf{Z}_{i}$ o vetor de covariáveis associadas ao cliente $i, i=1, \ldots, n$. A quantidade de interesse é o tempo médio até a inadimplência do cliente, dada pela área abaixo da curva de sobrevivência

$$
\mu=\int_{0}^{\infty} S(t) d t
$$

Neste caso,

$$
h\left(T_{i}\right)=T_{i},
$$

de forma que $\theta=E\left[T_{i}\right]=\mu$.

Um estimador para o tempo médio de inadimplência é baseado no estimador de Kaplan-Meier $\widehat{S}(t)$, dado por

$$
\hat{\theta}_{n}=\hat{\mu}=\int_{0}^{\infty} \widehat{S}(t) d t
$$

isto é, a área abaixo da curva de Kaplan-Meier, que é a soma de áreas de retângulos.

Por causa da censura à direita, pode-se ter problemas na determinação da cauda da função de sobrevivência. No caso do último tempo observado, $x_{\max }$, ser uma censura, a curva de sobrevivência não decai até zero e, portanto, a área abaixo da curva é $\infty$. Uma alternativa é definir $\widehat{S}(t)=0$ para $t \geq x_{\max }$. 
Nesse caso tem-se que

$$
\hat{\mu}=\int_{0}^{t_{\max }} \widehat{S}(t) d t
$$

Os pseudo-valores, calculados por

$$
\hat{\theta}_{n, i}=n \hat{\mu}_{n}-(n-1) \hat{\mu}_{n}^{-i}, \quad i=1, \ldots, n,
$$

também podem variar de $-\infty$ a $+\infty$. Portanto, em um modelo linear generalizado a distribuição escolhida pode ser a Normal e a função de ligação a $\log$, já que $\mu$ deve ser positiva. O tempo médio até a inadimplência, dadas as covariáveis, é estimado por

$$
\hat{\mu}\left(\mathbf{z}_{i}\right)=e^{\mathbf{z}_{i} \hat{\boldsymbol{\beta}}} .
$$

No caso sem censuras, $\hat{\mu}$ é a média amostral, ou seja

$$
\hat{\mu}=\frac{1}{n} \sum_{i} T_{i}=\bar{T} .
$$

Assim, o $i$-ésimo pseudo-valor é igual ao próprio tempo de inadimplência $T_{i}$

\subsection{Medidas de Performance}

Para comparar os modelos de credit scoring, usualmente são utlizadas algumas ferramentas, descritas brevemente a seguir.

\subsubsection{Estatística de Kolmogorov-Smirnov}

A estatística de Kolmogorov-Smirnov (KS) é utilizada para comparar a distribuição de duas amostras. Em modelos de credit scoring, essas duas amostras são representadas pelo escores dos bons e dos maus clientes. Sejam as distribuições desses escores representadas, respectivamente, por

$$
F_{b}(s)=\frac{\text { quantidade de bons clientes com escore } \leq s}{\text { total de bons clientes }}
$$

e 


$$
F_{m}(s)=\frac{\text { quantidade de maus clientes com escore } \leq s}{\text { total de maus clientes }}
$$

Espera-se que maus clientes tenham escores mais baixos que bons clientes e, por isso, que a curva de $F_{m}(s)$ fique acima da curva de $F_{b}(s)$ e que $F_{m}(s)$ se aproxime mais rapidamente de 1 .

A estatística de Kolmogorov-Smirnov é definida pela diferença máxima entre as duas distribuições, ou seja,

$$
K S=\sup _{s}\left\{\left|F_{m}(s)-F_{b}(s)\right|\right\}
$$

Como um bom modelo deve discriminar os clientes bons dos clientes maus, quanto maior o KS, melhor seria a performance do modelo. Segundo Oliveira e Andrade (2002), a interpretação do KS pode ser feita, empiricamente, segundo a Tabela 2.1.

Tabela 2.1: Nível de discriminação para diferentes valores de KS

\begin{tabular}{cc}
\hline Valores de KS & Nível de discriminação \\
\hline \hline Abaixo de $20 \%$ & Baixa discriminação \\
De $20 \%$ a $30 \%$ & Discriminação aceitável \\
De $30 \%$ a $40 \%$ & Boa discriminação \\
De $40 \%$ a $50 \%$ & Excelente discriminação \\
Acima de $50 \%$ & Não são muito comuns \\
\hline
\end{tabular}

Tomazela (2007) sugere que tão importante quanto a medida do KS é seu posicionamento na distribuição. Os melhores modelos apresentam KS nos primeiros decis da distribuição do escore.

A Figura 2.1 ilustra as curvas de $F_{b}(s)$ e $F_{m}(s)$ e indica o valor e posicionamento do KS.

\subsubsection{Curva ROC (Receiver Operating Characteristic) e Coefi- ciente de Gini}

A curva ROC representa em uma única curva a mesma informação contida nas duas curvas da Figura 2.1 (Thomas et al., 2002), sendo que no eixo horizontal tem-se $F_{b}(s)$ e no eixo vertical $F_{m}(s)$. Cada ponto na curva ROC 
Figura 2.1: Gráfico KS

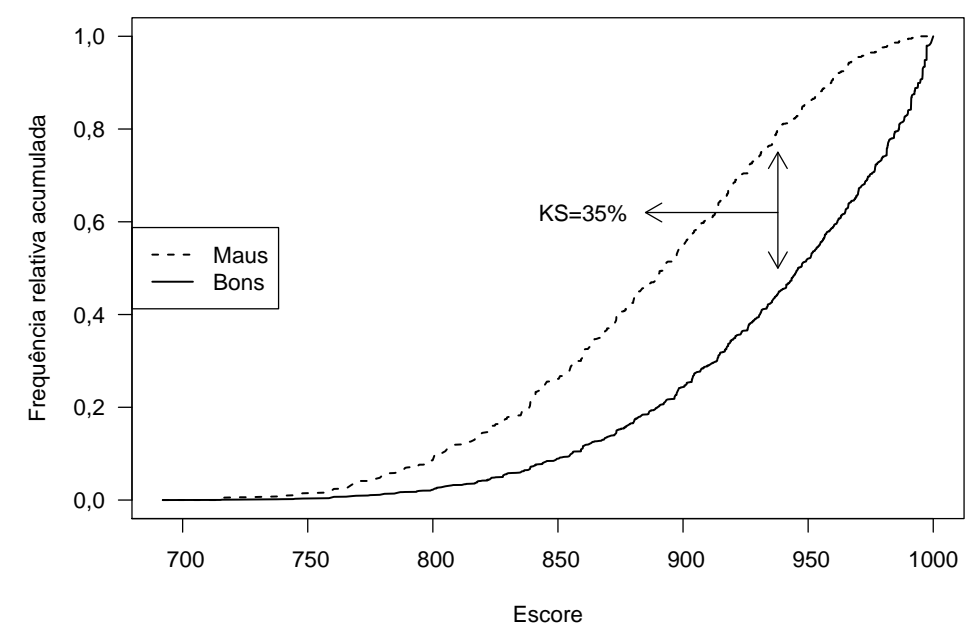

representa um escore $s$ que, neste caso, é considerado um ponto de corte, ou seja, o ponto que separa os clientes em maus (aqueles com escore menor que o ponto de corte) e bons. Portanto, $F_{m}(s)$ pode ser interpretada como a proporção de maus clientes que são classificados corretamente, sendo chamada de sensitividade. Por sua vez, $1-F_{b}(s)$ é chamada de especificidade, representando a proporção de bons clientes que são classificados corretamente. Equivalentemente, a curva ROC pode ser vista como um gráfico em que no eixo horizontal tem-se 1-especificidade e no eixo vertical tem-se sensitividade.

A Figura 2.2 mostra um exemplo de curva ROC. A linha descontínua na diagonal representa o caso em que $F_{b}(s)=F_{m}(s)$ para todo escore $s$, que corresponderia à situação em que a classificação dos clientes é feita de forma aleatória, de acordo com as proporções de bons e maus clientes na população. Consequentemente, quanto maior a distância entre a curva ROC e a diagonal, melhor a discriminação do modelo. Portanto, a área sob a curva ROC, que varia entre 0,5 e 1, também pode ser utilizada para avaliar o poder discriminatório do modelo.

Outra medida popular utilizada para avaliar a performance dos modelos de credit scoring é o coeficiente de Gini, definido como duas vezes a área entre a curva ROC e a diagonal $F_{b}(s)=F_{m}(s)$. Como o coeficiente de Gini varia entre 0 e 1 , pode ser mais conveniente utilizá-lo ao invés da curva ROC. 
Figura 2.2: Curva ROC

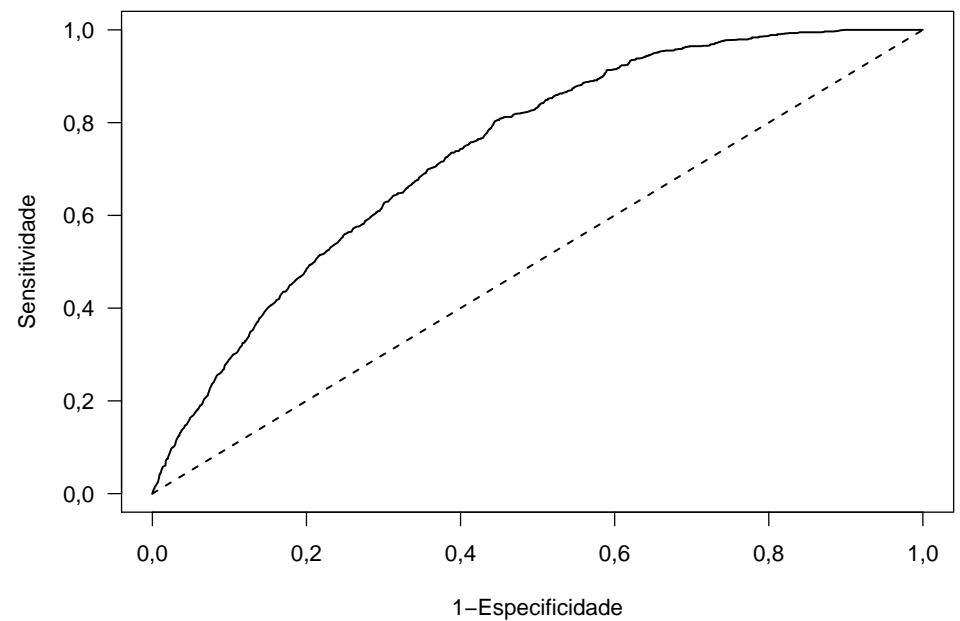

Segundo Oliveira e Andrade (2002), o poder discriminatório da área abaixo da curva ROC pode ser classificado empiricamente segundo os níveis apresentados na Tabela 2.2 .

Tabela 2.2: Nível de discriminação para diferentes valores de área abaixo da curva $\mathrm{ROC}$

\begin{tabular}{cc}
\hline Área Abaixo da Curva ROC & Nível de Discriminação \\
\hline \hline 0,5 & Não existe discriminação \\
De 0,7 a 0,8 & Discriminação aceitável \\
De 0,8 a 0,9 & Excelente discriminação \\
Acima de 0,9 & Discriminação acima do comum \\
\hline
\end{tabular}

Dentre as medidas, a curva ROC (ou, equivalentemente, o coeficiente de Gini) parece ser a mais adequada, pois resume o desempenho do modelo em toda a amplitude do escore, enquanto o KS pode ter um valor alto em apenas um dos possíveis escores (Pereira, 2004). 


\section{Capítulo 3}

\section{Aplicação a Dados de Crédito Pessoal}

Neste capítulo, são descritos os dados utilizados no estudo e detalhase como os modelos de credit scoring foram construídos. Além disso, os modelos são comparados por meio das medidas de performance descritas anteriormente.

\subsection{Sistema de Informações de Crédito do Banco Cen- tral do Brasil (SCR)}

O SCR é um banco de dados administrado pelo Banco Central do Brasil (BCB) que armazena informações sobre as carteiras de crédito das instituições participantes do Sistema Financeiro Nacional (SFN). As instituições financeiras (IFs) são responsáveis pelo encaminhamento mensal de dados sobre suas operações de crédito, bem como pela correção e exclusão das informações imprecisas.

Atualmente, no SCR são armazenadas de forma individualizada dados sobre as operações de crédito com valor igual ou superior a $\mathrm{R} \$ 5$ mil. Para operações abaixo desse valor, as informações são armazenadas de forma agregada.

O SCR tem como objetivo possibilitar ao BCB a detecção de riscos e adoção de medidas preventivas, de forma a proteger os recursos que os cidadãos confiam às IFs. Além disso, pode auxiliar as IFs na gestão de suas carteiras de crédito ao fornecer informações sobre as características e avaliação da capacidade financeira dos devedores. 


\subsection{Descrição e Análise dos Dados do Estudo}

Os dados, coletados do SCR, são referentes a 31.432 clientes pessoa física que em dezembro de 2004 iniciaram operação de crédito pessoal sem consignação em folha de pagamento, com as seguintes características:

- as IFs que concederam os empréstimos eram de um dos seguintes tipos: Bancos Comerciais, Bancos Múltiplos, Banco do Brasil ou Caixa Econômica Federal;

- as operações eram concedidas pelas próprias IFs, recebidas em função de negociação ou adquiridas de pessoa integrante ou não integrante do Sistema Financeiro Nacional, sem coobrigação (sem o compartilhamento do risco de crédito) do cedente;

- os recursos das operações eram de origem livre, ou seja, recursos que não precisam ser direcionados para alguma linha de crédito específica;

- as operações tinham valor igual ou superior a $\mathrm{R} \$ 5$ mil;

- as operações eram concedidas por prazo maior ou igual a 12 meses.

O termo operação será utilizado para designar operações com estas características.

Foram selecionados apenas os clientes que em dezembro de 2004 não possuíam outras operações em curso. Além disso, optou-se por selecionar apenas os clientes com uma única operação na data inicial, já que eram poucos os casos em que um mesmo cliente iniciava mais de uma operação, de forma que o número de clientes coincide com o número de operações. O período de acompanhamento foi de 48 meses, terminando em dezembro de 2008.

Em geral, a renegociação de uma operação é considerada como uma nova operação, bem identificada por um novo código. Portanto, as renegociações das operações iniciadas em dezembro de 2004 automaticamente não entrariam na base de dados. No entanto, constatou-se que algumas poucas operações eram renegociadas e continuavam com o mesmo código. Essas operações foram retiradas da base de dados.

O evento da inadimplência é caracterizado pelo atraso de 90 dias ou mais no pagamento de alguma das obrigações por parte do cliente. O tempo até a inadimplência foi medido em meses, a partir da data inicial. O dado é 
considerado censurado quando a operação sai da base de dados, seja porque o montante a ser pago caiu abaixo de $\mathrm{R} \$ 5$ mil, porque a operação foi liquidada ou por algum outro motivo desconhecido que impediu o acompanhamento da operação.

Os clientes foram classificados em dois grupos: maus, aqueles que se tornaram inadimplentes dentro de um período de acompanhamento préfixado, e bons, aqueles que dentro desse mesmo período não se tornaram inadimplentes (o que inclui os que foram censurados).

Os dados foram divididos em uma amostra de 19.000 clientes para a estimação dos parâmetros do modelo (amostra de desenvolvimento) e outra amostra com 12.432 clientes para a validação, utilizada para verificar o poder de predição do modelo.

Foram utilizadas as seguintes covariáveis, associadas às características dos clientes:

- idade, em anos;

- sexo;

- região ou estado onde mora: Centro-Oeste (CO), Nordeste (NE), Norte (NO), Sudeste (SE), São Paulo (SP) ou Sul (SU);

- tempo de relacionamento com a instituição financeira, em meses;

- status da autorização dada à instituição financeira para consultar seus dados no SCR (Sim ou Não).

Já com relação às características das operações, as seguintes informações foram disponibilizadas:

- prazo, em meses;

- tipo de indexador (Pós-fixado ou Pré-fixado);

- valor total, ou seja, o valor concedido ao cliente na data inicial, em reais.

Em alguns modelos, as covariáveis quantitativas foram categorizadas em três grupos de aproximadamente mesmo tamanho. A razão entre o percentual de maus e bons clientes para cada categoria é calculada da seguinte forma:

$$
\text { Razão }=\frac{\frac{R_{m i}}{R_{m}}}{\frac{R_{b i}}{R_{b}}}=\frac{R_{m i} \times R_{b}}{R_{b i} \times R_{m}}
$$


em que

$R_{m i}$ é o total de maus clientes na categoria $i$;

$R_{m}$ é o total de maus clientes na amostra;

$R_{b i}$ é o total de bons clientes na categoria $i$ e

$R_{b}$ é o total de bons clientes na amostra.

A Tabela 3.1 apresenta a distribuição de bons e maus clientes, considerando os 12 meses iniciais, em cada categoria de idade do cliente na amostra de desenvolvimento. Percebe-se que a razão é menor para faixas de idade mais elevada. As Tabelas para as demais covariáveis encontram-se no Apêndice A.

Tabela 3.1: Distribuição de bons e maus clientes para covariável idade

\begin{tabular}{ccccccc}
\hline Idade & \multicolumn{2}{c}{ Maus } & \multicolumn{2}{c}{ Bons } & Total & Razão \\
\hline \hline até 39 anos & 739 & $11,82 \%$ & 5.513 & $88,18 \%$ & 6.252 & 1,60 \\
40 a 51 anos & 493 & $7,61 \%$ & 5.982 & $92,39 \%$ & 6.475 & 0,98 \\
52 anos ou mais & 235 & $3,75 \%$ & 6.038 & $96,25 \%$ & 6.273 & 0,47 \\
\hline Total & 1.467 & $7,72 \%$ & 17.533 & $92,28 \%$ & 19.000 & \\
\hline
\end{tabular}

A Figura 3.1 apresenta as curvas de sobrevivência para a amostra de desenvolvimento, estimadas por Kaplan-Meier e considerando os 48 meses, para cada categoria da covariável idade do cliente. Pode-se perceber que, para tempos menores que 37 meses, a proporção de inadimplência é menor para faixas de idade mais elevada. Após esse período, a curva de sobrevivência para a faixa de 52 anos ou mais cruza as outras curvas. Esse comportamento indica que pode haver violação da suposição de proporcionalidade dos riscos de inadimplência. As curvas de sobrevivência para as outras covariáveis encontram-se no Apêndice A. No caso de sexo, praticamente não existe diferença entre as curvas de sobrevivência para o sexo feminino e masculino. Para a região, percebe-se que algumas curvas também se cruzam, com destaque para o cruzamento da curva da região Nordeste com as curvas das regiões Centro-Oeste e Sul. Para o tempo de relacionamento, a faixa dos 67 meses ou mais se destaca bastante das outras, apresentando menor proporção de inadimplência. No caso do prazo da operação, quanto maior o prazo, menor a proporção de inadimplência. Esse comportamento pode 
estar sendo influenciado pelo fato de que os tempos de censura tendem a ser maiores para operações com maior prazo. Além disso, para operações com valores semelhantes, as parcelas a serem pagas são menores para prazos maiores, o que pode diminuir a proporção de inadimplência. Para o indexador da operação, os tempos de falha são maiores para o indexador pré-fixado. No caso do total da operação, quanto maior o valor total, menor a proporção de inadimplência. Esse comportamento é influenciado pelo fato de que, para operações com prazos semelhantes, quanto maior o total, maior o tempo em que a operação fica na base de dados. Além disso, o total da operação concedida tem relação com a renda do cliente, o que também pode estar influenciando esse comportamento. Para a autorização do cliente, a proporção de inadimplência é menor para clientes que autorizam a consulta de seus dados no SCR.

Figura 3.1: Kaplan Meier por idade

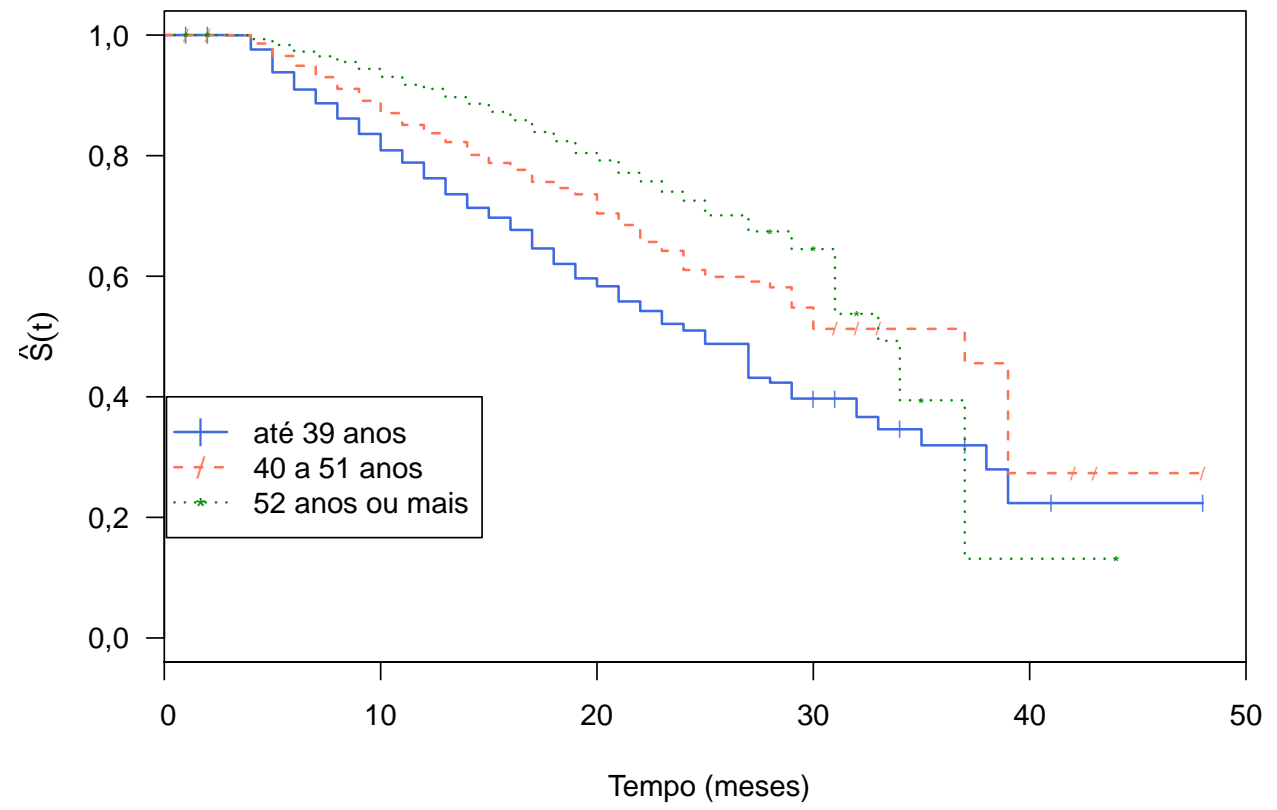

\subsection{Ajuste dos Modelos}

A amostra de desenvolvimento foi utilizada para o ajuste dos modelos, que foram então utilizados na atribuição de escores para os clientes da amostra de validação. 
Para os modelos de credit scoring baseados na probabilidade de inadimplência dos clientes, fixou-se um período de 12 meses para o cálculo dessa probabilidade.

Conforme já discutido, também foram considerados modelos de credit scoring para os quais não fosse necessária a fixação de um período. A medida escolhida para basear o cálculo dos escores foi o tempo médio até a inadimplência do cliente. Outras medidas interessantes seriam o tempo mediano e o terceiro quartil, mas, pelo fato dos dados apresentarem muitos tempos empatados, o mesmo valor foi obtido para cada um dos $i$-ésimos pseudo-valores calculados com base no estimador dessas medidas. O cálculo do tempo médio até a inadimplência só é possível ao utilizar-se o modelo de Cox e a metodologia baseada nos pseudo-valores.

Geralmente os modelos de credit scoring são ajustados considerandose apenas as covariáveis relativas às características dos clientes. Como o banco de dados utilizado não possui muitas informações desse tipo, optouse por utilizar também as covariáveis relativas à operação. Para verificar a sensibilidade dos modelos às informações sobre a operação, também foram construídos modelos em que essas covariáveis não foram incluídas.

É prática do mercado categorizar as covariáveis, pois a complexidade de analisar caso a caso a forma como a covariável quantitativa deve ser incluída no modelo não é compensada por um desempenho significativamente melhor do modelo. Além disso, na aplicação do modelo de credit scoring, o risco de cometer-se um erro é muito maior ao digitar o valor de uma covariável quantitativa. Todos os modelos foram inicialmente ajustados com todas as covariáveis categorizadas, sem iterações. Foram criadas variáveis indicadoras para representar as categorias de cada covariável, sendo que a casela de referência foi escolhida como sendo a categoria com a menor razão entre o percentual de maus e bons clientes. No entanto, como nosso objetivo é comparar os modelos, decidiu-se usar também as covariáveis quantitativas em sua forma original. Por simplicidade, optou-se por incluir as covariáveis na forma linear. A única exceção foi o valor total da operação, que foi incluído na forma logarítmica, pois o intervalo de variação dessa covariável é muito grande (de $\mathrm{R} \$ 5.000$ a $\mathrm{R} \$ 3.058 .874$ ). A seleção das covariáveis foi feita utilizando-se o método backward manualmente e adotando-se nível de significância de 5\% para a retirada da covariável do modelo. Os modelos nos quais 
não categorizou-se as covariáveis quantitativas serão referidos como modelos com covariáveis quantitativas, embora nesses modelos também existam covariáveis na forma categorizada.

\subsubsection{Regressão Logística}

Como na regressão logística o horizonte de tempo para o cálculo da probabilidade de inadimplência deve ser fixado a priori, as informações sobre a inadimplência ocorrida após os 12 meses iniciais não é utilizada nesse modelo. Dentro desse período de 12 meses, os clientes que apresentaram inadimplência (maus clientes) foram codificados com o valor um e os outros (bons clientes) com o valor zero. O índice de inadimplência foi de 7,72\% para a amostra de desenvolvimento e de 7,24\% para a amostra de validação.

Primeiramente, utilizou-se para a construção dos modelos tanto as covariáveis relacionadas às características do cliente quanto as relativas à operação. As estimativas dos pârametros do modelo, ao utilizar-se covariáveis categorizadas, encontram-se na Tabela B.2. Como exemplo de interpretação, verifica-se que um cliente na faixa etária de até 39 anos tem chance $2,25(\exp (1,178)-1)$ vezes maior de ser inadimplente nos 12 primeiros meses do que um cliente na faixa etária de 52 anos ou mais, que é a categoria de referência. Para o modelo com as covariáveis quantitativas, as estimativas encontram-se na Tabela B.3. Nesse caso, a diminuição de 1 ano na idade implica no aumento de $4,19 \%(\exp (0,041)-1)$ na chance do cliente tornar-se inadimplente dentro de um prazo de 12 meses.

Posteriormente, contruiu-se modelos em que foram consideradas apenas as covariáveis relativas às características do cliente. As estimativas dos

parâmetros estão na Tabela B.9 (covariáveis categorizadas) e na Tabela B.10 (covariáveis quantitativas).

Como os ecores mais altos em geral são atribuídos aos clientes com menor probabilidade de inadimplência, o cálculo do escore para o cliente $i$ é dado por

$$
s_{i}=\left[1-\hat{\pi}\left(\mathbf{z}_{i}\right)\right] \times 1.000, \quad i=1, \ldots, n,
$$

em que $\hat{\pi}\left(\mathbf{z}_{i}\right)$ é a probabilidade estimada do cliente com covariáveis $\mathbf{z}_{i}$ tornarse inadimplente dentro de um prazo de 12 meses. 


\subsubsection{Modelo de Cox}

No Modelo de Cox foram usadas todas as informações disponíveis no período de acompanhamento de 48 meses. O prazo de 12 meses para o cálculo da probabilidade de inadimplência pode ser fixado após o ajuste do modelo, o que é uma vantagem, pois, caso haja interesse em utilizar um prazo diferente, não é necessária a reestimação dos coeficientes.

Primeiramente, utilizou-se para a construção dos modelos tanto as covariáveis relacionadas às características do cliente quanto as relativas à operação. As estimativas dos pârametros do modelo, quando utiliza-se covariáveis categorizadas, encontram-se na Tabela B.4. Como exemplo de interpretação, verifica-se que um cliente na faixa etária de até 39 anos tem risco $1,25(\exp (0,811)-1)$ vezes maior de tornar-se inadimplente do que um cliente na faixa etária de 52 anos ou mais, que é a categoria de referência. Para o modelo com as variáveis quantitativas, as estimativas encontram-se na Tabela B.5. Nesse caso, a diminuição de 1 ano na idade, implica no aumento de $2,78 \%(\exp (0,027)-1)$ no risco do cliente tornar-se inadimplente.

Posteriormente, contruiu-se modelos considerando-se apenas as covariáveis relativas às características do cliente. As estimativas dos parâmetros estão na Tabela B.11 (covariáveis categorizadas) e na Tabela B.12 (covariáveis quantitativas).

Calcula-se a função de sobrevivência $\hat{S}\left(t \mid \mathbf{Z}_{i}=\mathbf{z}_{i}\right)$, utilizando a equação (2.13). O cálculo do escore para o cliente $i$ é dado por

$$
s_{i}=\hat{S}\left(t=12 \mid \mathbf{Z}_{i}=\mathbf{z}_{i}\right) \times 1.000 .
$$

O tempo médio estimado até a inadimplência do cliente $i, \hat{\mu}\left(\mathbf{z}_{i}\right)$, pode ser calculado conforme a equação (2.14). Como o último tempo corresponde também a uma censura, define-se que a função de sobrevivência é zero para $t \geq 48$ meses. O escore do $i$-ésimo cliente, baseado em seu tempo médio de inadimplência, fica dado por

$$
s_{i}=\frac{\hat{\mu}\left(\mathbf{z}_{i}\right)}{\hat{\mu}\left(\mathbf{z}_{i}\right)_{\max }} \times 1.000 .
$$

A divisão por $\hat{\mu}\left(\mathbf{z}_{i}\right)_{\max }$, o maior tempo médio estimado, é feita para que 
o escore passe a variar entre 0 e 1.000, da mesma forma como acontece para os escores baseados na probabilidade de inadimplência.

\subsubsection{Pseudo-valores}

Como o interesse é no efeito das covariáveis na função de sobrevivência para um tempo fixo, $\theta$ e $h\left(T_{i}\right)$ são definidos conforme o Exemplo 1 do Capítulo 2:

$$
h\left(T_{i}\right)=I\left(T_{i}>t^{*}\right)
$$

$\mathrm{e}$

$$
\theta=E\left[h\left(T_{i}\right)\right]=\mathrm{P}\left(h\left(T_{i}\right)=1\right)=\mathrm{P}\left(T_{i}>t^{*}\right)=S\left(t^{*}\right)
$$

O estimador utilizado para a função de sobrevivência é o estimador de Kaplan-Meier e o tempo é fixado em 12 meses.

Os pseudo-valores são utilizados como variável resposta em um modelo linear generalizado, assumindo distribuição Normal e com função de ligação logito. Primeiramente, utilizaram-se para a construção dos modelos tanto as covariáveis relacionadas às características do cliente quanto as relativas à operação. As estimativas dos pârametros do modelo com as covariáveis categorizadas encontram-se na Tabela B.6. Verifica-se que um cliente na faixa etária de até 39 anos tem chance 1,69 $(\exp (0,989)-1)$ vezes maior de ser inadimplente nos 12 primeiros meses do que um cliente na faixa etária de 52 anos ou mais, que é a categoria de referência. Note que no cálculo da razão de chances é feita a troca de sinal da estimativa do parâmetro, pois este é um modelo para $S(t)$. Para o modelo com as variáveis quantitativas, as estimativas encontram-se na Tabela B.7. Nesse caso, a diminuição de 1 ano na idade implica no aumento de $3,35 \%(\exp (0,033)-1)$ na chance do cliente tornar-se inadimplente dentro de um prazo de 12 meses.

Posteriormente, contruíram-se modelos apenas com as covariáveis relativas às características do cliente. As estimativas dos parâmetros estão na Tabela B.13 (covariáveis categorizadas) e na Tabela B.14 (covariáveis quantitativas).

O cálculo do escore para o cliente $i$ é dado por

$$
s_{i}=\hat{S}\left(t=12 \mid \mathbf{Z}_{i}=\mathbf{z}_{i}\right) \times 1.000,
$$


em que $\hat{S}\left(t=12 \mid \mathbf{Z}_{i}=\mathbf{z}_{i}\right)$ é calculada segundo 2.30.

Para o caso do tempo médio de inadimplência, os pseudo-valores devem ser recalculados, utilizando-se $\theta$ e $h\left(T_{i}\right)$ conforme o Exemplo 2 do Capítulo 2 :

$$
h\left(T_{i}\right)=T_{i}
$$

$\mathrm{e}$

$$
\theta=E\left[T_{i}\right]=\mu
$$

O estimador utilizado para o tempo médio de sobrevivência é a área abaixo da curva de sobrevivência, baseada no estimador de Kaplan-Meier.

Os pseudo-valores são utilizados como variável resposta em um modelo linear generalizado, assumindo-se distribuição Normal e com função de ligação log. Para os modelos com as covariáveis relativas às características do cliente e da operação, as estimativas dos parâmetros dos modelos encontram-se na Tabela B.8 (covariáveis categorizadas). O procedimento iterativo para a estimação dos parâmetros do modelo com as covariáveis quantitativas não convergiu. Para os modelos em que foram incluídas apenas as covariáveis relativas às características do cliente, as estimativas encontram-se na Tabela B.15 (covariáveis categorizadas) e na Tabela B.16 (covariáveis quantitativas).

O escore do $i$-ésimo cliente, baseado em seu tempo médio de inadimplência, fica dado por

$$
s_{i}=\frac{\hat{\mu}\left(\mathbf{z}_{i}\right)}{\hat{\mu}\left(\mathbf{z}_{i}\right)_{\max }} \times 1.000
$$

em que $\hat{\mu}\left(\mathbf{z}_{i}\right)$ é calculada segundo (2.31).

Os modelos que utilizam os pseudo-valores como variável resposta serão referidos apenas como pseudo-valores.

\subsection{Comparação dos Modelos}

Para os modelos em que são incluídas as covariáveis relativas às características do cliente e da operação, percebe-se que o modelo mais parcimonioso é o que utiliza os pseudo-valores para cálculo do tempo médio de inadimplência, com covariáveis categorizadas. Este também é o único modelo em que o indexador da operação é significativo. A covariável sexo só é 
significativa nos modelos de Cox. O prazo da operação só não é significativo nos modelos de regressão logística.

Para os modelos em que são incluídas apenas as covariáveis relativas às características do cliente, percebe-se que os modelos mais parcimoniosos são os que utilizam os pseudo-valores para cálculo do tempo médio de inadimplência. Nestes modelos, apenas idade e tempo de relacionamento são covariáveis significativas. Em todos os outros modelos, todas as covariáveis são significativas, com exceção de sexo. Esta covariável só é significativa no modelo de Cox com covariáveis quantitativas.

Ao comparar-se os modelos com e sem as características relativas à operação, percebe-se que os erros padrão das covariáveis que permaneceram no modelo são bem parecidos. Os modelos mais sensíveis à mudança nas estimativas são os que utilizam os pseudo-valores.

Após atribuir escores aos clientes da amostra de validação, utilizou-se as medidas de performance descritas na seção 2.4 para comparar o desempenho dos modelos de credit scoring. As medidas área sob a curva ROC e coeficiente de Gini são equivalentes, já que a segunda é construída com base na primeira.

Para os modelos em que são incluídas as covariáveis relativas às características do cliente e da operação, os resultados estão nas Tabelas 3.2 a 3.5 . O modelo com maior KS e maior área sob a curva ROC foi o com escores baseados na probabilidade de inadimplência, usando regressão logística e com as covariáveis quantitativas. O modelo com menor KS e menor área sob a curva ROC foi o com escores baseados no tempo médio de inadimplência, usando pseudo-valores e com todas as covariáveis categorizadas.

De acordo com a Tabela 2.1 da seção 2.4, apenas os modelos em que é utilizada a regressão logística apresentaram discriminação aceitável pela medida KS. Todos os outros apresentaram baixa discriminação. Em relação à área sob a curva ROC, todos os modelos apresentaram discriminação abaixo da aceitável, de acordo com a Tabela 2.2 da seção 2.4. Os modelos em que utiliza-se a regressão logística apresentaram valores para a área sob a curva ROC próximo a 0,7, ou seja, próximo da discriminação aceitável. Os modelos com escores baseados no tempo médio de inadimplência apresentaram performance muito ruim, praticamente não discriminando entre bons e maus clientes. 
Para os modelos em que são incluídas apenas as covariáveis relativas às características do cliente, os resultados estão nas Tabelas 3.6 a 3.9. O modelo com maior KS foi o com escores baseados no tempo médio de inadimplência, usando pseudo-valores e com as covariáveis quantitativas. O modelo com menor KS foi o com escores baseados no tempo médio de inadimplência, usando pseudo-valores e com as covariáveis categorizadas. O modelo com maior área sob a curva ROC foi o com escores baseados na probabilidade de inadimplência, usando regressão logística e com as covariáveis quantitativas. O modelo com menor área sob a curva ROC foi o com escores baseados no tempo médio de inadimplência, usando modelo de Cox e com as covariáveis categorizadas.

Neste caso, observa-se que praticamente todos os modelos apresentaram uma discriminação aceitável pela medida KS, de acordo com a Tabela 2.1 da seção 2.4. A única exceção foi o modelo com escores baseados no tempo médio de inadimplência, usando pseudo-valores e com as covariáveis categorizadas, que apresentou baixa discriminação. Em relação à área sob a curva ROC, os modelos apresentaram discriminação abaixo da aceitável, de acordo com a Tabela 2.2 da seção 2.4. Para os modelos que apresentaram discriminação aceitável pelo KS, percebe-se que os valores para a área sob a curva ROC estão próximos de 0,7 , valor para o qual a discriminação é aceitável.

Tabela 3.2: Medidas de performance - Modelos probabilidade de inadimplência com características de cliente e operação - Covariáveis categorizadas

\begin{tabular}{cccc}
\hline Medida de & \multicolumn{3}{c}{ Modelo } \\
performance & Regressão logística & Cox & Pseudo-valores \\
\hline \hline KS & 0,2647 & 0,1195 & 0,1686 \\
Área sob a curva ROC & 0,6723 & 0,5828 & 0,6176 \\
Coeficiente de Gini & 0,3447 & 0,1657 & 0,2352 \\
\hline
\end{tabular}


Tabela 3.3: Medidas de performance - Modelos probabilidade de inadimplência com características de cliente e operação - Covariáveis quantitativas

\begin{tabular}{cccc}
\hline Medida de & \multicolumn{3}{c}{ Modelo } \\
performance & Regressão logística & Cox & Pseudo-valores \\
\hline \hline KS & 0,2871 & 0,1611 & 0,1899 \\
Área sob a curva ROC & 0,6858 & 0,6041 & 0,6245 \\
Coeficiente de Gini & 0,3716 & 0,2083 & 0,2489 \\
\hline
\end{tabular}

Tabela 3.4: Medidas de performance - Modelos tempo médio de inadimplência com características de cliente e operação - Covariáveis categorizadas

\begin{tabular}{ccc}
\hline $\begin{array}{c}\text { Medida de } \\
\text { performance }\end{array}$ & Cox & $\begin{array}{c}\text { Modelo } \\
\text { Pseudo-valores }\end{array}$ \\
\hline \hline KS & 0,0618 & 0,0435 \\
Área sob a curva ROC & 0,5309 & 0,5089 \\
Coeficiente de Gini & 0,0617 & 0,0177 \\
\hline
\end{tabular}

\subsection{Modelos para Dados sem Censura}

Os dados em estudo apresentam muitas observações censuradas que, como será explicado adiante, podem influenciar a performance dos modelos. Na amostra de desenvolvimento, a proporção de inadimplentes é de $10,61 \%$, considerando-se o período de acompanhamento de 48 meses, e cai para $7,72 \%$ ao considerar-se os 12 primeiros meses.

Também há indícios de que a censura possa ser informativa, já que o tempo de acompanhamento da operação é influenciado tanto pelo seu prazo como pelo seu total. O prazo determina a priori um valor máximo para o tempo de censura. Além disso, o fato de que a operação sai da base de dados ao ter um saldo devedor abaixo de $\mathrm{R} \$ 5$ mil, faz com que o total da operação tenha relação com o tempo de censura dos dados.

No caso da regressão logística, a pouca quantidade de eventos pode subestimar a probabilidade de inadimplência (King e Zeng, 2001). No caso do modelo de Cox e dos pseudo-valores, uma das premissas é que a censura seja não informativa.

Para avaliar a influência dos dados censurados, optou-se por eliminá-los 
Tabela 3.5: Medidas de performance - Modelos tempo médio de inadimplência com características de cliente e operação - Covariáveis quantitativas

\begin{tabular}{cc}
\hline $\begin{array}{c}\text { Medida de } \\
\text { performance }\end{array}$ & $\begin{array}{c}\text { Modelo } \\
\text { Cox }\end{array}$ \\
\hline \hline KS & 0,0911 \\
Área sob a curva ROC & 0,5588 \\
Coeficiente de Gini & 0,1175 \\
\hline
\end{tabular}

Tabela 3.6: Medidas de performance - Modelos probabilidade de inadimplência com características de cliente - Covariáveis categorizadas

\begin{tabular}{cccc}
\hline Medida de & \multicolumn{3}{c}{ Modelo } \\
performance & Regressão logística & Cox & Pseudo-valores \\
\hline \hline KS & 0,2669 & 0,2565 & 0,2708 \\
Área sob a curva ROC & 0,6756 & 0,6746 & 0,6816 \\
Coeficiente de Gini & 0,3511 & 0,3492 & 0,3632 \\
\hline
\end{tabular}

da base e recalcular os modelos. Neste caso, tem-se 3.290 dados correspondentes aos eventos de falha, dos quais 1.900 compõem a amostra de desenvolvimento e 1.390 a amostra de validação. No caso da regressão logística, em que o tempo de acompanhamento é de 12 meses, a amostra de desenvolvimento tem $72.32 \%$ de clientes inadimplentes. Os modelos baseam os escores na probabilidade de inadimplência e levam em consideração características do cliente e da operação. No caso sem censuras, os pseudo-valores assumem apenas os valores 0 e 1 . Portanto, no modelo linear generalizado adotou-se distribuição binomial e função de ligação logito. Como explicado anteriormente, este modelo equivale ao da regressão logística. As estimativas dos pârametros dos modelos estão nas Tabelas B.17 a B.22 e as medidas de performance nas Tabelas 3.10 e 3.11. Observe que os resultados para a regressão logística e os pseudo-valores são os mesmos, já que os dois modelos são equivalentes no caso sem censuras.

Percebe-se que a performance dos modelos melhorou significativamente, sendo que as maiores variações foram para o modelo de Cox e os pseudovalores. Todos os modelos apresentaram boa discriminação pela medida KS e discriminação aceitável pala área sob a curva ROC. Logo, tem-se evidências de que os dados censurados podem ter afetado o desempenho dos modelos. 
Tabela 3.7: Medidas de performance - Modelos probabilidade de inadimplência com características de cliente - Covariáveis quantitativas

\begin{tabular}{cccc}
\hline Medida de & \multicolumn{3}{c}{ Modelo } \\
performance & Regressão logística & Cox & Pseudo-valores \\
\hline \hline KS & 0,2841 & 0,2796 & 0,2807 \\
Área sob a curva ROC & 0,6838 & 0,6829 & 0,6835 \\
Coeficiente de Gini & 0,3677 & 0,3658 & 0,3670 \\
\hline
\end{tabular}

Tabela 3.8: Medidas de performance - Modelos tempo médio de inadimplência com características de cliente - Covariáveis categorizadas

\begin{tabular}{ccc}
\hline $\begin{array}{c}\text { Medida de } \\
\text { performance }\end{array}$ & Cox & $\begin{array}{c}\text { Modelo } \\
\text { Pseudo-valores }\end{array}$ \\
\hline \hline KS & 0,2438 & 0,1953 \\
Área sob a curva ROC & 0,6637 & 0,6655 \\
Coeficiente de Gini & 0,3274 & 0,3310 \\
\hline
\end{tabular}

Tabela 3.9: Medidas de performance - Modelos tempo médio de inadimplência com características de cliente - Covariáveis quantitativas

\begin{tabular}{ccc}
\hline $\begin{array}{c}\text { Medida de } \\
\text { performance }\end{array}$ & Cox & $\begin{array}{c}\text { Modelo } \\
\text { Pseudo-valores }\end{array}$ \\
\hline \hline KS & 0,2629 & 0,2841 \\
Área sob a curva ROC & 0,6718 & 0,6808 \\
Coeficiente de Gini & 0,3436 & 0,3617 \\
\hline
\end{tabular}

Tabela 3.10: Medidas de performance - Modelos para dados sem censura - Covariáveis categorizadas

\begin{tabular}{cccc}
\hline Medida de & \multicolumn{3}{c}{ Modelo } \\
performance & Regressão logística & Cox & Pseudo-valores \\
\hline \hline KS & 0,3549 & 0,3584 & 0,3549 \\
Área sob a curva ROC & 0,7454 & 0,7281 & 0,7454 \\
Coeficiente de Gini & 0,4909 & 0,4562 & 0,4909 \\
\hline
\end{tabular}


Tabela 3.11: Medidas de performance - Modelos para dados sem censura - Covariáveis quantitativas

\begin{tabular}{cccc}
\hline Medida de & \multicolumn{3}{c}{ Modelo } \\
performance & Regressão logística & Cox & Pseudo-valores \\
\hline \hline KS & 0,3473 & 0,3504 & 0,3473 \\
Área sob a curva ROC & 0,7138 & 0,7151 & 0,7138 \\
Coeficiente de Gini & 0,4276 & 0,4301 & 0,4276 \\
\hline
\end{tabular}




\section{Capítulo 4}

\section{Conclusão}

Neste trabalho, foi avaliada a aplicabilidade e desempenho de uma nova metodologia, baseada em pseudo-valores, para construção de modelos de credit scoring. Essa nova abordagem foi comparada com metodologias já difundidas, como a regressão logística e o modelo de Cox. A aplicação prática foi feita a dados de operações de crédito pessoal sem consignação, coletados do Sistema de Informações de Crédito do Banco Central do Brasil. Para comparar a performance dos modelos, utilizou-se a estatística de Kolmogorov-Smirnov e a área sob a curva ROC.

Na aplicação apresentada, somente alguns modelos apresentaram discriminação aceitável pela medida KS. Em relação à area sob a curva ROC, a discriminação de todos os modelos ficou abaixo da aceitável. O banco de dados utilizado possui limitações, pois não armazena informações individualizadas de operações abaixo de $\mathrm{R} \$ 5$ mil. Além disso, não possui muitas informações relativas às características do cliente. Em geral, covariáveis importantes e que melhoram a performance dos modelos são aquelas relativas ao histórico de inadimplência do cliente. As instituições financeiras podem ter acesso a essas informações por meio de consultas a Centrais de In-

formação de Crédito como a Serasa. Como exemplo, pode-se citar o número de cheques sem fundo, dívidas vencidas e pendências financeiras.

Quando são incluídas nos modelos as covariáveis relativas às características do cliente e da operação, a única metodologia que fornece discriminação aceitável pela medida KS é a regressão logística. A performance dos modelos em que utiliza-se modelo de Cox ou pseudo-valores é bem inferior à dos modelos em que utiliza-se regressão logística. Os modelos baseados no tempo médio de inadimplência praticamente não discriminam entre bons e maus 
clientes.

Para os modelos em que considera-se apenas as covariáveis relativas às características do cliente, todos os modelos tiveram discriminação aceitável pela medida KS, exceto o com escores baseados no tempo médio de inadimplência, usando pseudo-valores e com as covariáveis categorizadas. Em relação à nova metodologia proposta, baseada nos pseudo-valores, percebese que em alguns casos sua performance é superior à das outras metodologias. O modelo com maior KS é o que utiliza os pseudo-valores para cálculo do tempo médio de inadimplência, com variáveis quantitativas. O segundo maior coeficiente de Gini é o do modelo que utiliza os pseudo-valores para cálculo da probabilidade de inadimplência, com covariáveis quantitativas. Seu valor é bem próximo ao do maior coeficiente de Gini, encontrado quando utiliza-se a regressão logística para o cálculo da probabilidade de inadimplência, com covariáveis quantitativas. Vale ressaltar que, no cálculo das medidas de performance, considera-se a mesma classificação de bons e maus clientes utilizada na regressão logística, o que acaba beneficiando esta metodologia em detrimento das outras.

Verifica-se que os modelos mais sensíveis à inclusão das covariáveis relativas às características da operação são os que utilizam as metodologias modelo de Cox ou pseudo-valores.

O modelo de Cox e a técnica baseada nos pseudo-valores pressupõem que a censura seja não informativa. Neste trabalho, existem alguns fatores que podem levar a uma violação dessa suposição. O prazo da operação determina um prazo máximo para o tempo de censura. Além disso, o fato de que a operação sai da base de dados ao ter um saldo devedor abaixo de $\mathrm{R} \$ 5$ mil, faz com que o total da operação tenha relação com o tempo de censura dos dados. Isto pode explicar a diferença nos resultados quando não considera-se nos modelos as covariáveis relativas à operação e também a considerável melhora na performance quando exclui-se os dados censurados. A regressão logística não mostra-se tão sensível às covariáveis de operação, já que é uma metodologia que não leva em consideração a censura. No entanto, ao retirar-se os dados censurados, a melhora na performance é mais significativa, indicando que o número reduzido de eventos também pode influenciar negativamente os resultados.

A seguir, faz-se uma breve análise das vantagens e desvantagens de cada 
metodologia.

Pode-se dizer que o modelo de regressão logística é de mais fácil implementação. No entanto, possui limitações como, por exemplo, não considerar a censura e ser necessária a fixação de um período de acompanhamento $a$ priori. Neste trabalho, definiu-se que os casos de censura seriam tratados como adimplência. De fato, para os dados em estudo, com baixa taxa de inadimplência, esse tratamento é conveniente. No entanto, o fato da proporção de inadimplentes ser muito baixa pode afetar o desempenho do modelo.

O modelo de análise de sobrevivência apresenta a vantagem de considerar a censura e de não ser necesária a determinação de um período de acompanhamento a priori. Portanto, com um único modelo é possível obter a probabilidade de um cliente superar determinados instantes de tempo sem apresentar inadimplência. Isso torna mais fácil a aplicação do modelo como ferramenta para que a análise de concessão de crédito seja feita de forma mais personalizada. Por exemplo, um cliente pode apresentar uma alta probabilidade de inadimplência para um período de 12 meses, o que definiria um baixo escore para esse cliente e, consequentemente, o crédito não seria concedido. No entanto, esse mesmo cliente poderia apresentar uma probabilidade de inadimplência aceitável se o crédito fosse concedido por um outro prazo. Ajustes na taxa de juros da operação também podem ser feitas com base nessa análise. Outra vantagem do modelo de Cox é não fazer suposição sobre a distribuição da variável resposta. No entanto, no caso de violação das suposições de proporcionalidade dos riscos e de censura não informativa, este modelo pode não apresentar uma boa performance.

Em relação ao modelo dos pseudo-valores, a censura também é levada em consideração. Além disso, a relação entre as covariáveis e a quantidade de interesse pode ser descrita de forma mais simples. No entanto, também existe o inconveniente da necessidade de se fixar um período de acompanhamento a priori, no caso de modelos para a probabilidade de inadimplência. Esta técnica baseia-se em condições que precisam ser melhor estudadas e provadas para cada caso específico. Sendo assim, seu uso pode ser justificável quando, por exemplo, a suposição de proporcionalidade dos riscos do modelo de Cox não for satisfeita. Também pressupõe que a censura é não informativa e pode não apresentar boa performance quando esta suposição é violada.

Metodologias que incorporem censura informativa podem ser estudadas 
futuramente. Além disso, modelos com fração de cura podem ser uma boa alternativa em situações em que a taxa de inadimplência é baixa. 


\section{Apêndice A}

\section{Tabelas e Gráficos da Análise Descri- tiva}

Tabela A.1: Distribuição de bons e maus clientes para covariável sexo

\begin{tabular}{ccccccc}
\hline Sexo & \multicolumn{2}{c}{ Maus } & \multicolumn{2}{c}{ Bons } & Total & Razão \\
\hline \hline Feminino & 538 & $7,52 \%$ & 6.621 & $92,48 \%$ & 7.159 & 0,97 \\
Masculino & 929 & $7,85 \%$ & 10.912 & $92,15 \%$ & 11.841 & 1,02 \\
\hline Total & 1.467 & $7,72 \%$ & 17.533 & $92,28 \%$ & 19.000 & \\
\hline
\end{tabular}

Tabela A.2: Distribuição de bons e maus clientes para covariável região

\begin{tabular}{ccccccc}
\hline Região & \multicolumn{2}{c}{ Maus } & \multicolumn{2}{c}{ Bons } & Total & Razão \\
\hline \hline Centro-Oeste & 193 & $12,93 \%$ & 1.300 & $87,07 \%$ & 1.493 & 1,77 \\
Nordeste & 192 & $11,41 \%$ & 1.491 & $88,59 \%$ & 1.683 & 1,54 \\
Norte & 112 & $13,43 \%$ & 722 & $86,57 \%$ & 834 & 1,85 \\
São Paulo & 316 & $7,44 \%$ & 3.931 & $92,56 \%$ & 4.247 & 0,96 \\
Sudeste & 464 & $5,50 \%$ & 7.969 & $94,50 \%$ & 8.433 & 0,70 \\
Sul & 190 & $8,23 \%$ & 2.120 & $91,77 \%$ & 2.310 & 1,07 \\
\hline Total & 1.467 & $7,72 \%$ & 17.533 & $92,28 \%$ & 19.000 & \\
\hline
\end{tabular}


Tabela A.3: Distribuição de bons e maus clientes para covariável tempo de relacionamento

\begin{tabular}{ccccccc}
\hline Tempo de Relacionamento & \multicolumn{2}{c}{ Maus } & \multicolumn{2}{c}{ Bons } & Total & Razão \\
\hline \hline até 3 meses & 533 & $8,46 \%$ & 5.766 & $91,54 \%$ & 6.299 & 1,10 \\
4 a 66 meses & 642 & $10,10 \%$ & 5.715 & $89,90 \%$ & 6.357 & 1,34 \\
67 meses ou mais & 292 & $4,60 \%$ & 6.052 & $95,40 \%$ & 6.344 & 0,58 \\
\hline Total & 1.467 & $7,72 \%$ & 17.533 & $92,28 \%$ & 19.000 & \\
\hline
\end{tabular}

Tabela A.4: Distribuição de bons e maus clientes para covariável prazo da operação

\begin{tabular}{ccccccc}
\hline Prazo da Operaçao & \multicolumn{2}{c}{ Maus } & \multicolumn{2}{c}{ Bons } & Total & Razão \\
\hline \hline 12 a 23 meses & 454 & $8,09 \%$ & 5.158 & $91,91 \%$ & 5.612 & 1,05 \\
24 a 35 meses & 551 & $8,35 \%$ & 6.049 & $91,65 \%$ & 6.600 & 1,09 \\
36 meses ou mais & 462 & $6,81 \%$ & 6.326 & $93,19 \%$ & 6.788 & 0,87 \\
\hline Total & 1.467 & $7,72 \%$ & 17.533 & $92,28 \%$ & 19.000 & \\
\hline
\end{tabular}

Tabela A.5: Distribuição de bons e maus clientes para covariável indexador da operação

\begin{tabular}{ccccccc}
\hline Indexador da Operação & \multicolumn{2}{c}{ Maus } & \multicolumn{2}{c}{ Bons } & Total & Razão \\
\hline \hline Pós-fixado & 91 & $7,54 \%$ & 1.116 & $92,46 \%$ & 1.207 & 0,97 \\
Pré-fixado & 1.376 & $7,73 \%$ & 16.417 & $92,27 \%$ & 17.793 & 1,00 \\
\hline Total & 1.467 & $7,72 \%$ & 17.533 & $92,28 \%$ & 19.000 & \\
\hline
\end{tabular}

Tabela A.6: Distribuição de bons e maus clientes para covariável total da operação

\begin{tabular}{ccccccc}
\hline Total da Operaçao & \multicolumn{2}{c}{ Maus } & \multicolumn{2}{c}{ Bons } & Total & Razão \\
\hline \hline $\mathrm{R} \$ 5.000$ a $\mathrm{R} \$ 5.960$ & 403 & $6,37 \%$ & 5.926 & $93,63 \%$ & 6.329 & 0,81 \\
$(\mathrm{R} \$ 5.960, \mathrm{R} \$ 8.275]$ & 539 & $8,50 \%$ & 5.800 & $91,50 \%$ & 6.339 & 1,11 \\
mais de $\mathrm{R} \$ 8.275$ & 525 & $8,29 \%$ & 5.807 & $91,71 \%$ & 6.332 & 1,08 \\
\hline Total & 1.467 & $7,72 \%$ & 17.533 & $92,28 \%$ & 19.000 & \\
\hline
\end{tabular}


Tabela A.7: Distribuição de bons e maus clientes para covariável autorização do cliente

\begin{tabular}{ccccccc}
\hline Autorização do Cliente & \multicolumn{2}{c}{ Maus } & \multicolumn{2}{c}{ Bons } & Total & Razão \\
\hline \hline Não & 747 & $8,85 \%$ & 7.690 & $91,15 \%$ & 8.437 & 1,16 \\
Sim & 720 & $6,82 \%$ & 9.843 & $93,18 \%$ & 10.563 & 0,87 \\
\hline Total & 1.467 & $7,72 \%$ & 17.533 & $92,28 \%$ & 19.000 & \\
\hline
\end{tabular}

Figura A.1: Kaplan Meier por sexo

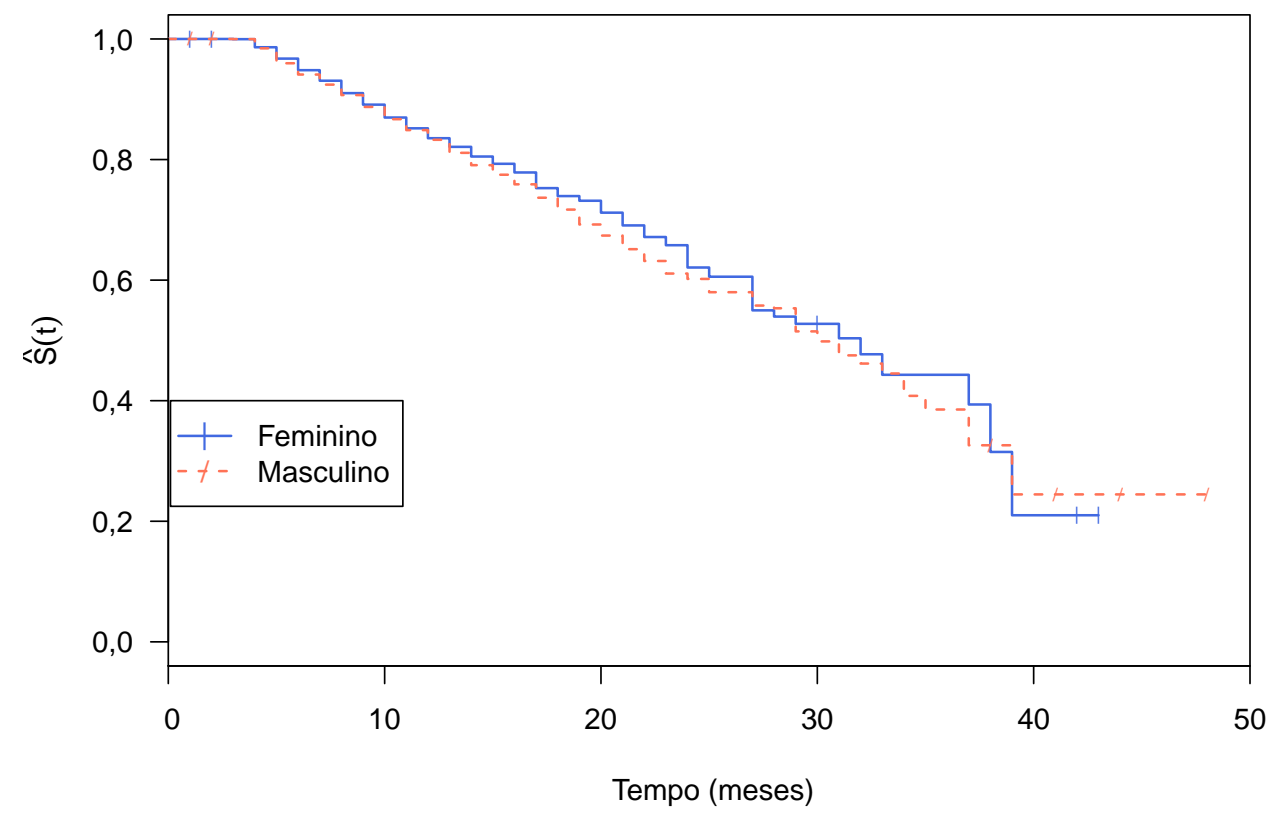


Figura A.2: Kaplan Meier por região

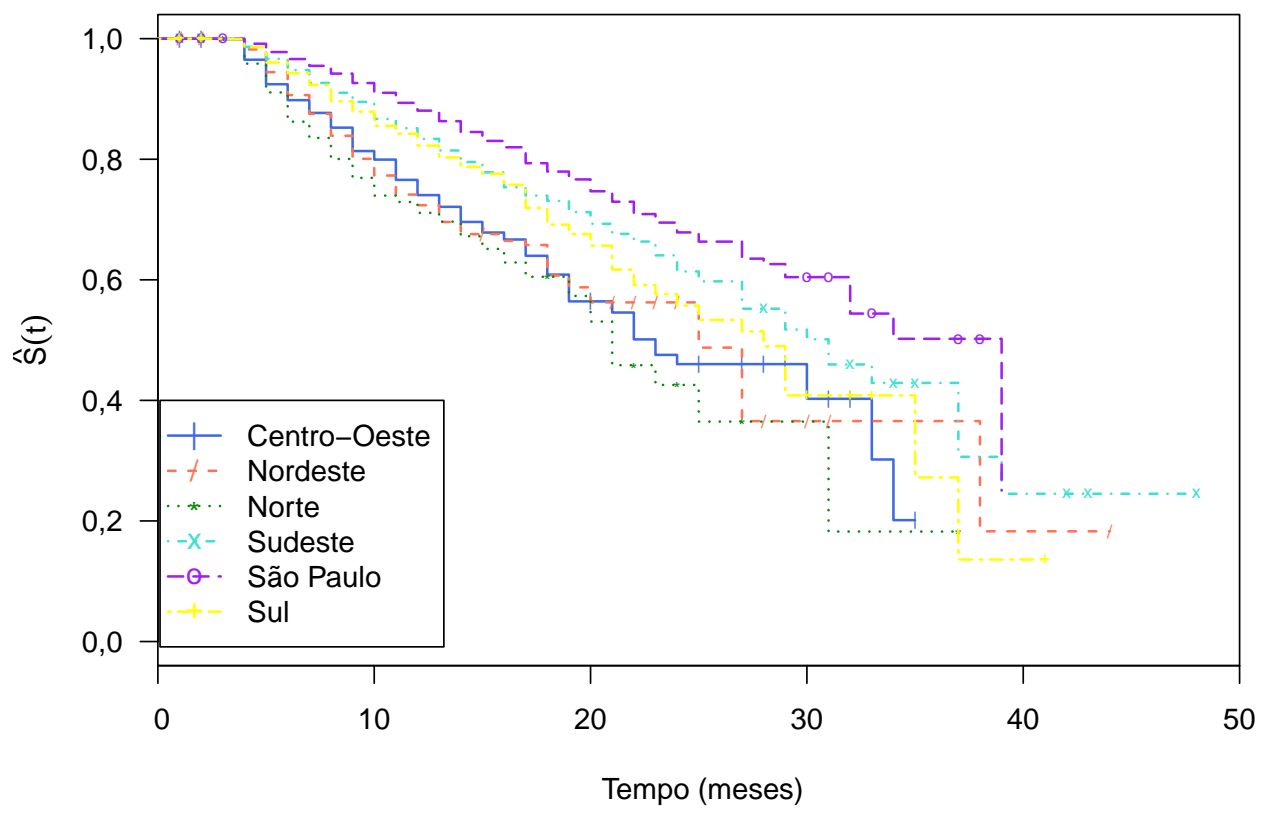

Figura A.3: Kaplan Meier por tempo de relacionamento

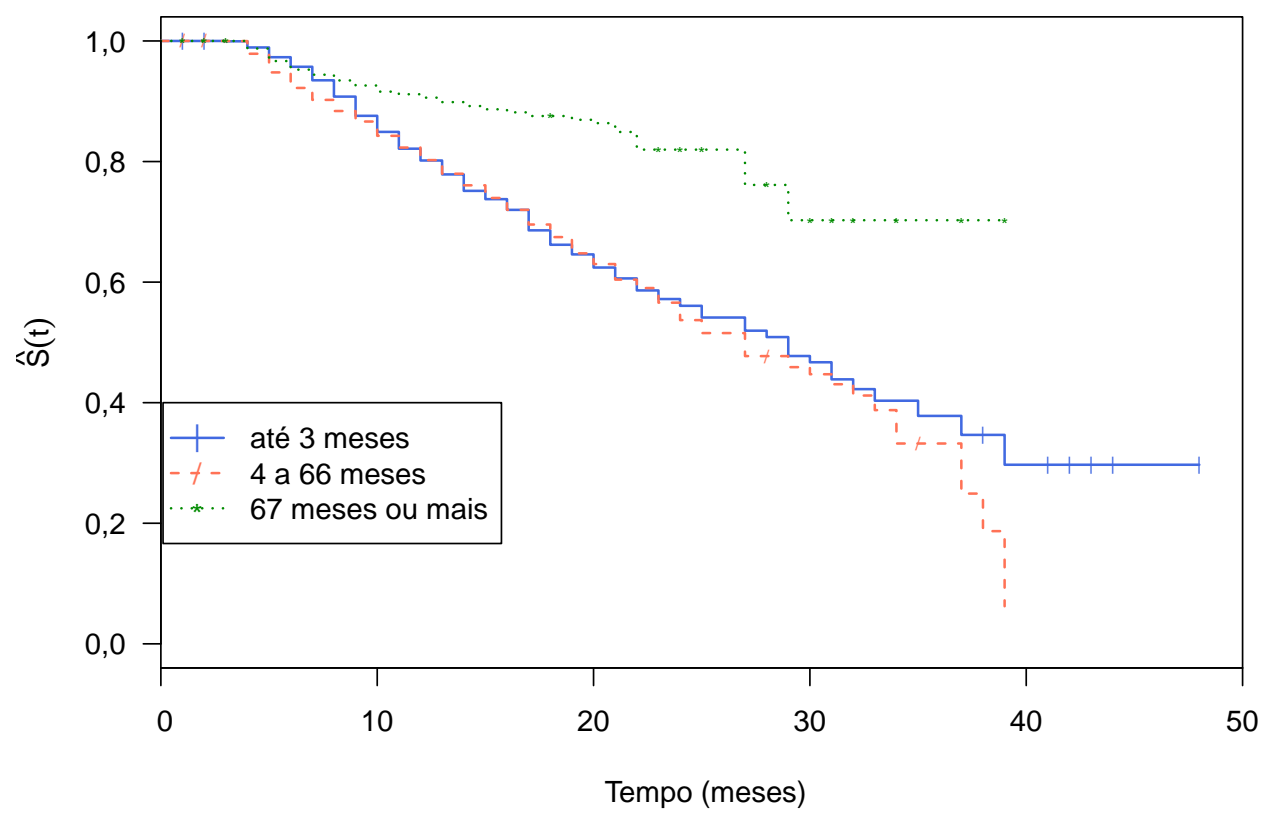


Figura A.4: Kaplan Meier por prazo da operação

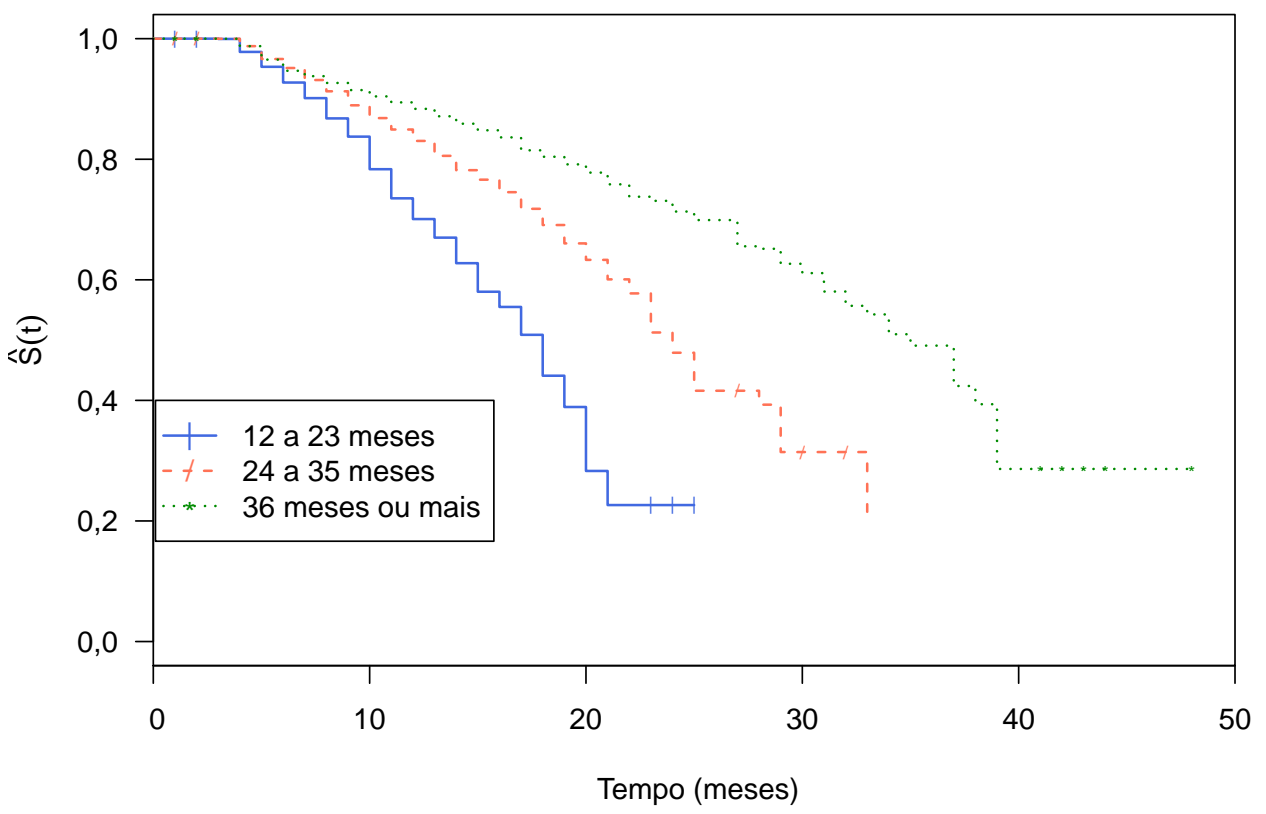

Figura A.5: Kaplan Meier por indexador da operação

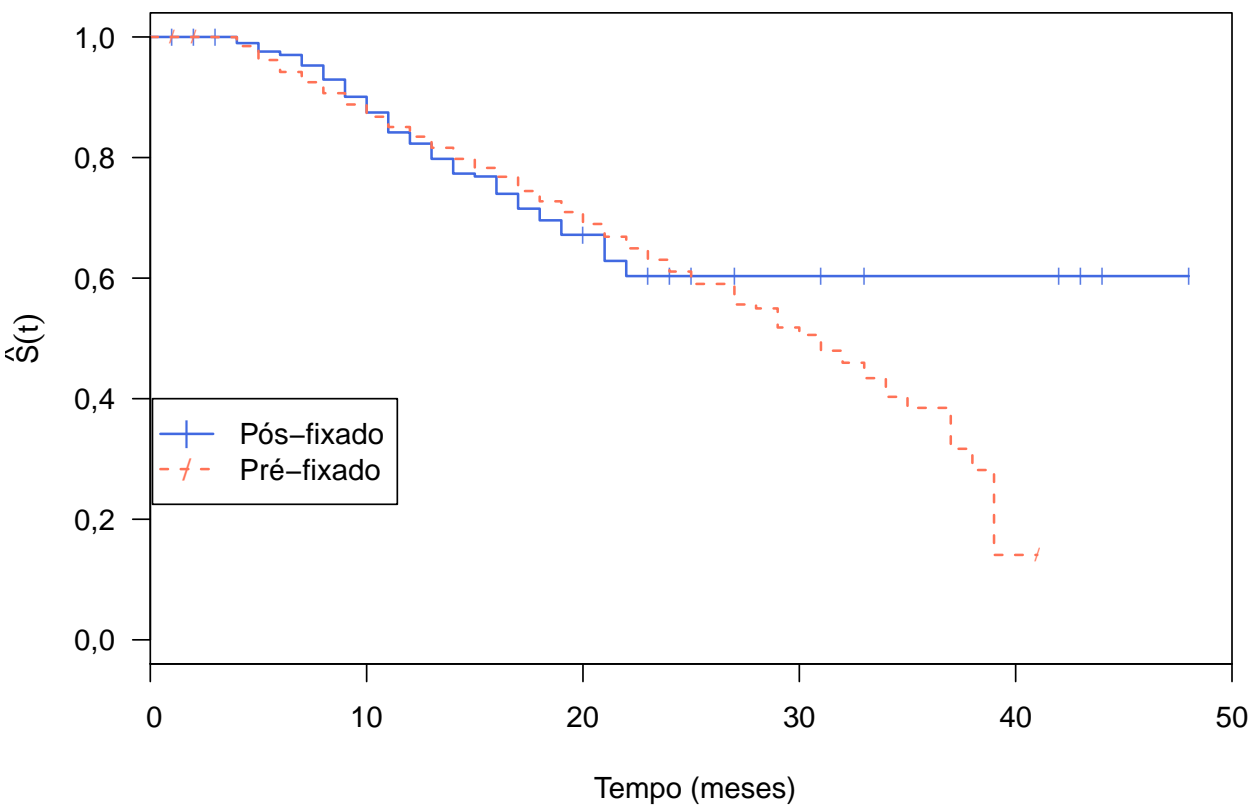


Figura A.6: Kaplan Meier por total da operação

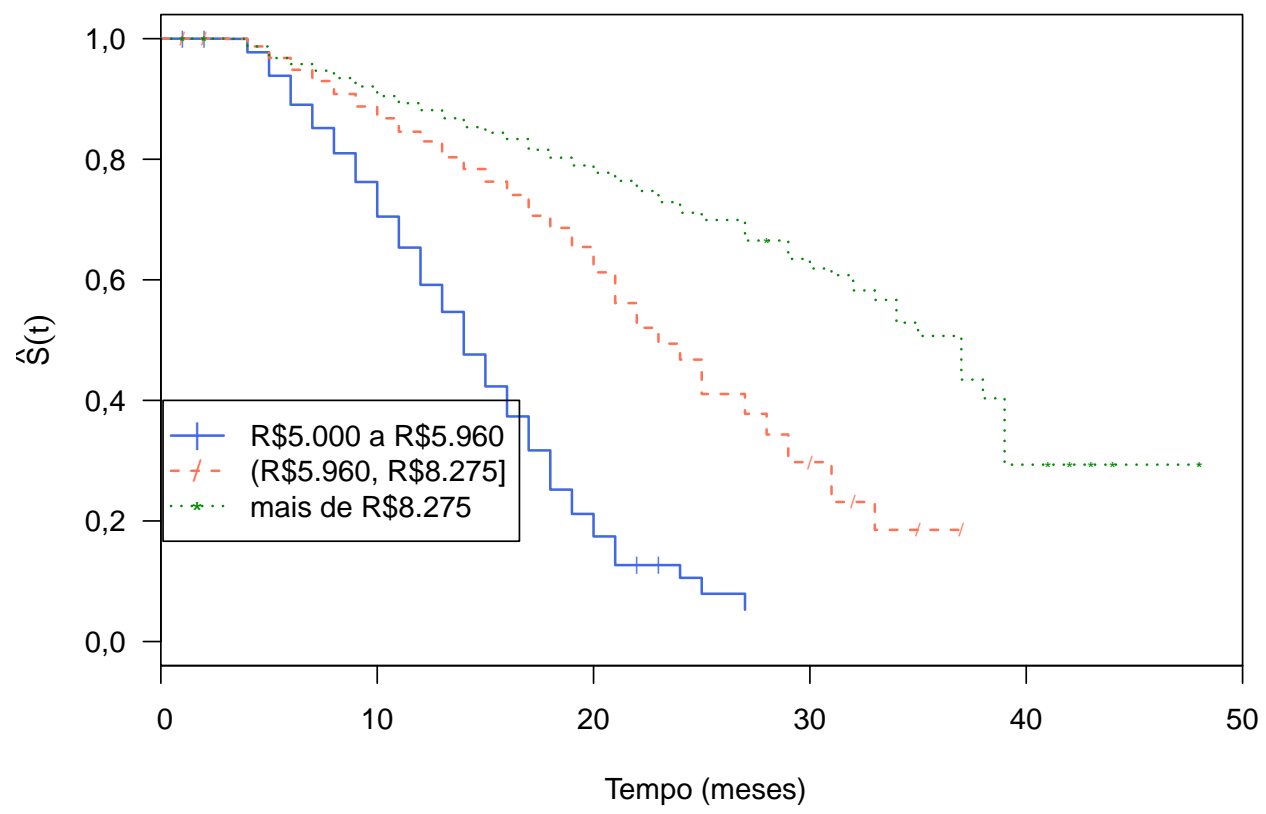

Figura A.7: Kaplan Meier por autorização do cliente

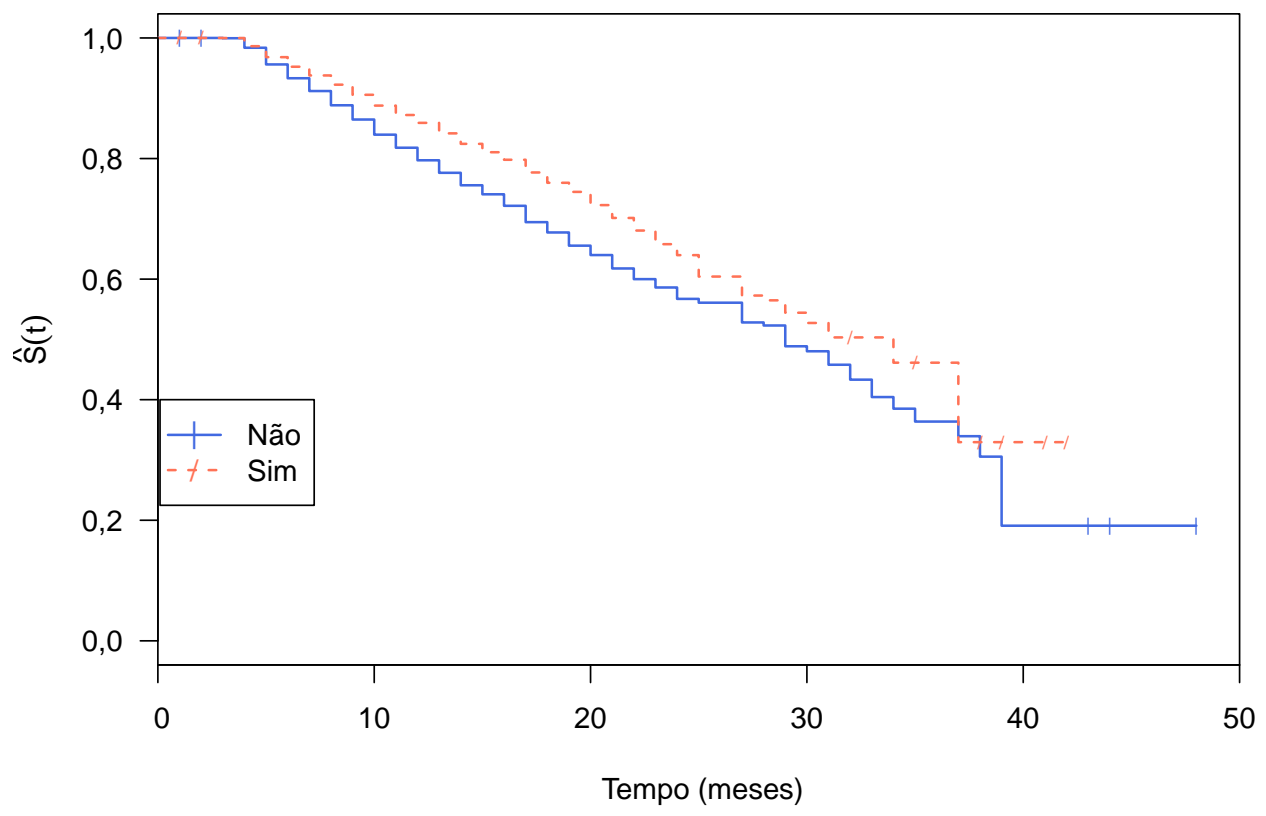




\section{Apêndice B}

\section{Tabelas dos Resultados dos Modelos}

Tabela B.1: Valores para as covariáveis categorizadas

\begin{tabular}{cc}
\hline Covariável & Valor \\
\hline \hline idade1 & idade até 39 anos \\
idade2 & idade de 40 a 51 anos \\
idade3 & idade de 52 anos ou mais \\
sexoF & sexo feminino \\
sexoM & sexo masculino \\
regiaoCO & região Centro-Oeste \\
regiaoNE & região Nordeste \\
regiaoNO & região Norte \\
regiaoSP & região São Paulo \\
regiaoSE & região Sudeste \\
regiaoSU & região Sul \\
tempo_relaciona1 & tempo de relacionamento de até 3 meses \\
tempo_relaciona2 & tempo de relacionamento de 4 a 66 meses \\
tempo_relaciona3 & tempo de relacionamento de 67 meses ou mais \\
prazo_opera1 & prazo da operaçao de 12 a 23 meses \\
prazo_opera2 & prazo da operaçao de 24 a 35 meses \\
prazo_opera3 & prazo da operaçao de 36 meses ou mais \\
indexPOS & indexador da operação: pós-fixado \\
indexPRE & indexador da operação: pré-fixado \\
total_opera1 & total da operaçao de R $\$ 5.000$ a R $\$ 5.960$ \\
total_opera2 & total da operaçao no intervalo $(\mathrm{R} \$ 5.960, \mathrm{R} \$ 8.275]$ \\
total_opera3 & total da operaçao de mais de R $\$ 8.275$ \\
autorizaNAO & status da autorização do cliente: Não \\
autorizaSIM & status da autorização do cliente: Sim \\
\hline
\end{tabular}


Tabela B.2: Estimativas dos coeficientes e erros padrão do modelo de regressão logística para probabilidade de inadimplência, com características de cliente e operação - Covariáveis categorizadas

\begin{tabular}{cccc}
\hline Covariável & Estimativa & Erro Padrão & P-valor \\
\hline \hline Intercepto & $-4,208$ & 0,104 & $<0,001$ \\
idade1 & 1,178 & 0,079 & $<0,001$ \\
idade2 & 0,741 & 0,082 & $<0,001$ \\
idade3 & $\cdot$ & $\cdot$ & $\cdot$ \\
regiaoCO & 0,819 & 0,093 & $<0,001$ \\
regiaoNE & 0,782 & 0,093 & $<0,001$ \\
regiaoNO & 0,835 & 0,115 & $<0,001$ \\
regiaoSE & 0,298 & 0,077 & $<0,001$ \\
regiaoSP & $\cdot$ & $\cdot$ & $\cdot$ \\
regiaoSU & 0,374 & 0,091 & $<0,001$ \\
tempo_relaciona1 & 0,471 & 0,078 & $<0,001$ \\
tempo_relaciona2 & 0,651 & 0,075 & $<0,001$ \\
tempo_relaciona3 & $\cdot$ & $\cdot$ & $\cdot$ \\
total_opera1 & $\cdot$ & $\cdot$ & $\cdot$ \\
total_opera2 & 0,235 & 0,070 & $<0,001$ \\
total_opera3 & 0,240 & 0,070 & $<0,001$ \\
autorizaNAO & 0,168 & 0,058 & $<0,001$ \\
autorizaSIM & $\cdot$ & $\cdot$ & $\cdot$ \\
\hline
\end{tabular}


Tabela B.3: Estimativas dos coeficientes e erros padrão do modelo de regressão logística para probabilidade de inadimplência, com características de cliente e operação - Covariáveis quantitativas

\begin{tabular}{cccc}
\hline Covariável & Estimativa & Erro Padrão & P-valor \\
\hline \hline Intercepto & $-2,474$ & 0,614 & $<0,001$ \\
idade & $-0,041$ & 0,002 & $<0,001$ \\
regiaoCO & 0,798 & 0,093 & $<0,001$ \\
regiaoNE & 0,769 & 0,093 & $<0,001$ \\
regiaoNO & 0,804 & 0,115 & $<0,001$ \\
regiaoSE & 0,278 & 0,078 & $<0,001$ \\
regiaoSP & $\cdot$ & $\cdot$ & $\cdot$ \\
regiaoSU & 0,359 & 0,091 & $<0,001$ \\
tempo_relaciona & $-0,005$ & 0,001 & $<0,001$ \\
$\log ($ total_opera) & 0,178 & 0,068 & 0,009 \\
autorizaNAO & 0,126 & 0,058 & 0,029 \\
autorizaSIM & $\cdot$ & $\cdot$ & $\cdot$ \\
\hline
\end{tabular}


Tabela B.4: Estimativas dos coeficientes e erros padrão do modelo de Cox para probabilidade de inadimplência, com características de cliente e operação - Covariáveis categorizadas

\begin{tabular}{cccc}
\hline Covariável & Estimativa & Erro Padrão & P-valor \\
\hline \hline idade1 & 0,811 & 0,062 & $<0,001$ \\
idade2 & 0,482 & 0,065 & $<0,001$ \\
idade3 & $\cdot$ & $\cdot$ & $\cdot$ \\
sexoF & $\cdot$ & $\cdot$ & $\cdot$ \\
sexoM & 0,106 & 0,047 & 0,023 \\
regiaoCO & 0,669 & 0,075 & $<0,001$ \\
regiaoNE & 0,691 & 0,078 & $<0,001$ \\
regiaoNO & 0,766 & 0,096 & $<0,001$ \\
regiaoSE & 0,250 & 0,062 & $<0,001$ \\
regiaoSP & $\cdot$ & $\cdot$ & $\cdot$ \\
regiaoSU & 0,343 & 0,072 & $<0,001$ \\
tempo_relaciona1 & 0,415 & 0,068 & $<0,001$ \\
tempo_relaciona2 & 0,558 & 0,066 & $<0,001$ \\
tempo_relaciona3 & $\cdot$ & $\cdot$ & $\cdot$ \\
prazo_opera1 & 1,150 & 0,064 & $<0,001$ \\
prazo_opera2 & 0,505 & 0,054 & $<0,001$ \\
prazo_opera3 & $\cdot$ & $\cdot$ & $\cdot$ \\
total_opera1 & $\cdot$ & $\cdot$ & $\cdot$ \\
total_opera2 & $-0,993$ & 0,060 & $<0,001$ \\
total_opera3 & $-1,656$ & 0,063 & $<0,001$ \\
autorizaNAO & 0,220 & 0,046 & $<0,001$ \\
autorizaSIM & $\cdot$ & $\cdot$ & $\cdot$ \\
\hline
\end{tabular}


Tabela B.5: Estimativas dos coeficientes e erros padrão do modelo de Cox para probabilidade de inadimplência, com características de cliente e operação - Covariáveis quantitativas

\begin{tabular}{cccc}
\hline Covariável & Estimativa & Erro Padrão & P-valor \\
\hline \hline idade & $-0,027$ & 0,002 & $<0,001$ \\
sexoF & $\cdot$ & $\cdot$ & $\cdot$ \\
sexoM & 0,115 & 0,047 & 0,014 \\
regiaoCO & 0,616 & 0,075 & $<0,001$ \\
regiaoNE & 0,696 & 0,078 & $<0,001$ \\
regiaoNO & 0,715 & 0,096 & $<0,001$ \\
regiaoSE & 0,221 & 0,061 & $<0,001$ \\
regiaoSP & $\cdot$ & $\cdot$ & $\cdot$ \\
regiaoSU & 0,296 & 0,072 & $<0,001$ \\
tempo_relaciona & $-0,003$ & 0,000 & $<0,001$ \\
prazo & $-0,052$ & 0,003 & $<0,001$ \\
$\log$ (total_opera) & $-1,628$ & 0,076 & $<0,001$ \\
autorizaNAO & 0,197 & 0,046 & $<0,001$ \\
autorizaSIM & $\cdot$ & $\cdot$ & $\cdot$ \\
\hline
\end{tabular}


Tabela B.6: Estimativas dos coeficientes e erros padrão do modelo de pseudovalores para probabilidade de inadimplência, com características de cliente e operação - Covariáveis categorizadas

\begin{tabular}{cccc}
\hline Covariável & Estimativa & Erro Padrão & P-valor \\
\hline \hline Intercepto & 2,788 & 0,123 & $<0,001$ \\
idade1 & $-0,989$ & 0,086 & $<0,001$ \\
idade2 & $-0,580$ & 0,090 & $<0,001$ \\
idade3 & $\cdot$ & $\cdot$ & $\cdot$ \\
regiaoCO & $-0,731$ & 0,098 & $<0,001$ \\
regiaoNE & $-0,746$ & 0,097 & $<0,001$ \\
regiaoNO & $-0,596$ & 0,122 & $<0,001$ \\
regiaoSE & $-0,236$ & 0,082 & 0,004 \\
regiaoSP & $\cdot$ & $\cdot$ & $\cdot$ \\
regiaoSU & $-0,287$ & 0,095 & 0,003 \\
tempo_relaciona1 & $-0,523$ & 0,082 & $<0,001$ \\
tempo_relaciona2 & $-0,455$ & 0,081 & $<0,001$ \\
tempo_relaciona3 & $\cdot$ & $\cdot$ & $\cdot$ \\
prazo_opera1 & $-0,757$ & 0,079 & $<0,001$ \\
prazo_opera2 & $-0,405$ & 0,081 & $<0,001$ \\
prazo_opera3 & $\cdot$ & $\cdot$ & $\cdot$ \\
total_opera1 & $\cdot$ & $\cdot$ & $\cdot$ \\
total_opera2 & 0,397 & 0,065 & $<0,001$ \\
total_opera3 & 1,071 & 0,084 & $<0,001$ \\
autorizaNAO & $-0,143$ & 0,061 & 0,018 \\
autorizaSIM & $\cdot$ & $\cdot$ & $\cdot$ \\
\hline
\end{tabular}


Tabela B.7: Estimativas dos coeficientes e erros padrão do modelo de pseudovalores para probabilidade de inadimplência, com características de cliente e operação - Covariáveis quantitativas

\begin{tabular}{cccc}
\hline Covariável & Estimativa & Erro Padrão & P-valor \\
\hline \hline Intercepto & $-13,106$ & 1,027 & $<0,001$ \\
idade & 0,033 & 0,003 & $<0,001$ \\
regiaoCO & $-0,692$ & 0,098 & $<0,001$ \\
regiaoNE & $-0,691$ & 0,097 & $<0,001$ \\
regiaoNO & $-0,494$ & 0,123 & $<0,001$ \\
regiaoSE & $-0,194$ & 0,081 & 0,016 \\
regiaoSP & $\cdot$ & $\cdot$ & $\cdot$ \\
regiaoSU & $-0,236$ & 0,095 & 0,013 \\
tempo_relaciona & 0,004 & 0,001 & $<0,001$ \\
prazo & 0,032 & 0,003 & $<0,001$ \\
$\log$ (total_opera) & 1,407 & 0,115 & $<0,001$ \\
autorizaNAO & $-0,149$ & 0,060 & 0,013 \\
autorizaSIM & $\cdot$ & $\cdot$ & $\cdot$ \\
\hline
\end{tabular}

Tabela B.8: Estimativas dos coeficientes e erros padrão do modelo de pseudovalores para tempo médio de inadimplência, com características de cliente e operação - Covariáveis categorizadas

\begin{tabular}{cccc}
\hline Covariável & Estimativa & Erro Padrão & P-valor \\
\hline \hline Intercepto & 4,253 & 0,070 & $<0,001$ \\
idade2 & 0,153 & 0,046 & 0,001 \\
idade3 & $\cdot$ & $\cdot$ & $\cdot$ \\
regiaoSE & 0,297 & 0,050 & $<0,001$ \\
regiaoSP & $\cdot$ & $\cdot$ & $\cdot$ \\
tempo_relaciona2 & $-0,304$ & 0,059 & $<0,001$ \\
tempo_relaciona3 & $\cdot$ & $\cdot$ & $\cdot$ \\
prazo_opera1 & $-0,559$ & 0,060 & $<0,001$ \\
prazo_opera2 & $-0,571$ & 0,057 & $<0,001$ \\
prazo_opera3 & $\cdot$ & $\cdot$ & $\cdot$ \\
indexPOS & $\cdot$ & $\cdot$ & $\cdot$ \\
indexPRE & $-0,830$ & 0,056 & $<0,001$ \\
total_opera1 & $\cdot$ & $\cdot$ & $\cdot$ \\
total_opera3 & 0,519 & 0,046 & $<0,001$ \\
autorizaNAO & $-0,212$ & 0,048 & $<0,001$ \\
autorizaSIM & $\cdot$ & $\cdot$ & $\cdot$ \\
\hline
\end{tabular}


Tabela B.9: Estimativas dos coeficientes e erros padrão do modelo de regressão logística para probabilidade de inadimplência, com características de cliente Covariáveis categorizadas

\begin{tabular}{cccc}
\hline Covariável & Estimativa & Erro Padrão & P-valor \\
\hline \hline Intercepto & $-4,050$ & 0,095 & $<0,001$ \\
idade1 & 1,180 & 0,079 & $<0,001$ \\
idade2 & 0,745 & 0,082 & $<0,001$ \\
idade3 & $\cdot$ & $\cdot$ & $\cdot$ \\
regiaoCO & 0,833 & 0,092 & $<0,001$ \\
regiaoNE & 0,785 & 0,093 & $<0,001$ \\
regiaoNO & 0,834 & 0,115 & $<0,001$ \\
regiaoSE & 0,299 & 0,077 & $<0,001$ \\
regiaoSP & $\cdot$ & $\cdot$ & $\cdot$ \\
regiaoSU & 0,378 & 0,091 & $<0,001$ \\
tempo_relaciona1 & 0,478 & 0,078 & $<0,001$ \\
tempo_relaciona2 & 0,654 & 0,074 & $<0,001$ \\
tempo_relaciona3 & $\cdot$ & $\cdot$ & $\cdot$ \\
autorizaNAO & 0,165 & 0,058 & 0,004 \\
autorizaSIM & $\cdot$ & $\cdot$ & $\cdot$ \\
\hline
\end{tabular}

Tabela B.10: Estimativas dos coeficientes e erros padrão do modelo de regressão logística para probabilidade de inadimplência, com características de cliente Covariáveis quantitativas

\begin{tabular}{cccc}
\hline Covariável & Estimativa & Erro Padrão & P-valor \\
\hline \hline Intercepto & $-0,887$ & 0,109 & $<0,001$ \\
idade & $-0,041$ & 0,002 & $<0,001$ \\
regiaoCO & 0,807 & 0,093 & $<0,001$ \\
regiaoNE & 0,769 & 0,093 & $<0,001$ \\
regiaoNO & 0,799 & 0,115 & $<0,001$ \\
regiaoSE & 0,277 & 0,078 & $<0,001$ \\
regiaoSP & $\cdot$ & $\cdot$ & $\cdot$ \\
regiaoSU & 0,361 & 0,091 & $<0,001$ \\
tempo_relaciona & $-0,004$ & 0,001 & $<0,001$ \\
autorizaNAO & 0,122 & 0,058 & 0,035 \\
autorizaSIM & $\cdot$ & $\cdot$ & $\cdot$ \\
\hline
\end{tabular}


Tabela B.11: Estimativas dos coeficientes e erros padrão do modelo de Cox para probabilidade de inadimplência, com características de cliente - Covariáveis categorizadas

\begin{tabular}{cccc}
\hline Covariável & Estimativa & Erro Padrão & P-valor \\
\hline \hline idade1 & 0,910 & 0,062 & $<0,001$ \\
idade2 & 0,513 & 0,065 & $<0,001$ \\
idade3 & $\cdot$ & $\cdot$ & $\cdot$ \\
regiaoCO & 0,712 & 0,075 & $<0,001$ \\
regiaoNE & 0,768 & 0,078 & $<0,001$ \\
regiaoNO & 0,931 & 0,096 & $<0,001$ \\
regiaoSE & 0,268 & 0,061 & $<0,001$ \\
regiaoSP & $\cdot$ & $\cdot$ & $\cdot$ \\
regiaoSU & 0,379 & 0,072 & $<0,001$ \\
tempo_relaciona1 & 0,511 & 0,067 & $<0,001$ \\
tempo_relaciona2 & 0,642 & 0,065 & $<0,001$ \\
tempo_relaciona3 & $\cdot$ & $\cdot$ & $\cdot$ \\
autorizaNAO & 0,201 & 0,046 & $<0,001$ \\
autorizaSIM & $\cdot$ & $\cdot$ & $\cdot$ \\
\hline
\end{tabular}

Tabela B.12: Estimativas dos coeficientes e erros padrão do modelo de Cox para probabilidade de inadimplência, com características de cliente - Covariáveis quantitativas

\begin{tabular}{cccc}
\hline Covariável & Estimativa & Erro Padrão & P-valor \\
\hline \hline idade & $-0,032$ & 0,002 & $<0,001$ \\
sexoF & $\cdot$ & $\cdot$ & $\cdot$ \\
sexoM & 0,099 & 0,047 & 0,034 \\
regiaoCO & 0,673 & 0,075 & $<0,001$ \\
regiaoNE & 0,753 & 0,078 & $<0,001$ \\
regiaoNO & 0,909 & 0,096 & $<0,001$ \\
regiaoSE & 0,261 & 0,061 & $<0,001$ \\
regiaoSP & $\cdot$ & $\cdot$ & $\cdot$ \\
regiaoSU & 0,359 & 0,072 & $<0,001$ \\
tempo_relaciona & $-0,005$ & 0,000 & $<0,001$ \\
autorizaNAO & 0,166 & 0,046 & $<0,001$ \\
autorizaSIM & $\cdot$ & $\cdot$ & $\cdot$ \\
\hline
\end{tabular}


Tabela B.13: Estimativas dos coeficientes e erros padrão do modelo de pseudovalores para probabilidade de inadimplência, com características de cliente - Covariáveis categorizadas

\begin{tabular}{cccc}
\hline Covariável & Estimativa & Erro Padrão & P-valor \\
\hline \hline Intercepto & 3,116 & 0,123 & $<0,001$ \\
idade1 & $-1,159$ & 0,095 & $<0,001$ \\
idade2 & $-0,695$ & 0,099 & $<0,001$ \\
idade3 & $\cdot$ & $\cdot$ & $\cdot$ \\
regiaoCO & $-0,821$ & 0,099 & $<0,001$ \\
regiaoNE & $-0,915$ & 0,096 & $<0,001$ \\
regiaoNO & $-0,847$ & 0,120 & $<0,001$ \\
regiaoSE & $-0,322$ & 0,086 & $<0,001$ \\
regiaoSP & $\cdot$ & $\cdot$ & $\cdot$ \\
regiaoSU & $-0,401$ & 0,100 & $<0,001$ \\
tempo_relaciona1 & $-0,535$ & 0,086 & $<0,001$ \\
tempo_relaciona2 & $-0,526$ & 0,086 & $<0,001$ \\
tempo_relaciona3 & $\cdot$ & $\cdot$ & $\cdot$ \\
autorizaNAO & $-0,188$ & 0,062 & 0,003 \\
autorizaSIM & $\cdot$ & $\cdot$ & $\cdot$ \\
\hline
\end{tabular}

Tabela B.14: Estimativas dos coeficientes e erros padrão do modelo de pseudovalores para probabilidade de inadimplência, com características de cliente - Covariáveis quantitativas

\begin{tabular}{cccc}
\hline Covariável & Estimativa & Erro Padrão & P-valor \\
\hline \hline Intercepto & $-0,004$ & 0,120 & 0,976 \\
idade & 0,041 & 0,003 & $<0,001$ \\
regiaoCO & $-0,786$ & 0,099 & $<0,001$ \\
regiaoNE & $-0,885$ & 0,097 & $<0,001$ \\
regiaoNO & $-0,797$ & 0,120 & $<0,001$ \\
regiaoSE & $-0,305$ & 0,086 & $<0,001$ \\
regiaoSP & $\cdot$ & $\cdot$ & $\cdot$ \\
regiaoSU & $-0,387$ & 0,099 & $<0,001$ \\
tempo_relaciona & 0,005 & 0,001 & $<0,001$ \\
autorizaNAO & $-0,183$ & 0,062 & 0,003 \\
autorizaSIM & $\cdot$ & $\cdot$ & $\cdot$ \\
\hline
\end{tabular}


Tabela B.15: Estimativas dos coeficientes e erros padrão do modelo de pseudovalores para tempo médio de inadimplência, com características de cliente - Covariáveis categorizadas

\begin{tabular}{cccc}
\hline Covariável & Estimativa & Erro Padrão & P-valor \\
\hline \hline Intercepto & 3,545 & 0,038 & $<0,001$ \\
idade1 & $-0,118$ & 0,054 & 0,029 \\
idade3 & $\cdot$ & $\cdot$ & $\cdot$ \\
tempo_relaciona1 & $-0,116$ & 0,055 & 0,035 \\
tempo_relaciona2 & $-0,279$ & 0,061 & $<0,001$ \\
tempo_relaciona3 & $\cdot$ & $\cdot$ & $\cdot$ \\
\hline
\end{tabular}

Tabela B.16: Estimativas dos coeficientes e erros padrão do modelo de pseudovalores para tempo médio de inadimplência, com características de cliente - Covariáveis quantitativas

\begin{tabular}{cccc}
\hline Covariável & Estimativa & Erro Padrão & P-valor \\
\hline \hline Intercepto & 3,146 & 0,090 & $<0,001$ \\
idade & 0,004 & 0,002 & 0,045 \\
tempo_relaciona & 0,001 & 0,000 & $<0,001$ \\
\hline
\end{tabular}


Tabela B.17: Estimativas dos coeficientes e erros padrão do modelo de regressão logística para dados sem censura - Covariáveis categorizadas

\begin{tabular}{cccc}
\hline Covariável & Estimativa & Erro Padrão & P-valor \\
\hline \hline Intercepto & $-0,172$ & 0,091 & 0,059 \\
idade1 & 0,665 & 0,127 & $<0,001$ \\
idade3 & $\cdot$ & $\cdot$ & $\cdot$ \\
regiaoCO & 0,423 & 0,178 & 0,017 \\
regiaoNE & 0,717 & 0,201 & $<0,001$ \\
regiaoNO & 0,944 & 0,287 & 0,001 \\
regiaoSU & $\cdot$ & $\cdot$ & $\cdot$ \\
tempo_relaciona2 & $\cdot$ & $\cdot$ & $\cdot$ \\
tempo_relaciona3 & 0,825 & 0,126 & $<0,001$ \\
prazo_opera1 & 1,590 & 0,171 & $<0,001$ \\
prazo_opera3 & $\cdot$ & $\cdot$ & $\cdot$ \\
indexPOS & 0,614 & 0,238 & 0,010 \\
indexPRE & $\cdot$ & $\cdot$ & $\cdot$ \\
total_opera1 & 0,732 & 0,126 & $<0,001$ \\
total_opera3 & $\cdot$ & $\cdot$ & $\cdot$ \\
\hline
\end{tabular}

Tabela B.18: Estimativas dos coeficientes e erros padrão do modelo de regressão logística para dados sem censura - Covariáveis quantitativas

\begin{tabular}{cccc}
\hline Covariável & Estimativa & Erro Padrão & P-valor \\
\hline \hline Intercepto & 9,408 & 1,282 & $<0,001$ \\
idade & $-0,028$ & 0,005 & $<0,001$ \\
regiaoCO & 0,346 & 0,176 & 0,049 \\
regiaoNE & 0,724 & 0,201 & 0,000 \\
regiaoNO & 0,963 & 0,286 & 0,001 \\
regiaoSU & $\cdot$ & $\cdot$ & $\cdot$ \\
tempo_relaciona & 0,009 & 0,001 & $<0,001$ \\
prazo_opera & $-0,044$ & 0,006 & $<0,001$ \\
indexPOS & 0,643 & 0,241 & 0,008 \\
indexPRE & $\cdot$ & $\cdot$ & $\cdot$ \\
$\log ($ total_opera $)$ & $-0,721$ & 0,139 & $<0,001$ \\
\hline
\end{tabular}


Tabela B.19: Estimativas dos coeficientes e erros padrão do modelo de Cox para dados sem censura - Covariáveis categorizadas

\begin{tabular}{cccc}
\hline Covariável & Estimativa & Erro Padrão & P-valor \\
\hline \hline idade1 & 0,304 & 0,051 & $<0,001$ \\
idade3 & $\cdot$ & $\cdot$ & $\cdot$ \\
regiaoCO & 0,232 & 0,072 & 0,001 \\
regiaoNE & 0,314 & 0,074 & $<0,001$ \\
regiaoNO & 0,481 & 0,096 & $<0,001$ \\
regiaoSU & $\cdot$ & $\cdot$ & $\cdot$ \\
tempo_relaciona2 & $\cdot$ & $\cdot$ & $\cdot$ \\
tempo_relaciona3 & 0,523 & 0,050 & $<0,001$ \\
prazo_opera1 & 0,717 & 0,064 & $<0,001$ \\
prazo_opera2 & 0,166 & 0,055 & 0,002 \\
prazo_opera3 & $\cdot$ & $\cdot$ & $\cdot$ \\
indexPOS & 0,269 & 0,094 & 0,004 \\
indexPRE & $\cdot$ & $\cdot$ & $\cdot$ \\
total_opera1 & 0,470 & 0,058 & $<0,001$ \\
total_opera2 & 0,208 & 0,057 & $<0,001$ \\
total_opera3 & $\cdot$ & $\cdot$ & $\cdot$ \\
\hline
\end{tabular}

Tabela B.20: Estimativas dos coeficientes e erros padrão do modelo de Cox para dados sem censura - Covariáveis quantitativas

\begin{tabular}{cccc}
\hline Covariável & Estimativa & Erro Padrão & P-valor \\
\hline \hline idade & $-0,013$ & 0,002 & $<0,001$ \\
regiaoCO & 0,178 & 0,072 & 0,014 \\
regiaoNE & 0,288 & 0,074 & $<0,001$ \\
regiaoNO & 0,454 & 0,096 & $<0,001$ \\
regiaoSU & $\cdot$ & $\cdot$ & $\cdot$ \\
tempo_relaciona & 0,004 & 0,000 & $<0,001$ \\
prazo_opera & $-0,028$ & 0,003 & $<0,001$ \\
indexPOS & 0,258 & 0,094 & 0,006 \\
indexPRE & $\cdot$ & $\cdot$ & $\cdot$ \\
$\log ($ total_opera $)$ & $-0,490$ & 0,066 & $<0,001$ \\
\hline
\end{tabular}


Tabela B.21: Estimativas dos coeficientes e erros padrão do modelo de pseudovalores para dados sem censura - Covariáveis categorizadas

\begin{tabular}{cccc}
\hline Covariável & Estimativa & Erro Padrão & P-valor \\
\hline \hline Intercepto & 0,172 & 0,091 & 0,059 \\
idade1 & $-0,665$ & 0,127 & $<0,001$ \\
idade3 & $\cdot$ & $\cdot$ & $\cdot$ \\
regiaoCO & $-0,423$ & 0,178 & 0,017 \\
regiaoNE & $-0,717$ & 0,201 & $<0,001$ \\
regiaoNO & $-0,944$ & 0,287 & 0,001 \\
regiaoSU & $\cdot$ & $\cdot$ & $\cdot$ \\
tempo_relaciona2 & $\cdot$ & $\cdot$ & $\cdot$ \\
tempo_relaciona3 & $-0,825$ & 0,126 & $<0,001$ \\
prazo_opera1 & $-1,590$ & 0,171 & $<0,001$ \\
prazo_opera3 & $\cdot$ & $\cdot$ & $\cdot$ \\
indexPOS & $-0,614$ & 0,238 & 0,010 \\
indexPRE & $\cdot$ & $\cdot$ & $\cdot$ \\
total_opera1 & $-0,732$ & 0,126 & $<0,001$ \\
total_opera3 & $\cdot$ & $\cdot$ & $\cdot$ \\
\hline
\end{tabular}

Tabela B.22: Estimativas dos coeficientes e erros padrão do modelo de pseudovalores para dados sem censura - Covariáveis quantitativas

\begin{tabular}{cccc}
\hline Covariável & Estimativa & Erro Padrão & P-valor \\
\hline \hline Intercepto & $-9,408$ & 1,282 & $<0,001$ \\
idade & 0,028 & 0,005 & $<0,001$ \\
regiaoCO & $-0,346$ & 0,176 & 0,049 \\
regiaoNE & $-0,724$ & 0,201 & 0,000 \\
regiaoNO & $-0,963$ & 0,286 & 0,001 \\
regiaoSU & $\cdot$ & $\cdot$ & $\cdot$ \\
tempo_relaciona & $-0,009$ & 0,001 & $<0,001$ \\
prazo_opera & 0,044 & 0,006 & $<0,001$ \\
indexPOS & $-0,643$ & 0,241 & 0,008 \\
indexPRE & $\cdot$ & $\cdot$ & $\cdot$ \\
$\log ($ total_opera $)$ & 0,721 & 0,139 & $<0,001$
\end{tabular}




\section{Apêndice C}

\section{Gráficos das Medidas de Performance}

Figura C.1: Gráfico KS - Probabilidade de inadimplência - Regressão logística com características de cliente e operação
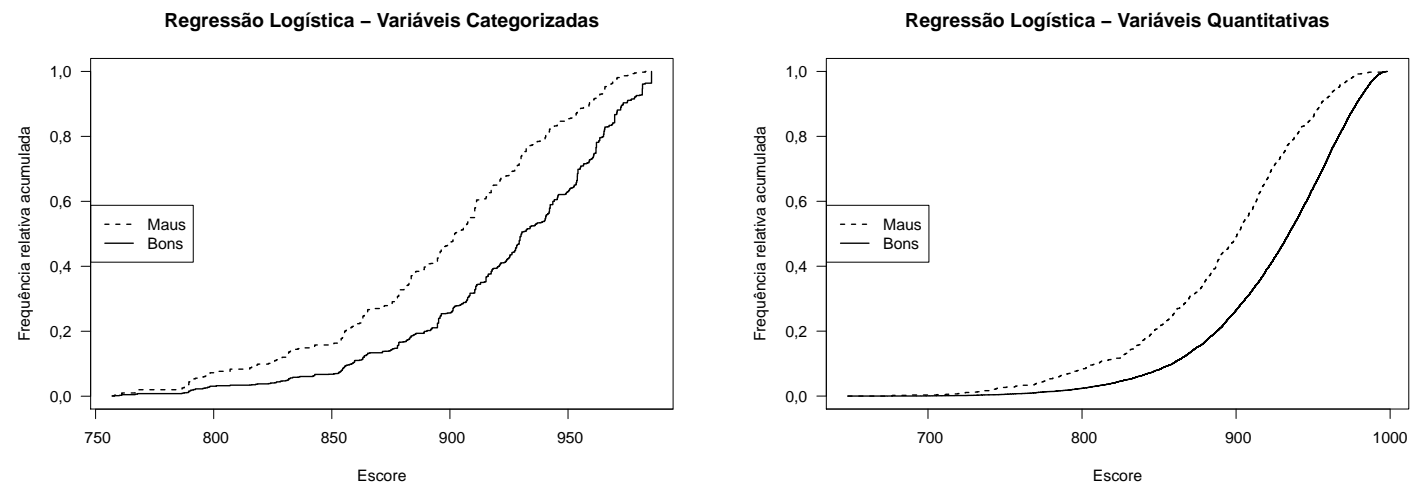

Figura C.2: Gráfico KS - Probabilidade de inadimplência - Modelo de Cox com características de cliente e operação
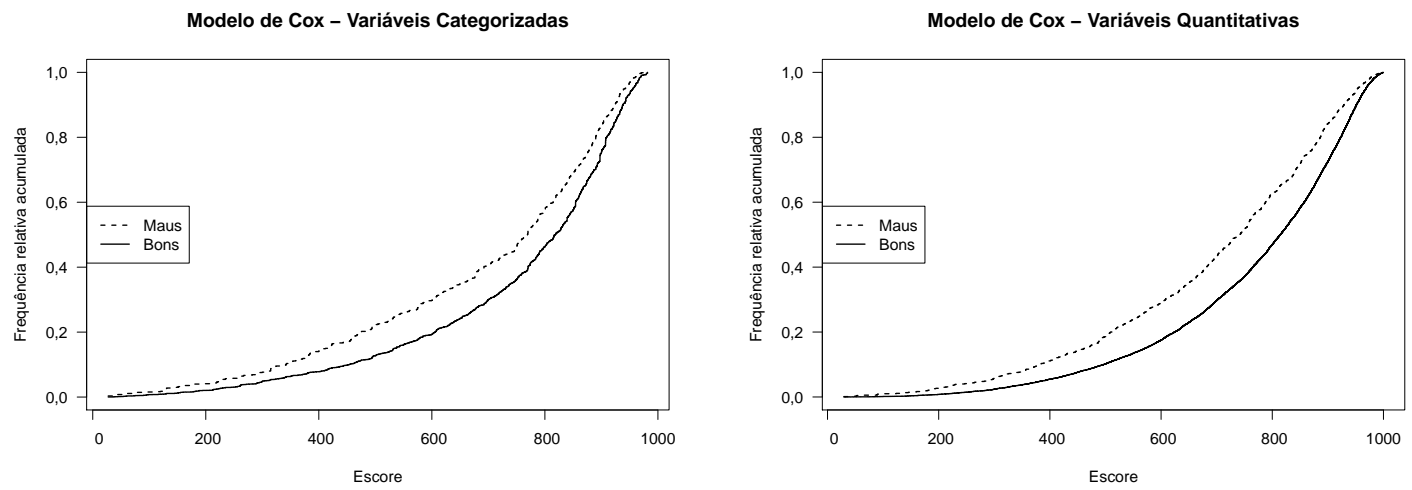
Figura C.3: Gráfico KS - Probabilidade de inadimplência - Pseudo-valores com características de cliente e operação
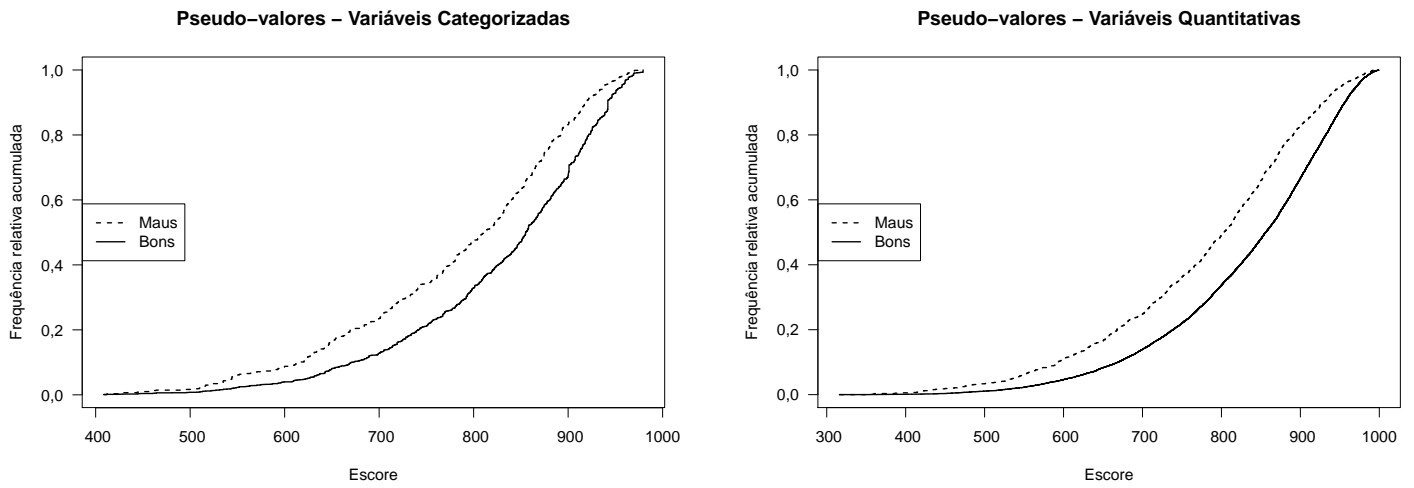

Figura C.4: Gráfico KS - Tempo médio de inadimplência - Modelo de Cox com características de cliente e operação
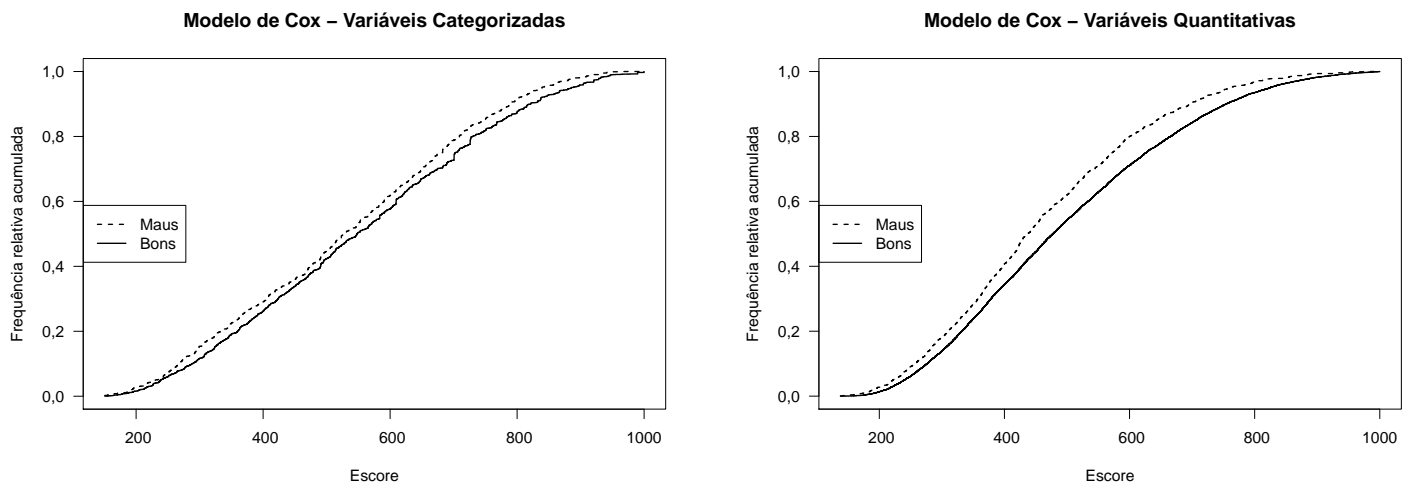

Figura C.5: Gráfico KS - Tempo médio de inadimplência - Pseudo-valores com características de cliente e operação

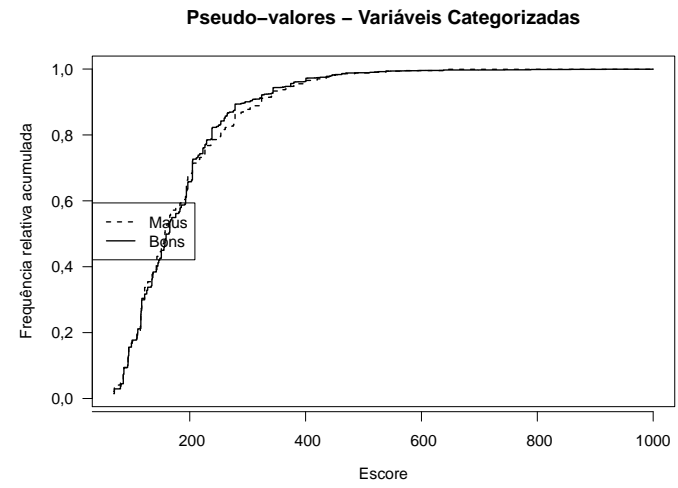


Figura C.6: Curva ROC - Probabilidade de inadimplência - Regressão logística com características de cliente e operação
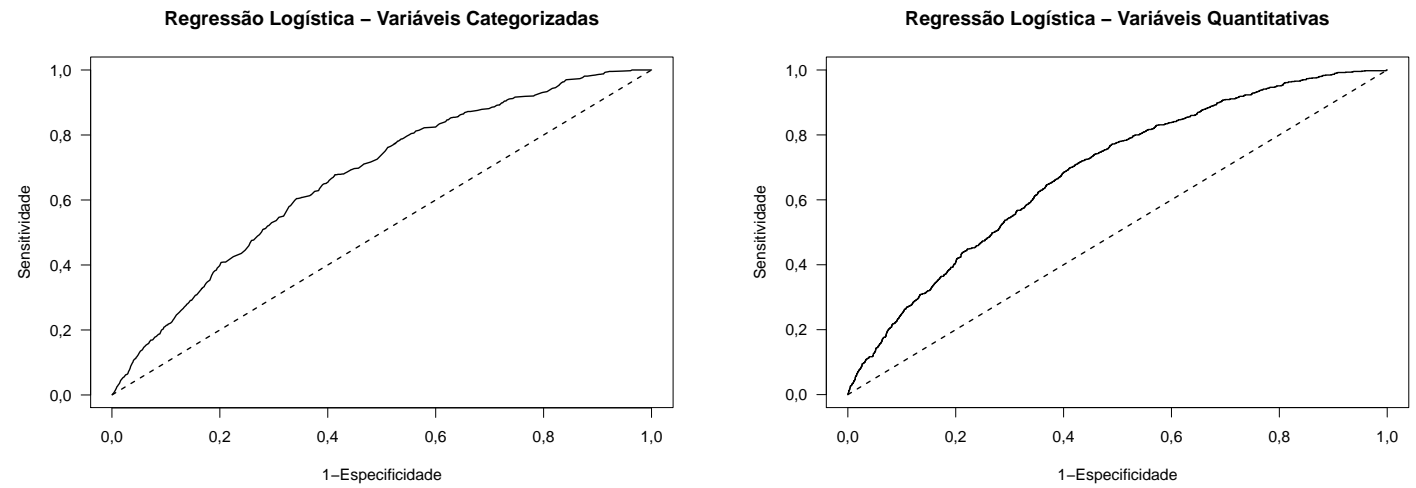

Figura C.7: Curva ROC - Probabilidade de inadimplência - Modelo de Cox com características de cliente e operação
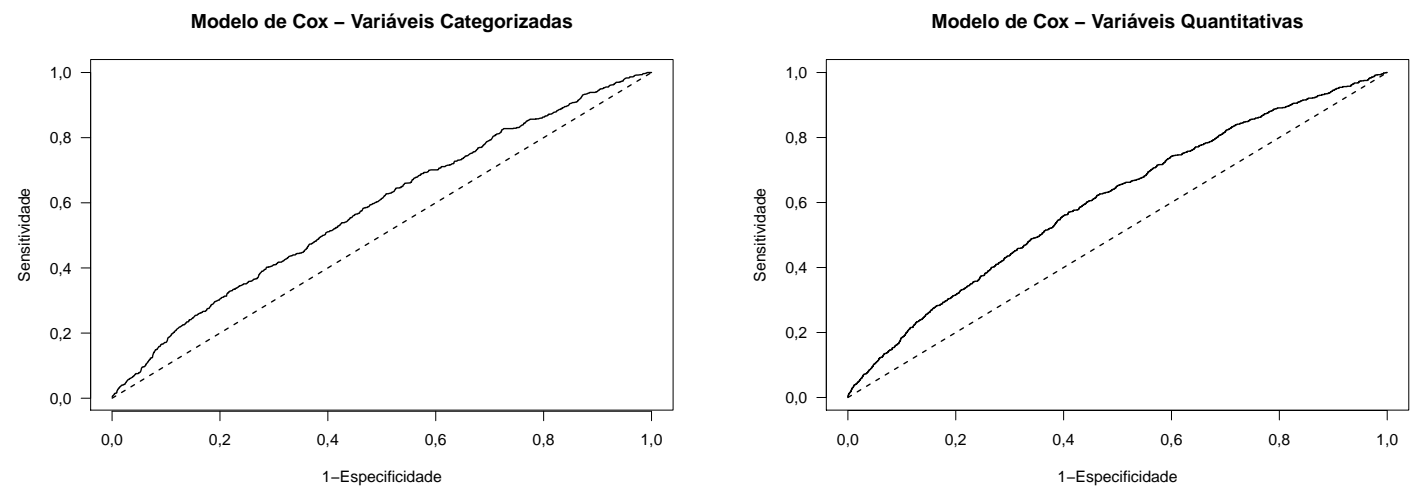

Figura C.8: Curva ROC - Probabilidade de inadimplência - Pseudo-valores com características de cliente e operação
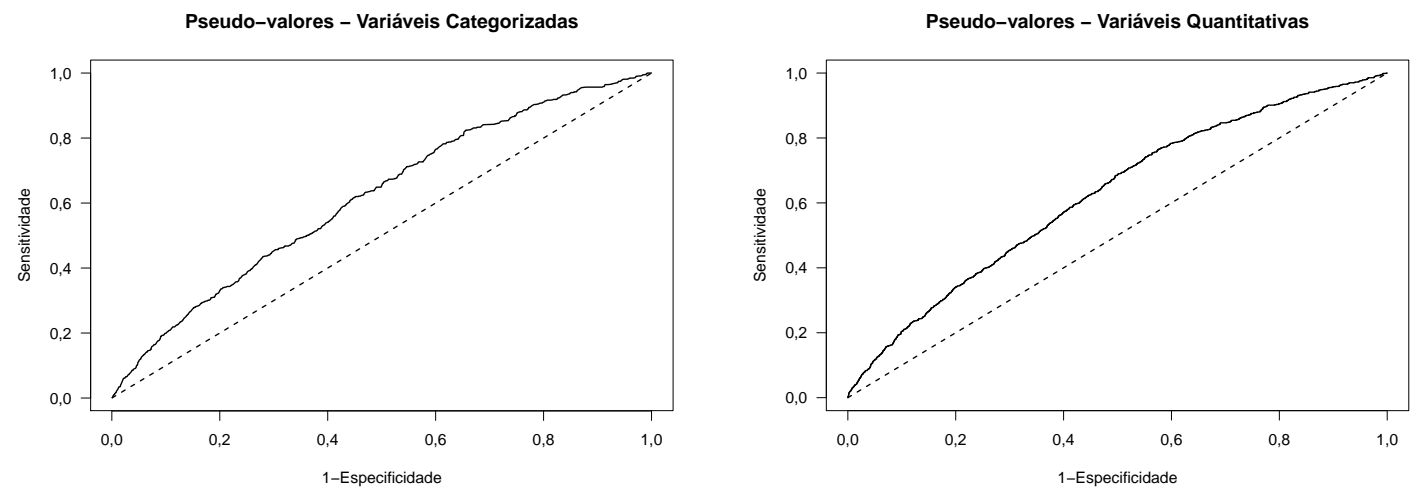
Figura C.9: Curva ROC - Tempo médio de inadimplência - Modelo de Cox com características de cliente e operação
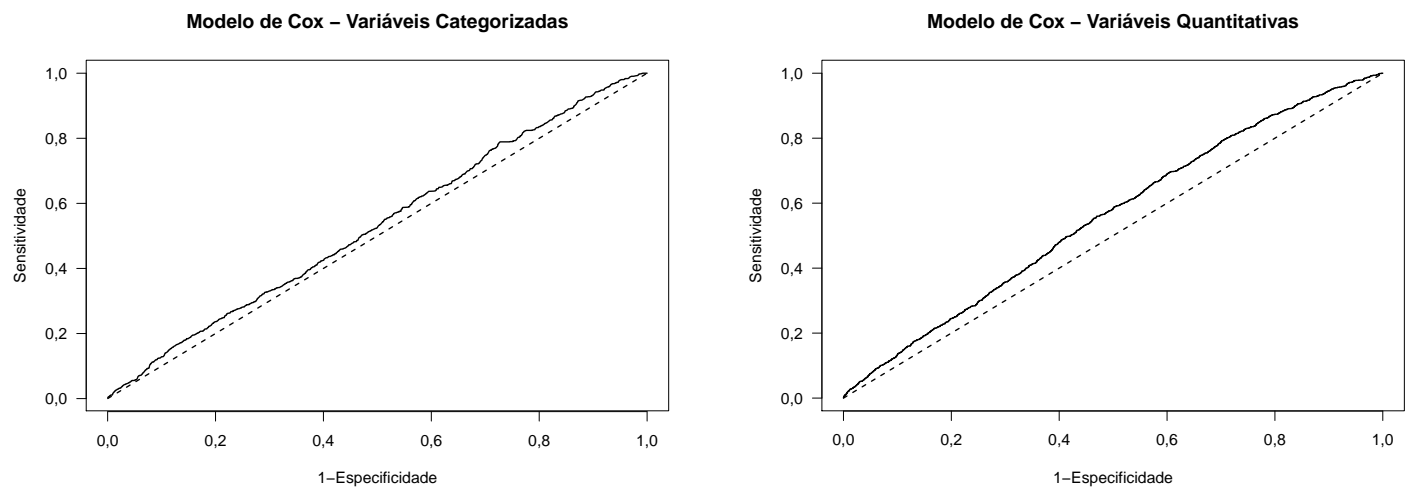

Figura C.10: Curva ROC - Tempo médio de inadimplência - Pseudo-valores com características de cliente e operação

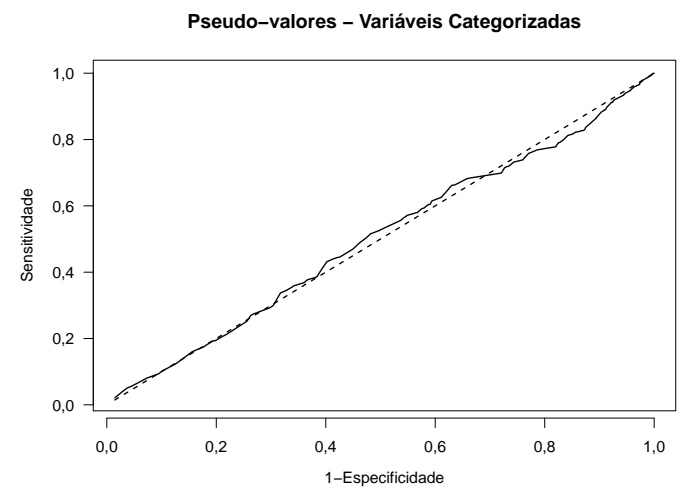

Figura C.11: Gráfico KS - Probabilidade de inadimplência - Regressão logística com características de cliente
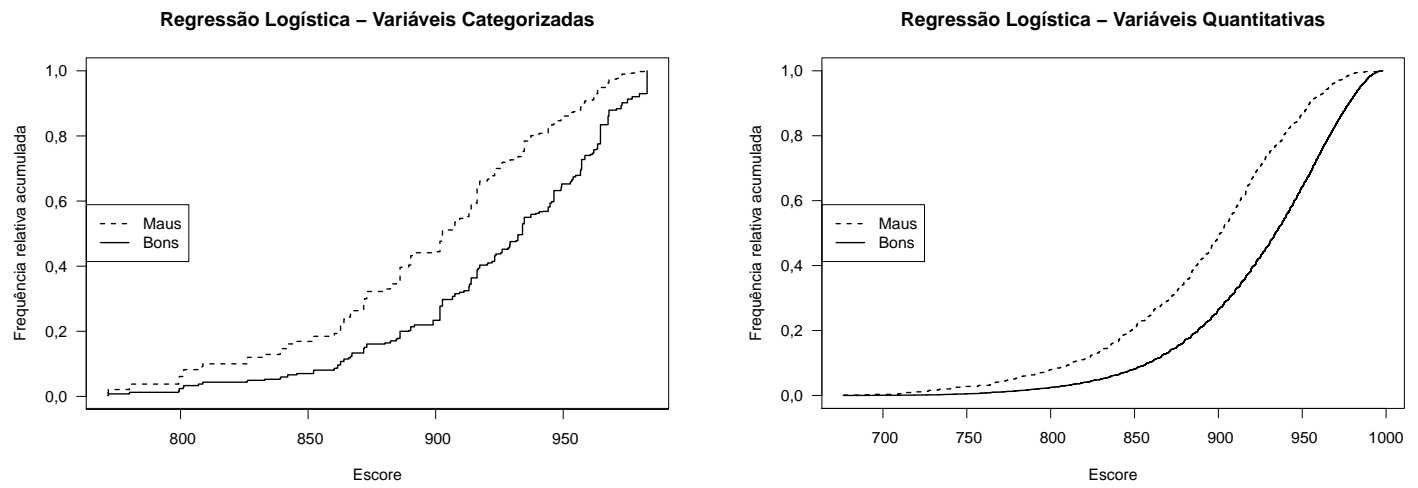
Figura C.12: Gráfico KS - Probabilidade de inadimplência - Modelo de Cox com características de cliente

Modelo de Cox - Variáveis Categorizadas

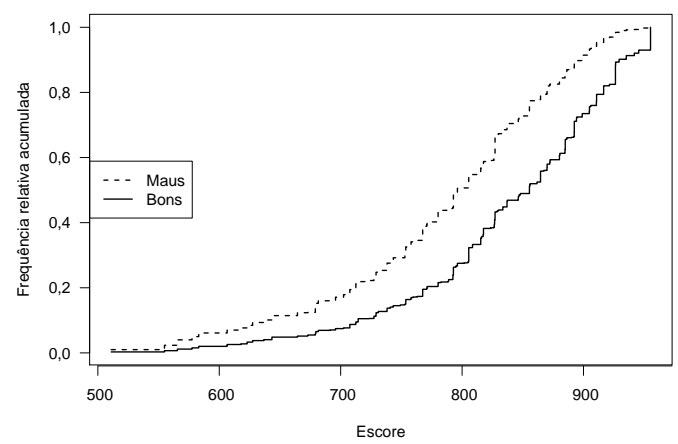

Modelo de Cox - Variáveis Quantitativas

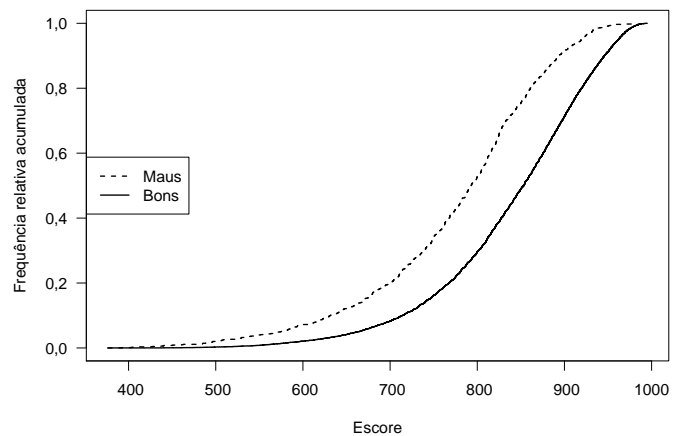

Figura C.13: Gráfico KS - Probabilidade de inadimplência - Pseudo-valores com características de cliente
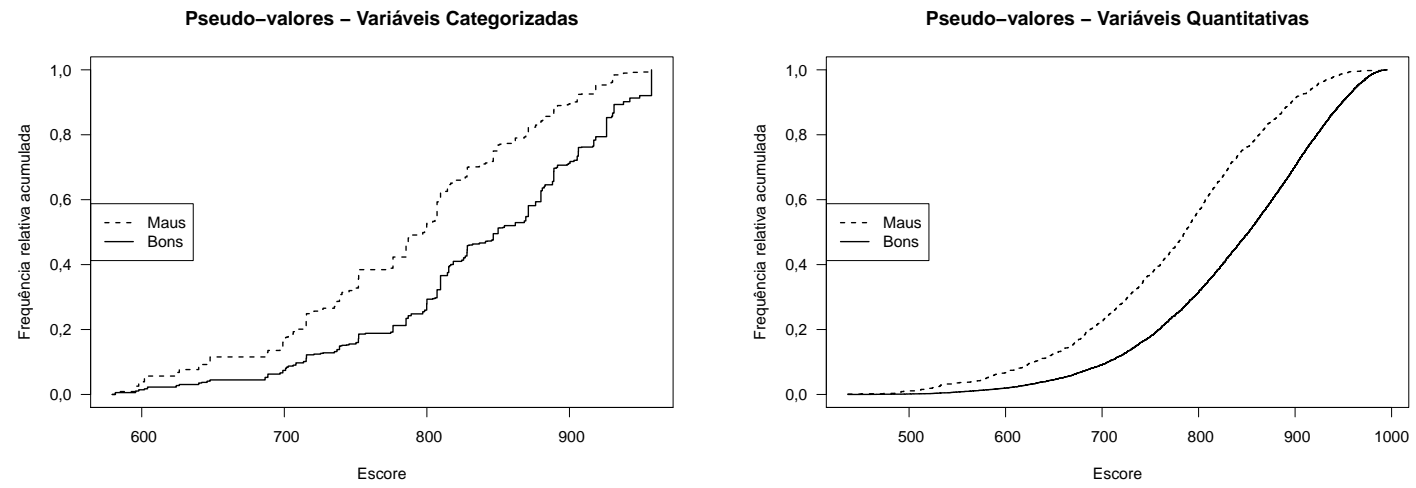

Figura C.14: Gráfico KS - Tempo médio de inadimplência - Modelo de Cox com características de cliente
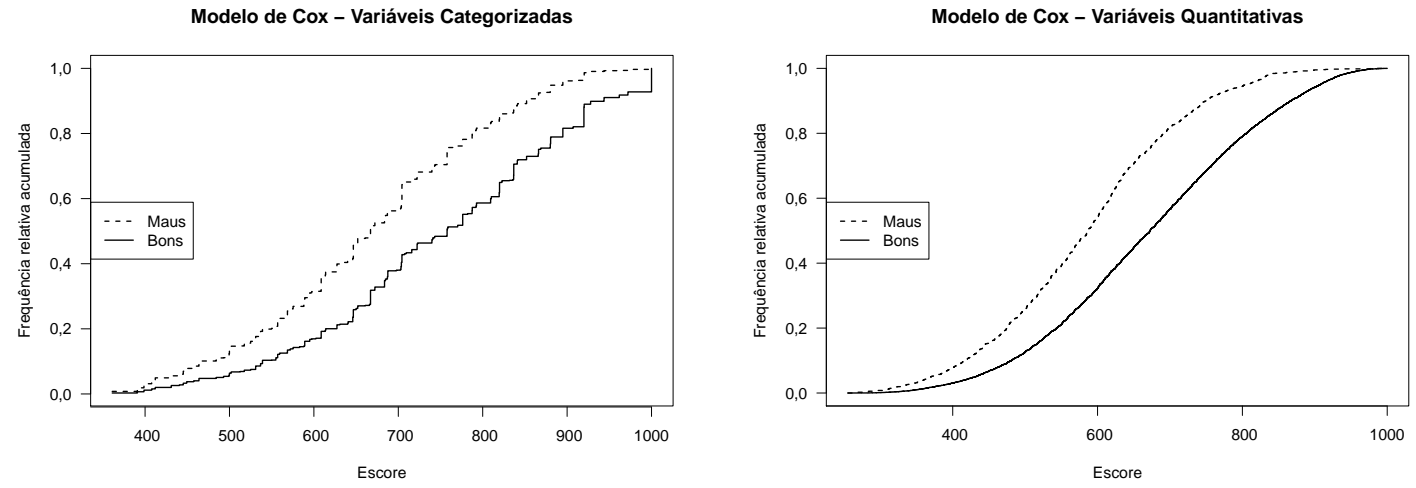
Figura C.15: Gráfico KS - Tempo médio de inadimplência - Pseudo-valores com características de cliente
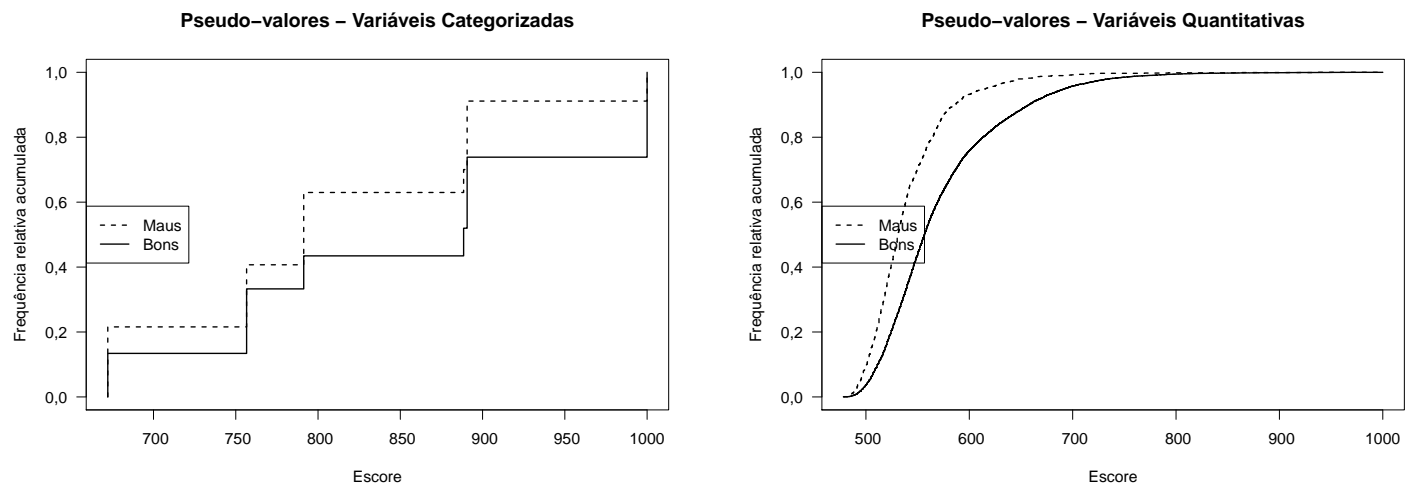

Figura C.16: Curva ROC - Probabilidade de inadimplência - Regressão logística com características de cliente
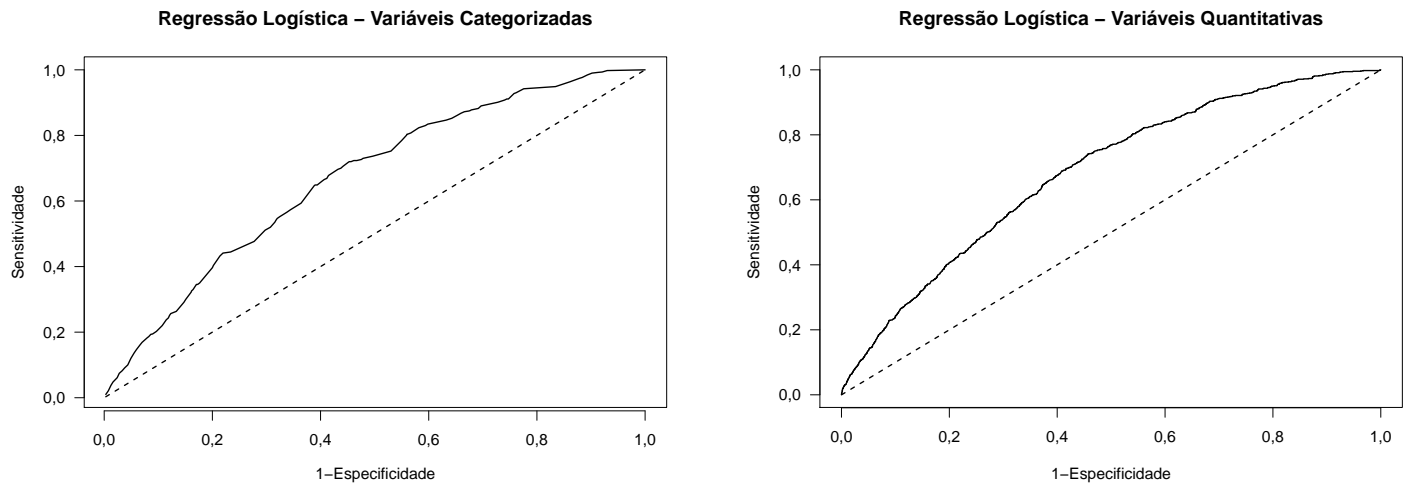

Figura C.17: Curva ROC - Probabilidade de inadimplência - Modelo de Cox com características de cliente
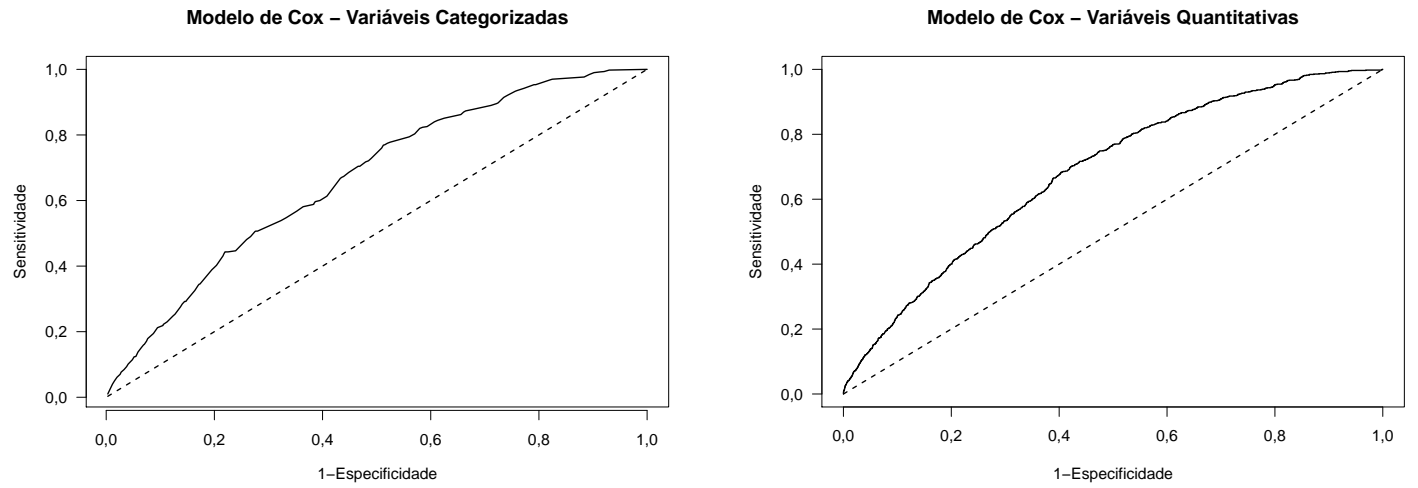
Figura C.18: Curva ROC - Probabilidade de inadimplência - Pseudo-valores com características de cliente

Pseudo-valores - Variáveis Categorizadas

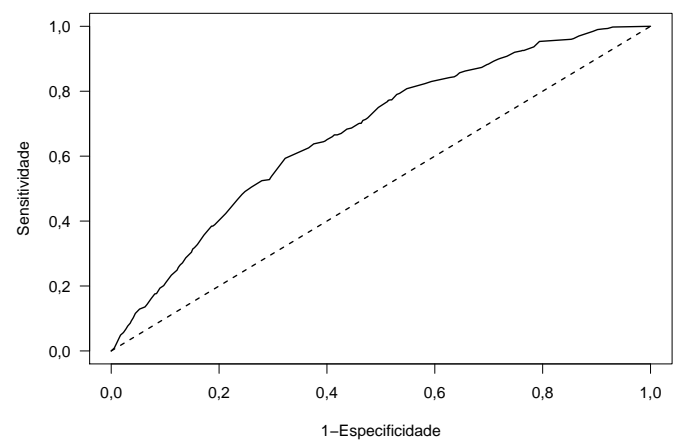

Pseudo-valores - Variáveis Quantitativas

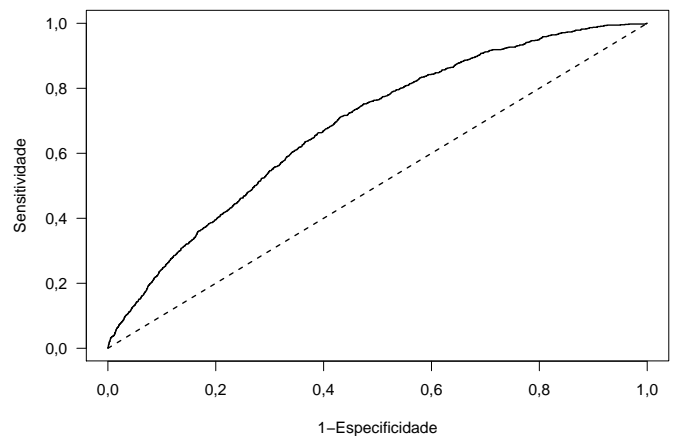

Figura C.19: Curva ROC - Tempo médio de inadimplência - Modelo de Cox com características de cliente

Modelo de Cox - Variáveis Categorizadas

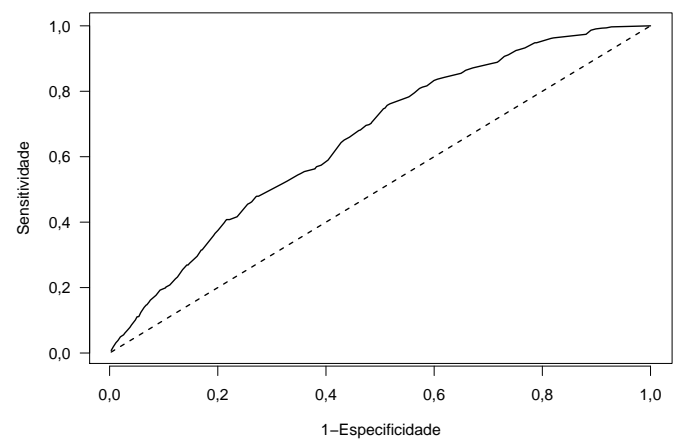

Modelo de Cox - Variáveis Quantitativas

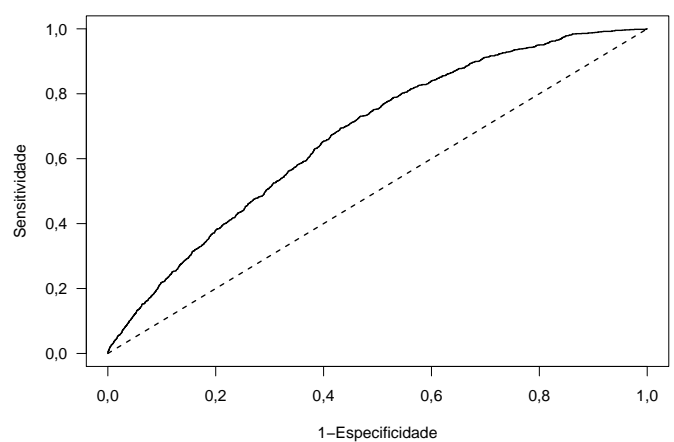

Figura C.20: Curva ROC - Tempo médio de inadimplência - Pseudo-valores com características de cliente
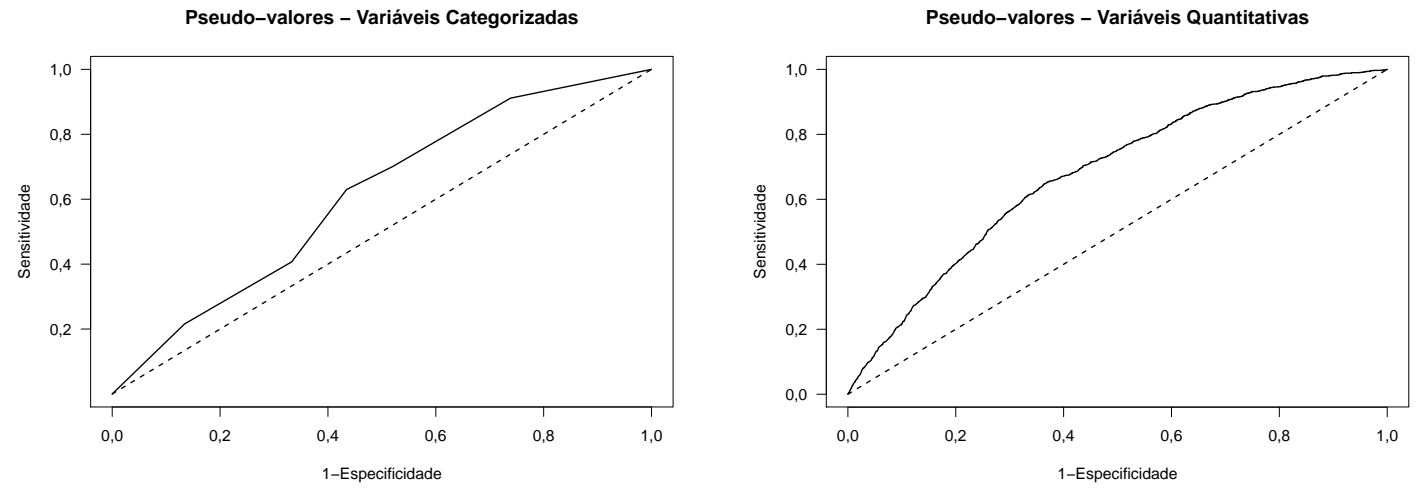


\section{Referências Bibliográficas}

Agresti, A. (2002), Categorical Data Analysis, John Wiley and Sons, New York.

Andersen, P. K., Borgan, Ø., Gill, R. D. e Keiding, N. (1993), Statistical Models Based on Counting Processes, Springer-Verlag, New York.

Andersen, P. K., Hansen, M. G. e Klein, J. P. (2004), 'Regression analysis of restricted mean survival time based on pseudo-observations', Lifetime Data Analysis 10(4), 335-350.

Andersen, P. K., Klein, J. P. e Rosthøj, S. (2003), 'Generalised linear models for correlated pseudo-observations, with applications to multi-state models', Biometrika 90(1), 15-27.

Assaf Neto, A. e Silva, C. A. T. (1997), Administração do Capital de Giro, Atlas, São Paulo.

Basel Committee on Banking Supervision (2004), Internal convergence of capital measurement and capital standards. A revised framework.

Breslow, N. (1972), 'Contribuição à discussão do artigo de D. R. Cox', Journal of the Royal Statistical Society 34(2), 216-217.

Chaia, A. J. (2003), Modelos de gestão do risco de crédito e sua aplicabilidade ao mercado brasileiro, Dissertação de Mestrado, Faculdade de Economia, Administração e Contabilidade, Universidade de São Paulo, São Paulo.

Colosimo, E. A. e Giolo, S. R. (2006), Análise de sobrevivência aplicada, Edgard Blücher, São Paulo.

Cox, D. R. (1972), 'Regression models and life-tables', Journal of the Royal Statistical Society 34(2), 187-220.

Cox, D. R. (1975), 'Partial likelihood', Biometrika 62(2), 269-276.

Efron, B. (1977), 'The efficiency of Cox's likelihood function for censored data', Journal of the American Statistical Association 72(359), 557-565. 
Garthwaite, P. H., Jolliffe, I. T. e Jones, B. (2002), Statistical Inference, Oxford University Press, New York.

Graw, F., Gerds, T. A. e Schumacher, M. (2009), 'On pseudo-values for regression analysis in competing risks models', Lifetime Data Analysis 15(2), 241-255.

Greenwood, M. (1926), 'The natural duration of cancer', Reports on Public Health and Medical Subjects 33, 1-26.

Hardin, J. W. e Hilbe, J. M. (2003), Generalized estimating equations, Chapman and Hall, London.

Helms, F. (2003), Estimating LTC premiums using gees for pseudo-values, Dissertação de Mestrado, Zentrum Mathematik,Technische Universität München, München.

Hinkley, D. V. (1983), Jackknife methods, in 'Encyclopedia of Statistical Sciences', John Wiley and Sons, New York, pp. 280-7.

Hosmer, D. W. e Lemeshow, S. (2000), Applied logistic regression, John Wiley and Sons, New York.

Hosmer, D. W., Lemeshow, S. e May, S. (2008), Applied survival analysis: regression modeling of time-to-event data, John Wiley and Sons, New York.

Kaplan, E. L. e Meier, P. (1958), 'Nonparametric estimation from incomplete observations', Journal of the American Statistical Association 53(282), 457-481.

King, G. e Zeng, L. (2001), 'Logistic regression in rare events data', Political Analysis 9(2), 137-163.

Klein, J. P. e Moeschberger, M. L. (1997), Survival analysis: techniques for censored and truncated data, Springer, New York.

Kleinbaum, D. G. (1995), Survival analysis: a self-learning text, SpringerVerlag, New York.

Lawless, G. F. (2003), Statistical models and methods for lifetime data, John Wiley and Sons, New York.

Liang, K.-Y. e Zeger, S. L. (1986), 'Longitudinal data analysis using generalized linear models', Biometrika 73(1), 13-22.

Malik, M. e Thomas, L. (2007), Modeling credit risk of portfolio of consumer loans, Technical report, School of Management, University of Southampton.

URL: http://ssrn.com/abstract=1287845 
Manly, B. F. J. (1998), Randomization, bootstrap and Monte Carlo methods in biology, Chapman and Hall, London.

Miller, R. G. (1974), 'The jackknife - a review', Biometrika 61(1), 1-15.

Oliveira, J. G. C. e Andrade, F. W. M. (2002), 'Comparação entre medidas de performance de modelos de credit scoring', Tecnologia de Crédito pp. $35-47$.

Paula, G. A. (2004), Modelos de regressão com apoio computacional. Instituto de Matemática e Estatística, Universidade de São Paulo.

Pereira, G. H. A. (2004), Modelos de risco de crédito de clientes: Uma aplicação a dados reais, Dissertação de Mestrado, Instituto de Matemática e Estatística, Universidade de São Paulo, São Paulo.

Quenouille, M. H. (1956), 'Notes on bias in estimation', Biometrika 43(3/4), 353-360.

Rosa, P. T. M. (2000), Modelos de credit scoring: Regressão logística, chaid e real, Dissertação de Mestrado, Instituto de Matemática e Estatística, Universidade de São Paulo, São Paulo.

Thomas, L. C., Edelman, D. B. e Crook, J. N. (2002), Credit Scoring and Its Applications, Siam, Philadelphia.

Thorburn, D. (1976), 'Some asymptotic properties of jackknife statistics', Biometrika 63(2), 305-313.

Thorburn, D. (1977), 'On the asymptotic normality of the jackknife', Scandinavian Journal of Statistics 4(3), 113-118.

Tomazela, S. (2007), Avaliação de desempenho de modelos de credit score ajustados por análise de sobrevivência, Dissertação de Mestrado, Instituto de Matemática e Estatística, Universidade de São Paulo, São Paulo.

Tukey, J. W. (1958), 'Bias and confidence in not-quite large samples (abstract)', The Annals of Mathematical Statistics 29(2), 614.

Tunes-da-Silva, G. e Klein, J. P. (2009), 'Regression analysis of mean qualityadjusted survival time based on pseudo-observations', Statistics in Medicine 28(7), 1054-1066. 